\title{
Manager
}

Edilson Antonio Catopan

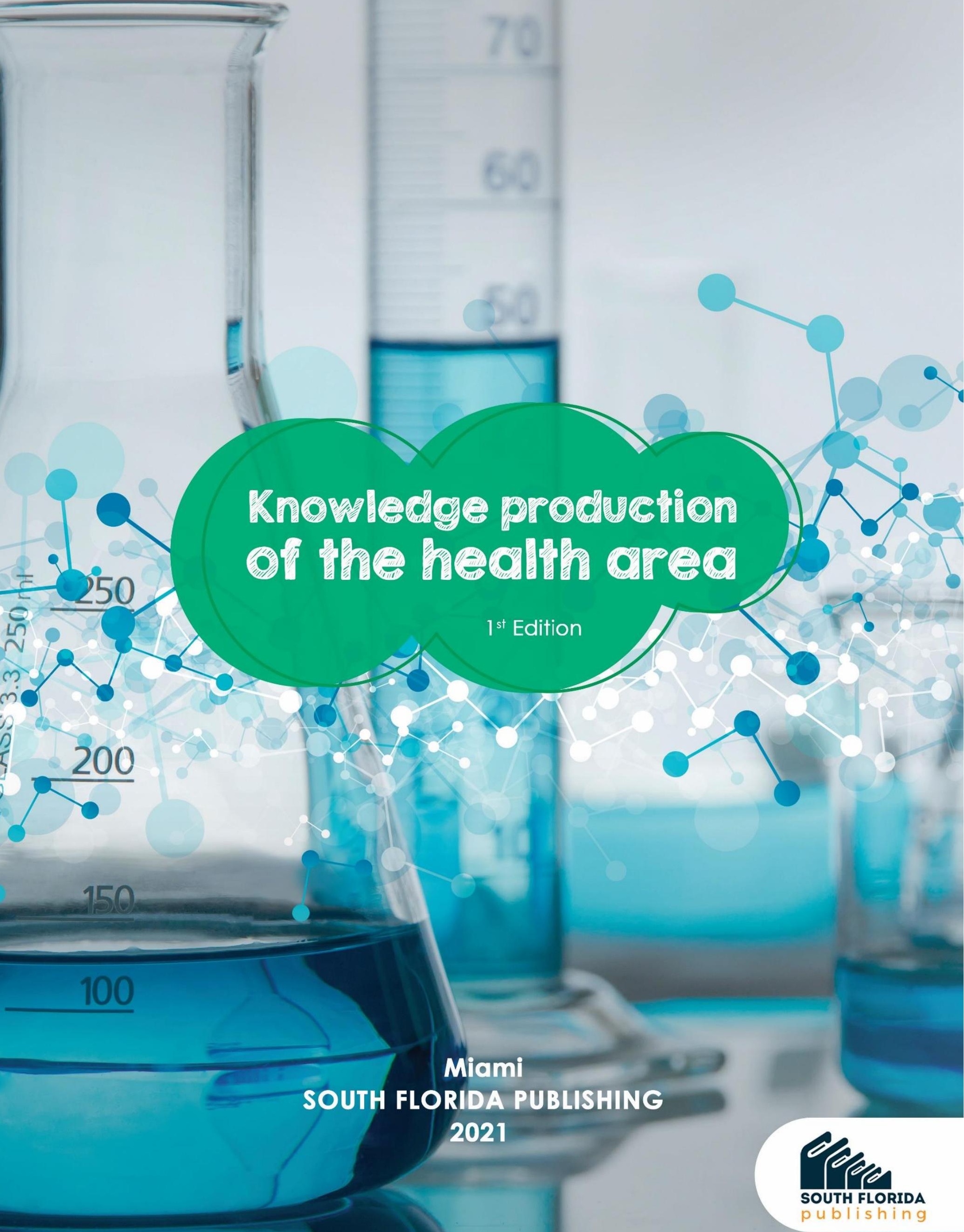


Manager

Edilson Antonio Catapan

\section{Knowledge production of the health area}

$1^{\text {ST }}$ Edition 


\author{
2021 by South Florida Publishing \\ Copyright ( ) South Florida Publishing \\ Text Copyright (C) 2021 The Author \\ Edition Copyright (@) 2021 South Florida Publishing \\ Executive Director: Barbara Luzia Sartor Bonfim Catapan \\ Diagramming: Sabrina Binotti \\ Art Editing: Sabrina Binotti \\ Review: The Author
}

The content of the papers and their data on their form, correctness and reliability are from responsibility of the author. The download of the work and the sharing are allowed as long as the credits are attributed to the author, but without the possibility of altering it in any way or using it for commercial purposes.

\title{
Editor-In-Chief
}

Edilson Antonio Catapan, South Florida Publishing, Miami, United States of America

\section{Editorial Board}

Adriana Karin Goelzer Leinig, Federal University of Paraná, Curitiba, Brazil.

Ana María Golpe Cervelo, Faculty of Economic Sciences and Administration,

Montevideo, Uruguay.

António Cardoso, Fernando Pessoa University, Porto, Portugal.

Barbara Luzia Sartor Bonfim Catapan, Pontifical Catholic University of Paraná,

Curitiba, Brazil.

Daniel Molina Botache, Uniminuto University, Bogota, Colombia.

Ernesto O'Connor, Argentine Catholic University, Buenos Aires, Argentina.

Gustavo Símaro, Faculty of Economic Sciences, Buenos Aires, Argentina.

Rahmi Deniz Özbay, University of Marmara, Istanbul, Turkey.

Sema Yilmaz Genç, University of Kocaeli, Kocaeli, Turkey.

Sérgio António Neves Lousada, University of Madeira, Funchal, Portugal.

Sergio Raul Jimenez Jerez, National Polytechnic Institute (IPN), México City, Mexico.

Susana Parés, National University of Córdoba, Córdoba, Argentina.

Valeria Torchelli, Faculty of Economic Sciences, Buenos Aires, Argentina. 


\begin{tabular}{|l|}
\hline International Data of Cataloging in Publication (CIP) \\
\hline \hline C357k $\quad$ Catapan, Edilson Antonio \\
Knowledge production of the health area / Edilson Antonio \\
Catapan. Miami: South Florida Publishing, 2021. \\
114 p. \\
Format: PDF \\
System requirements: Adobe Acrobat Reader \\
Access mode: World Wide Web \\
Includes: Bibliography \\
ISBN: 978-1-7361138-3-7 \\
DOI: 10.47172/sfp2020.ed.0000002 \\
1. Health area. 2. Knowledge production. \\
I. Catapan, Edilson Antonio. III. Title. \\
\hline
\end{tabular}

South Florida Publishing - Miami https://southfloridapublishing.com/ contact@southfloridapublishing.com 


\section{PRESENTATION}

The book "Knowledge production of the health area vol.01, edited and published by South Florida Publishing, gather nine chapters which approach themes of relevance in the context of health sciences and are available in Spanish.

Thus, the articles address: Therapeutic inertia of the family physician in patients with hypertensive decontrol; The medical student: his ideas and thoughts; Study of risk factors for breast cancer in Uruguayan women; Knowledge, attitudes and practices of health professionals regarding HIV/AIDS at the first level of care; Knowledge, attitudes and practices of health professionals regarding HIV/AIDS at the first level of care; Nursing care for patients with COVID-19; Gymnastics of talent: development of competencies and skills in the work environment.

In this way, we thank all the authors for the commitment and dedication put into their work and hope to contribute to the scientific community, in the advancement of knowledge and science.

Good reading to one and all! Prof. Edilson Antonio Catapan, PhD 
SUMMARY

CHAPTER 01

INERCIA TERAPÉUTICA DEL MÉDICO FAMILIAR EN PACIENTES CON DESCONTROL HIPERTENSIVO

CHAPTER 02 .

EL ESTUDIANTE DE MEDICINA: SUS IDEAS Y RENGLONES

CHAPTER 03

ESTUDIO DE LOS FACTORES DE RIESGO PARA EL CANCER DE MAMA EN MUJERES URUGUAYAS

CHAPTER 04 32

CONOCIMIENTOS, ACTITUDES Y PRÁCTICAS DE LOS PROFESIONALES DE LA SALUD ANTE ELVIH/SIDA EN EL PRIMER NIVEL DE ATENCIÓN

CHAPTER 05 43

ACTITUDES PROAMBIENTALISTAS EN ESTUDIANTES MIEMBROS Y NO MIEMBROS DE LAS BRIGADES ACADEMIC OF VIGILANCIA, EDUCACIÓN Y FISCALIZACIÓN AMBIENTAL LA ESCUELAPROFESIONAL DE LA PSICOLOGÍA UNIVERSIDAD ANDINA DEL CUSCO, 2017

CHAPTER 06 56

GIMNÁSTICA DEL TALENTO, DESARROLLO DE COMPETENCIAS Y HABILIDADES EN ENTORNO LABORAL

CHAPTER 07 67

REHABILITACIÓN PROTÉSICA EN PACIENTE CON OSTEOPOROSIS BAJO TRATAMIENTO CON BIFOSFONATOS

CHAPTER 08. .74

VALIDACIÓN APLICATIVO MÓVIL PARA DETECCIÓN DEL BURNOUT EN DOCENTES BOGOTÁ-COLOMBIA

CHAPTER 09 87

NURSING CARE IN COVID-19 PATIENTS

MANAGER. 108 


\section{CHAPTER 01}

INERCIA TERAPÉUTICA DEL MÉDICO FAMILIAR EN PACIENTES CON DESCONTROL HIPERTENSIVO

Jesús Javier Mejía Inglés

Higher academic background: Médico Familiar

Current Institution: Jefatura de Departamento Clínico en Atención Familiar. Unidad Médica Familiar 77, Madero Tamaulipas, Instituto Mexicano del Seguro Social, México. Full address (can be institutional or personal, as you prefer): Blvd. Adolfo López Mateos S/N, Col. Las Conchitas, Madero Tamaulipas.

E-mail: jesadry.28@gmail.com

\section{José Felíx Mendoza González}

Higher academic background: Médico Familiar

Current Institution: Servicio de Atención Familiar. Unidad Médica Familiar 12, Tamasopo San Luis Potosí, Instituto Mexicano del Seguro Social, México.

Full address (can be institutional or personal, as you prefer): Kilómetro 2, carretera Tamasopo Agua buena, San Luis Potosí, CP. 79700.

E-mail: p_pox@hotmail.com

\section{Liliana Aurora Carrillo Aguiar}

Higher academic background: Médico Familiar., Master en Ciencias Médicas., Profesor Titular de la Residencia en Medicina Familiar.

Current Institution: Unidad Médica Familiar 77, Madero Tamaulipas, Instituto Mexicano del Seguro Social, México.

Full address (can be institutional or personal, as you prefer): Blvd. Adolfo López Mateos S/N, Col. Las Conchitas, Madero Tamaulipas.

E-mail: lilifha@hotmail.com

\section{Brian González Pérez}

Higher academic background: Médico Familiar., Doctor en Ciencias de la Salud., Master en Ciencias Médicas., Master en Innovación y Tecnología Educativa., Profesor Investigador.

Current Institution: Servicio de Atención Familiar. Unidad Médica Familiar 38, Tampico Tamaulipas, Instituto Mexicano del Seguro Social, México. Facultad de Medicina "Dr. Alberto Romo Caballero" Universidad Autónoma de Tamaulipas, Tampico, Tamaulipas, México.

Full address (can be institutional or personal, as you prefer): Calle Argentina y Canadá 107 Col. Infonavit C.P. 89310, Tampico, Tamaulipas.

E-mail: brian.gonzalez.perez@gmail.com

\section{Ricardo Salas Flores}

Higher academic background: Endocrinólogo Pediatra., Master en Ciencias Médicas., Profesor Investigador.

Current Institution: Coordinación de Educación en Salud e Investigación. Hospital General Regional No. 6, Madero, Tamaulipas, Instituto Mexicano del Seguro Social, México. Facultad de Medicina "Dr. Alberto Romo Caballero" Universidad Autónoma de Tamaulipas, Tampico, Tamaulipas, México. 
Full address (can be institutional or personal, as you prefer): Blvd. Adolfo López Mateos S/N, Col. Las Conchitas, Madero Tamaulipas.

E-mail: risafl@yahoo.com

\section{Wilberto Sánchez Márquez}

Higher academic background. Doctor en Desarrollo Educativo., Profesor Investigador. Current Institution: Facultad de Medicina "Dr. Alberto Romo Caballero" Universidad Autónoma de Tamaulipas, Tampico, Tamaulipas, México.

Full address (can be institutional or personal, as you prefer): Centro Universitario Sur, Cto. Interior S/N CP 89337, Tampico, Tamaulipas

E-mail:wsanchez@docentes.uat.edu.mx

RESUMEN: INTRODUCCION: En el manejo de los pacientes portadores de hipertensión arterial, la inercia terapéutica se define como la reticencia de los médicos familiares a optimizar la terapia farmacológica y no lograr los objetivos de control de presión arterial siendo una de las principales causas del descontroly de aparición de complicaciones cardiovasculares. OBJETIVO: Conocer la inercia terapéutica del médico familiar en el manejo de pacientes con hipertensión arterial sistémica descontrolada de la Unidad de Medicina Familiar No 77. METODOS: Se realizó un estudio observacional, descriptivo, transversal y retrospectivo, en pacientes de ambos sexos, de edades entre los 18 y 79 años de edad con hipertensión arterial descontrolada de enero a marzo 2018, donde se evaluaron las características de las determinaciones de presión arterial e intervenciones terapéuticas del médico familiar registradas en el expediente clínico. Se incluyeron las variables edad, género, presión arterial sistólica, diastólica, índice de masa corporal, cambios en el tratamiento, ajuste de medicamentos y años de evolución. La inercia terapéutica se cuantificó como el número de pacientes a los que no se les modificó el tratamiento farmacológico, dividido entre el númerode pacientes que no han conseguido el objetivo de control y multiplicado por 100, clasificándola como leve A (<20\%), moderada, B (20-50\%) y severa C (>50\%). Se aplicaron estadísticas descriptivas, medidas de tendencia central y análisis de asociación entre variables cualitativas mediante la prueba de $\mathrm{X}^{2}$. Un valor de $\mathrm{p}<0.05$ fue considerado como significativo.

RESULTADOS: Se estudiaron un total de 150 casos de pacientes con hipertensión arterial descontrolada, el $56 \%(n=84)$ fueron femeninos y $44 \%(n=66)$ masculinos. La edad cronológica promedio de la población estudiada fue de $61.6 \pm 8.6$ años. El promedio de IMC fue $28.3 \pm 3.7$, de sistólica $127 \pm 10.1$, diastólica $79.3 \pm 6.2$ y para el tiempo de evolución de la enfermedad $8.5 \pm 4.4$ años. Los fármacos prescritos fueron diuréticos $28.3 \%$, seguido de los calcio-antagonistas con $19.7 \%$, IECA $18.5 \%$, ARA II $17.3 \%$ y en último lugar los beta-bloqueadores $16.2 \%$. En el $77.3 \%$ de los casosno presentaron inercia terapéutica y en 34 pacientes $(22.7 \%)$ se encontró una inercia terapéutica moderada $(>20 \%$ ) asociada a la falta de cambios en el tratamiento $(p<0.001)$ y con los años de evolución de la presión arterial de $p<0.002$. CONCLUSIONES: La inercia terapéutica encontrada tiene una severidad moderada y es importante la capacitación del médico familiar en las guías de práctica clínica y la supervisión estricta de los pacientescon hipertensión descontrolada.

PALABRAS-CLAVE: Inercia terapéutica; Hipertensión arterial; Médico familiar, Atención médica, Serviciosde salud. 


\section{INTRODUCCION}

La hipertensión arterial sistémica es un síndrome de etiología múltiple caracterizado por la elevación persistente de las cifras de presión arterial a cifras $\geq 140 / 90 \mathrm{~mm} / \mathrm{Hg}$. Es considerada como un predictor de morbimortalidad para enfermedades cardiovasculares, entre las que destacan la enfermedad cerebrovascular, el infarto del miocardio, la insuficiencia cardiaca, la enfermedad arterial periférica y la insuficiencia renal (1). La hipertensión arterial causa anualmente 9.4 millones de muertes en el mundo y contribuye al $12.8 \%$ de la mortalidad por todas las causas (2). En los últimos años, su prevalencia en países de bajos ingresos ha sido de $40 \%$ (3) y en México durante el año 2016 la prevalencia fue de $30.2 \%$ (4).

De acuerdo con la Encuesta Nacional de Salud y Nutrición de Medio Camino 2016, realizada porel Instituto Nacional de Salud Pública (INSP) y la Secretaría de Salud, uno de cada cuatro adultos en México padece hipertensión arterial, es decir, 25.5 por ciento de la población, de los cuales aproximadamente el 40 por ciento ignora que tiene esta enfermedad, y ello repercute en su condición de salud; y cerca del 60 por ciento que conoce el diagnóstico, solamente la mitad están controlados (5).

El diagnóstico oportuno, conocimiento de la enfermedad, acceso a fármacos antihipertensivos y servicios de salud de calidad son fundamentales para el control de la hipertensión (6). Sin embargo el hecho de no iniciar o intensificar el tratamiento de acuerdo con las guías de práctica clínica basadas enla evidencia, se reconoce cada vez más como un fenómeno que contribuye al manejo inadecuado de las condiciones crónicas y se conoce como inercia terapéutica (7). Por definición, la inercia terapéutica es lafalla de un proveedor de servicios de salud para iniciar o intensificar la terapia farmacológica cuando no se han logrado metas de control óptimas (8).

En el caso concreto del manejo de los pacientes portadores de hipertensión arterial se define la inercia terapéutica, como la reticencia de los médicos familiares a optimizar la terapia farmacológica y no lograr los objetivos de control de presión arterial siendo una de las principales causas del descontroly de aparición de complicaciones cardiovasculares (9). La principal manifestación de la inercia terapéutica es la falta de aumento de la dosis o número de medicamentos antihipertensivos para intensificar el tratamiento cuando la presión arterial aumenta o permanece por encima de los objetivos terapéuticos (10). Entre las principales causas descritas en la literatura causantes de mal control hipertensivo, destacan la 
metodología inadecuada de medida de la presión arterial, la falta de cumplimiento terapéutico de los pacientes y la inercia terapéutica de los médicos (11).

La inercia terapéutica depende muy especialmente de la formación y actitud del médico (12) y esampliamente reconocida como una causa mayor del mal control de la hipertensión arterial y de otras enfermedades crónicas (13). Las repercusiones clínicas derivadas de la inercia terapéutica, que supone la no intensificación de las medidas higiénico-dietéticas o farmacológicas, incluye el retraso en el iniciodel tratamiento y la falta de un correcto plan de seguimiento que garantice la detección e intervención ante complicaciones de la enfermedad (14).

Diferentes estudios realizados en nuestro país han aportado información indirecta sobre la magnitud actual del problema de la inercia terapéutica en la práctica clínica de atención primaria y especializada, en todos ellos se observó que la actitud terapéutica del médico ante el mal control de la presión arterial no es la recomendada por las guías de práctica clínica (15). Nuestro estudio permitirá conocer la inercia terapéutica del médico familiar en el manejo de pacientes con hipertensión arterial sistémica descontrolada de la Unidad de Medicina Familiar No 77.

\section{METODOS}

Se realizó un estudio observacional, transversal, descriptivo y retrospectivo en pacientes de ambos sexos, de edades entre los 18 y 79 años de edad con hipertensión arterial descontrolada que acudieron a la consulta externa de Medicina Familiar de la Unidad de Medicina Familiar No 77 en el periodo comprendido de enero a marzo 2018. Previo consentimiento informado, se evaluaron las características de las determinaciones de presión arterial e intervenciones terapéuticas del médico familiar registradas en el expediente clínico. Se incluyeron las variables edad, género, presión arterial sistólica, diastólica, índice de masa corporal (IMC), cambios en el tratamiento, ajuste de medicamentosy años de evolución. La inercia terapéutica se cuantificó como el número de pacientes a los que no se lesmodificó el tratamiento farmacológico, dividido entre el número de pacientes que no han conseguido el objetivo de control y multiplicado por 100, clasificándola como leve A (<20\%), moderada, B (20-50\%)y severa $C(>50 \%)$. Los datos recolectados se analizaron con ayuda del paquete estadístico Statistical Package for Social Sciences para Windows (versión 19; SPSS Inc., Chicago IL, USA). Se aplicaron estadísticas descriptivas, medidas de tendencia 
central y análisis de asociación entre variables cualitativas mediante la prueba de X2. Un valor de $\mathrm{p}<0.05$ fue considerado como significativo. El protocolo de investigación fue aprobado por el Comité Local de Investigación en Salud 2804 del Instituto Mexicano del Seguro Social.

\section{RESULTADOS}

Se estudiaron un total de 150 casos de pacientes con hipertensión arterial descontrolada, el $56 \%(n=84)$ fueron femeninos y $44 \%(n=66)$ masculinos. La edad cronológica promedio de la población estudiada fue de $61.6 \pm 8.6$ años. El promedio de IMC fue $28.3 \pm 3.7$, de sistólica $127 \pm 10.1$, diastólica $79.3 \pm 6.2$ y para el tiempo de evolución de la enfermedad $8.5 \pm 4.4$ años. Los fármacos prescritos fueron diuréticos $28.3 \%$, seguido de los calcio-antagonistas con $19.7 \%$, IECA $18.5 \%$, ARA $17.3 \%$ y en último lugar los beta-bloqueadores $16.2 \%$. En el $77.3 \%$ de los casos no presentaron inercia terapéutica y en 34 pacientes $(22.7 \%)$ se encontró una inercia terapéutica moderada (>20\%) asociada a la falta de cambios en el tratamiento ( $p$ $<0.001$ ) y con los años de evolución de la presión arterial de $p<0.002$. (Tabla 1).

Tabla 1.- Características generales de la población estudiada.

\begin{tabular}{|c|c|c|}
\hline \multirow[t]{2}{*}{ Información general de los pacientes } & \multicolumn{2}{|c|}{$\begin{array}{l}\text { Hipertensión Arterial Descontrolada } \\
\qquad(n=150)\end{array}$} \\
\hline & $N$ & $\%$ \\
\hline \multicolumn{3}{|c|}{ Sexo } \\
\hline Hombres & 66 & 44 \\
\hline Mujeres & 84 & 56 \\
\hline $\mathrm{IMC}(\mathrm{kg} / \mathrm{m} 2)^{*}$ & \multirow{4}{*}{\multicolumn{2}{|c|}{$\begin{array}{c}28.3+3.7 \\
127+10.1 \\
79.3+6.2 \\
8.5+4.4\end{array}$}} \\
\hline Sistólica $(\mathrm{mmHg})^{*}$ & & \\
\hline Diastólica $(\mathrm{mmHg})^{*}$ & & \\
\hline Tiempo de evolución (años) * & & \\
\hline \multicolumn{3}{|c|}{ Fármacos Prescritos } \\
\hline Diuréticos & 91 & 26.4 \\
\hline Calcio-antagonistas & 70 & 19.7 \\
\hline IECA & 68 & 18.5 \\
\hline ARA II & 59 & 17.4 \\
\hline Beta-bloqueadores & 58 & 16.2 \\
\hline \multicolumn{3}{|c|}{ Inercia Terapéutica ** } \\
\hline $\mathrm{Si}$ & 34 & 22.3 \\
\hline No & $\begin{array}{c}11 \\
6\end{array}$ & 77.3 \\
\hline
\end{tabular}

IECA (Inhibidores de la Enzima Convertidora de Angiotensina), ARA II (Antagonista de los receptores de angiotensina II). ${ }^{*}$ Valores expresados como + DE. ${ }^{*}$ Estadísticamente significativo $p<$ 0.05. Fuente: Los autores. 


\section{DISCUSIÓN}

Para el control del paciente hipertenso, existe una gran variabilidad en el tratamiento farmacológico, en muchos casos, no se han instrumentado medidas no farmacológicas, y en un elevado porcentaje no existe un adecuado control de las cifras tensionales, con los consecuentes incrementos en el riesgo de daño en los órganos blanco, la discapacidad, los costos de la atención y su repercusión en la economía familiar, en los sistemas de salud y en el país (16). El manejo de pacientes con hipertensión arterial descontrolada por parte del médico familiar implica el riesgo de ocurrencia de la inerciaterapéutica, sabiendo que existen barreras como una falsa impresión de buen control de la enfermedad,la percepción de mala adherencia del paciente y la falta de entrenamiento y organización. El instrumentopara medir con exactitud la inercia terapéutica, basado en la definición operacional de $\mathrm{O}^{\prime}$ Connor et al., para poder establecer este fenómeno, permitió hacer la medición en todos los pacientes con hipertensión arterial sistémica no controlada (17).

Studios transversales multicéntricos indican que la magnitud de la Inercia terapéutica en el tratamiento de la hipertensión arterial en España y Latinoamérica oscila entre el 51 y $85 \%$ de los hipertensos no controlados (18), lo cual difiere con los resultados obtenidos en el presente estudio, donde el cálculo fue de $22.7 \%$ y clasificada en un grado moderado de severidad. Lo anterior se debió posiblemente al bajo número de casos estudiados que favorece el aumento de margen de error, así como el subregistro de tensiones arteriales elevadas por parte de los médicos familiares.

La proporción de pacientes jóvenes con cifras de hipertensión arterial descontrolada es baja, encontrando mayor número de casos en la edad promedio de 61 años, lo cual es coincidente con lo reportado en la literatura, en un estudio de inercia clínica en una unidad de Medicina Familiar de Acapulco Guerrero, donde la edad mínima fue de 37 años y un promedio de 63 años en los pacientes estudiados con esta enfermedad crónica (19).

En la revisión de expedientes donde el médico ha realizado algún cambio al tratamiento antihipertensivo en el manejo de la hipertensión arterial descontrolada se encontró un $66 \%$ en nuestro estudio, comparado con lo realizado con Caro y Colaboradores en el 2002 (20) donde obtuvieron solo $34.7 \%$ y en el 2006 fue de $46.7 \%$ lo cual representa una cifra menor. 
Se determinó el número de casos donde no se realiza el ajuste de dosis resultando en un $66.7 \%$ y la congruencia de apego al algoritmo de tratamiento de acuerdo con la guía de práctica clínica en el manejo de hipertensión, pero no se reportan estudios en la literatura donde se haga referencia a este apartado.

\section{CONCLUSIONES}

La inercia terapéutica encontrada tiene una severidad moderada y es importante la capacitación del médico familiar en las guías de práctica clínica y la supervisión estricta de los pacientes con hipertensión descontrolada. 


\section{REFERENCIAS}

1.- Norma Oficial Mexicana NOM-030-SSA2-2009. Para la prevención, detección, diagnóstico, tratamiento y control de la hipertensión arterial sistémica. México. 2009. [consultado Noviembre, 2020]Disponible En:

https://www.cndh.org.mx/sites/default/files/doc/Programas/VIH/Leyes\%20y\%20norma s\%20y\%20regla mentos/Norma\%200ficial\%20Mexicana/NOM-030-SSA2-2009.pdf

2.- Lim SS, Vos T, Flaxman AD, Danaei G, Shibuya K, Adair-Rohani H, et al. A comparative risk assessment of burden of disease and injury attributable to 67 risk factors and risk factor clusters in 21 regions, 1990-2010: a systematic analysis for the Global Burden of Disease Study 2010. Lancet 2012; 380(9859): 2224-60. https://doi.org/10.1016/S0140-6736(12)61766-8

3.- World Health Organization. Chapter 1. Burden: mortality, morbidity and risk factors. En: WorldHealth Organization. Global status report on noncommunicable diseases 2010. Ginebra: WHO, 2011:9-32 [citado noviembre, 2020]. Disponible en: https://www.who.int/nmh/publications/ncd_report_chapter1.pdf?ua=1

4. Campos-Nonato I, Hernández-Barrera L, Pedroza-Tobías A, Medina C, Barquera S. Hipertensión arterial en adultos mexicanos: prevalencia, diagnóstico y tipo de tratamiento Ensanut MC 2016. Salud Publica Mex. 2018; 60(3): 233-43. https://doi.org/10.21149/8813

5.- Patricia López. Uno de cada cuatro connacionales con hipertensión, 31 millones de mexicanos. Gaceta UNAM. Mayo 20, 2019. [consultado Noviembre, 2020 ] Disponible En:

https://www.gaceta.unam.mx/con-hipertension-31-millones-de-mexicanos/

6.- World Health Organization. A global brief on hypertension. Silent killer, global public health crisis.Ginebra: WHO, 2013 [citado Noviembre, 2020].

Disponible en:

https://apps.who.int/iris/bitstream/handle/10665/79059/WHO_DCO_WHD_2013.2_en g.pdf?sequence $=1$

7.- Aujoulat I, Jacquemin P, Rietzschel E, Scheen A, Tréfois P, Wens J, Darras E, Hermans MP. Factorsassociated with clinical inertia: an integrative review. Adv Med Educ Pract. 2014 May 8;5:141-7. doi: 10.2147/AMEP.S59022.

8.-Roa L, Monreal M, Carmona J, Aguilar E, Coll R, Suárez C. Inercia terapéutica en prevenciónsecundaria de enfermedad cardiovascular. Registro frena. Medicina Clínica 2016; 134(2): 57-63.

9.- Giugliano D, Esposito K. Clinical Inertia as a clinical safeguard. JAMA 2011; 305 (15): 1591-1592.

10.- Fine L, Cutler J. Hypertension and the Treating Physician Understanding and Reducing Therapeuticlnertia. Hypertension 2016; 47: 319-320.

11.- James PA, Oparil S, Carter BL, Cushman WC, Dennison-Himmelfarb C, Handler $\mathrm{J}$, et al 2014 evidence-based guideline for the management of high blood pressure in adults; report from the panel members appointed to the Eighth JOINT National Committee (JNC 8) JAMA 2014; 311 (5):507-20.

12.- Barrios V, Escobar C. Utilidad de la terapia combinada en la prevención y tratamiento de laenfermedad cardiovascular. Rev Clin Esp. 2010; 210(5): 230-236 
13.- Redon J, Coca A, Lázaro P, Dolores M, Cabañas M, Gil N et al. Factors associated with therapeuticinertia in hypertension: validation of a predictive model. Journal of Hypertension 2015; 28: 1770-1777.

14.- Butler J, Papadimitriou L, Georgiopoulou V, Skopicki H, Dunbar S, Kalogeropoulos A. Comparing Sodium Intake Strategies in Heart Failure: Rationale and Design of the Prevent Adverse Outcomes in Heart Failure by Limiting Sodium (PROHIBIT) Study. Circ Heart Fail. 2015 May;8(3):636-45. doi: 10.1161/CIRCHEARTFAILURE.114.001700.

15.- Whelton PK, Carey RM, Aronow WS, Casey DE Jr, Collins KJ, Dennison Himmelfarb C, DePalmaSM, Gidding S, Jamerson KA, Jones DW, MacLaughlin EJ, Muntner P, Ovbiagele B, Smith SC Jr, Spencer CC, Stafford RS, Taler SJ, Thomas RJ, Williams KA Sr, Williamson JD, Wright JT Jr. 2017 ACC/AHA/AAPA/ABC/ACPM/AGS/APhA/ASH/ASPC/NMA/PCNA Guideline for the Prevention, Detection, Evaluation, and Management of High Blood Pressure in Adults: A Report of the American College of Cardiology/American Heart Association Task Force on Clinical Practice Guidelines. Hypertension. 2018 Jun; 71(6):e13e115. doi: 10.1161/HYP.0000000000000065. Epub 2017 Nov 13.

Erratum in: Hypertension. 2018 Jun;71(6):e140-e144.

16.- Diagnóstico y Tratamiento de la Hipertensión Arterial en el Primer nivel de Atención, México: Instituto Mexicano del Seguro Social; 08/07/2014. [consultado Noviembre, 2020 ] Disponible En: http://cenetec-difusion.com/gpcsns/?page_id $=5223$

17.- O'Connor PJ, Sperl-Hillen JAM, Johnson PE, et al. Clinical Inertia and Outpatient Medical Errors. In: Henriksen K, Battles JB, Marks ES, et al., editors. Advances in Patient Safety: From Research to Implementation (Volume 2: Concepts and Methodology). Rockville (MD): Agency for HealthcareResearch and Quality (US); 2005 Feb. Available from:

https://www.ncbi.nlm.nih.gov/books/NBK20513/

18.-Pallarés V, Pascual R. Non-compliance and therapeutic inertia: two unanswered questions in clinicalpractice. Curr Med Research Op 2014; 30 (5): 839-840.

19.- García G, Reyes M. Inercia clínica en pacientes con Diabetes Mellitus en una Unidad de Medicina Familiar de Acapulco Guerrero. Aten Fam 2017; 4 (3): 102-106

20.- Caro JL et al. Control de la presión arterial en la población hipertensa española atendida en atención primaria. Estudio PRESCAP 2006. Medicina Clínica 2008;130(18): 681-687 


\section{Bernabé Ríos Nava}

Unidad Académica de Medicina Universidad Autónoma de Nayarit Dirección electrónica: brios1954@gmail.com

\section{J. Ramón Olivo Estrada}

Unidad Académica de Economía Universidad Autónoma de Nayarit Dirección electrónica: olivojr@gmail.com

RESUMEN: Presentamos nuestra vivencia pedagógica en la unidad de aprendizaje de Socioantropología de la Salud (SaS) con los estudiantes de los grupos A y B de primer ingreso a la carrera de Médico Cirujano (ciclo escolar 2016-2017) en la Unidad Académica de Medicina (UAM) de la Universidad Autónoma de Nayarit(UAN) en su incursión a los laberintos de la lectura y escritura académicas. De nuestra intervención resaltamos el trabajo realizado durante la implementación del taller y la elaboración de la autobiografía. Nuestro propósito fue colaborar mutuamente para la comprensión y puesta en práctica de diversas habilidades, destrezas y conocimientos en la lectura y producción de textos académico-científicos.

PALABRAS-CLAVE: Estudiantes primer ingreso; Escritura académica; talleres. 


\title{
1. INTRODUCCIÓN
}

\author{
"Raramente somos \\ conscientes de la estrecha \\ interrelación que existe entrela \\ escritura, pensar, saber \\ y ser". \\ Cassany, Daniel. 2006
}

Nuestra vivencia pedagógica en la unidad de aprendizaje de Socioantropología de la Salud (SaS) se llevó a cabo con los estudiantes de los grupos A y B de primer ingreso a la carrera de Médico Cirujano (ciclo escolar 2016-2017) en la Unidad Académica de Medicina (UAM) de la Universidad Autónoma deNayarit (UAN) en su incursión a los laberintos de la lectura y escritura académicas. Resaltamos el trabajo desarrollado durante la implementación del taller y la elaboración de la autobiografía, con el propósito de colaborar mutuamente para la comprensión y puesta en práctica de diversas habilidades, destrezas y conocimientos en la lectura y producción de textos académico-científicos.

La generación 2016-2021. Se conforma por un total de 166 estudiantes, de los cuales el $46 \%$ sonhombres y el $54 \%$ mujeres; a los grupos A y B pertenecen un total de 83 estudiantes ( $50 \%$ del total). Sus

rasgos demográficos son muy característicos: juventud, edad, soltería. Su presencia en los espacios universitarios les representará un cambio trascendental en todos los órdenes de su vida, porque en estos se llevará a cabo la socialización sistemática, ordenada y jerárquica en relación a la generación y transmisión de conocimientos, valores y actitudes que constituyen los ethos profesionales. (De Garay, s/f)En lo académico, las nuevas vivencias marcarán por siempre sus vidas futuras; en sus habilidades para la expresión oral y escrita, de acuerdo a diversos autores, mostrarán, por su naturaleza, diversas limitantes. Aun cuando pasaron tres años de formación preparatoriana, ésta no los dotó de lo necesario para enfrentarlos nuevos desafíos. Es en la universidad donde aprenderán las estrategias para participar con suficienciaen la cultura discursiva de su disciplina mediante diversas actividades en la producción y análisis de los textos académico-científicos cuyo fin es el aprendizaje universitario (Carlino, 2005:13).

El contexto universitario nayarita se muestra inhospito y agreste para el desarrollo de estas habilidades y conocimientos. A su falta de pericia se suman la falta de formación, lo atiborrado de los programas: "todo está bien saturado", "justo, sin 
espacio" y la opinión que nos hemos formado como docentes: "[...] no comprenden lo que leen", "[...]deberían llegar al nivel superior sabiendo estudiar y escribir mejor", “están acostumbrados a memorizar el texto" (Fernández, 2007:277). Son contadas las unidades de aprendizaje dedicadas al desarrollo de estas "[...] prácticas de lenguaje y pensamiento propías del ámbito académico superior" (alfabetización académica) (Carlino, 2005:13). En el caso de la UAM, son dos las unidades de aprendizaje que atienden estos menesteres: Desarrollo de Habilidades del Pensamiento (DHP) y Ensayo Científico (EC), las que representan el 3 \% del plan de estudios; además, el perfil de egreso no enfatiza las habilidades en la comunicación o expresión oral y escrita (UAM, 2017), como sí lo hacen el programa de Qfb (UACQBF, 2017) o el de Enfermería (UAE, 2017).

\section{LA UNIDAD DE APRENDIZAJE SOCIOANTROPOLOGÍA DE LA SALUD}

Como resultado de la reforma universitaria a principios del presente siglo, la UAM cambió su programa de Medicina General Integral (A-36) por el de Competencias Profesionales Integradas (CPI); en ese momento apareció SaS siendo ubicada en el primer semestre y formando parte del Tronco Básicode Área (TBA). Su propósito fue acompañar al estudiante en el estudio del fenómeno de la salud- enfermedad mediante el conocimiento y la aplicación de metodologías de las ciencias sociales a fin de entender la relación y el impacto que tienen en éste las circunstancias socioeconómicas, culturales y políticas de nuestro entorno. Se constituye por cuatro grandes temas, y tiene una duración de 18 sesionessemanales de dos horas. La investigación de un tema de salud es la actividad transversal, que los estudiantes desarrollan a lo largo del ciclo escolar.

\section{NUESTRA PROPUESTA METODOLÓGICA}

Desde el año 2015 nos dimos cuenta de la serie de problemas y limitaciones que mostraban los trabajos finales que entregaban los estudiantes, a los aspectos de limpieza se sumaban los de estructura, coherencia, cohesión, ortográfica, sintáctica. A partir de diversas pláticas grupales advertimos el escaso tiempo que sus docentes dedicaron en estas cuestiones. Ante ello decidimos contribuir a cambiar este panorama escolar y una pregunta fue nuestro eje ¿cómo incorporamos actividades de lectura y escrituraacadémicas que fortalezcan sus habilidades y destrezas a la vez 
de que hacerlas atractivas?

Una empresa de esta envergadura será posible no con una materia ni con un ciclo escolar, no es una propuesta remedial, implica, "[...] que cada una de las cátedras esté dispuesta a abrir las puertas de lacultura de la disciplina que enseña para que de verdad puedan ingresar los estudiantes, que provienen de otras culturas". (Carlino, 2005:15) En tanto eso llega a nuestra realidad universitaria nayarita bien vale lapena fortalecer y difundir las experiencias que están surgiendo. Después de varias reuniones introdujimos en el mes de agosto de 2016, entre otros, los siguientes cambios en la organización del programa: se solicitaron dos trabajos de investigación (una autobiografía y un ensayo) cuyo tiempo de elaboración, decada uno, osciló entre dos meses y medio; cada una de las 18 sesiones fue dividida en dos, en la primera se abordaron los temas del programa y la segunda fue dedicada al taller de lectura y escritura (Tle) en elcual se trabajarián los dos escritos.

\section{EL TALLER Y EL NACIMIENTO DE IDEAS-PÁRRAFOS-IDEAS}

"Me gusta el término taller por su connotación artesanal porque se venga de los atracones del saber y de sus modelos, porque evoca el aprendizaje y la paciencia"

Boniface Claire, 1992. Tomado de Triogla, 2008:19

Nuestra concepción del Tle ha cambiado al paso de estos meses. No se constituyó tal cual (formalmente) en un principio: objetivos, actividades, tiempos y materiales (Troglia, 2008:19). La primerapropuesta fue desarrollarlo en los espacios dedicados a las tutorías, lo que no funcionó por el alto ausentismo. La solución llegó al momento de abrirle un espacio en las sesiones del programa. Tenemos claro que la razón de ser del taller se basa no solo en el proceso de construcción de un texto, como procesofinal, sino que a su interior hay grandes etapas muy definidas como la planificación, el proceso de creacióny el resultado (Martínez, 2014:14); cada una con dinámicas y requerimientos específicos. Imaginamos altaller como el espacio que se distinguiera de las clases ordinarias: permitir la circulación del saber, la coordinación compartida, el trabajo cooperativo, propiciar el funcionamiento democrático, la participación no forzada, el humor y el juego (Troglia y Stapich, 2008:13). Lo pensamos, también, como el sitio donde pudiera germinar el trabajo individual en sus primeras "pinceladas" al dar respuesta a la Guía para explorar el problema retórico (Propósito, Audiencia, Autor, y Escrito) (Cassany, 1995:55), y como fase de 
preparación para su posterior incorporación a la "comunidad discursiva" de la disciplina; entendiendo por ello "[...] al conjunto de personas que comparten un grupo determinado de géneros discursivos" (Cassany, 2006:25).

El espíritu del Tle: a escribir se aprende escribiendo, se sustentó en la visión del enfoque metodológico "centrado en el proceso" donde la composición de los textos apuntó a generar y ordenar ideas (a pensar), hacer esquemas, revisar los borradores (pulir la estructura de la frase), corregirlos, reformularlos, en síntesis "[...]enseñar a esculpir y no enseñar esculturas" (Cassany, 1990:73). Se partió de una organización muy simple: una breve exposición del tema del día ("De lo que hay que saber para escribir bien; de las ganas de hacerlo; de lo que se puede escribir; "Accionar máquinas"; elaboración de párrafos; géneros discursivos), responder cómo el tema nos ayuda para la escritura de nuestro texto, indicaciones generales, tiempo para escribir y comentarios finales sobre los avances.

El Tle rompió con el empleo de tiempos de la sesión dedicada al programa. Se aprovechó para la conversación entre pares y con los docentes, comentar los avances, las dudas, las inquietudes, pararse y caminar por los pasillos a manera de que las ideas empezaran a fluir, sorber poco a poco el agua o el caféo simplemente seleccionar del teléfono celular la música, ponerse los audifónos y continuar escribiendo "Si lo importante es aprender a comunicar[...]dejémos escribir a los alumnos en clase, para que[...]practiquen y aprendan a hacerlo[...]aprenderán[...]a reflexionar, a desarrollar ideas, a compartir, a analizar la lengua". (Cassany, s/f) El estar al tanto del avance del trabajo y hacer los comentarios pertinentes fue una oportunidad para entender la importancia de la escritura como un proceso recursivo y etapas a las cuales atender "[...[la planificación (o preescritura), la textualización (o escritura) y la revisión(o reescritura)" (Cassany, 1999:15). ¿Llegarán a ser escritores y con ello a destacar en su disciplina? No lo sabemos, pero creemos, eso sí, mantener ese espíritu de libertad y apertura a la lectura y la escritura para todos y no olvidar que "[...]No para que todos sean artistas, sino para que nadie sea esclavo" (Rodari, 1995:8 citado por Troglia y Stapich, 2008:17).

\section{LA AUTOBIOGRAFÍA}

Se le ubica en el campo de la literatura, se dice que el autor se mueve entre lo real y lo imginario,puede anotar de más o de menos y que [...] "el elemento subjetivo 
interviene[...]Comencemos[...]a tratar las[...]autobiografías [...]como libros de literatura en los que sus autores[...]fueron poco a poco transformándolos en arte" (Avilés, 1997:49) La tomamos para trabajarla como un escrito de corte científico y porque desde nuestra visión es un (escrito-puerta) con el cual abrimos el panorama para conocer más adelante otros géneros académicos propios de la disciplina: el ensayo, la historia clínica, el informe de salud, "Aprender a escribir un escrito es aprender a desarrollar la práctica social correspondiente" (Cassany, 2006:21).

Además, reune varios atributos que permean la escritura y la lectura como "[...]el acto de [..]cincelar un autorretrato" (Zavala, 2013:88); hablo de mí, de mis días y años pasados, de mis metas y mis anhelos, de mis ratos de tristeza y soledad, me doy a conocer al otro y paso a la posteridad; nos acercamos a la revisión de diversos autores y sus escritos científicos; entendemos los primeros pasos de la investigación; el elaborarse de manera individual permite re-conocer sus maneras individuales de trabajo, el estilo personal de escribir, y los recursos de que disponen: el uso del diccionario, el empleo denuevos vocablos y su significado; la construcción de la atmósfera que rodea la escritura: el espacio físico, el momento del día, tipo de vestimenta, bebidas a consumir, la iluminación y la música.

El tema central tomó las vivencias en la universidad durante los primeros dos meses y medio. Y fue acompañado de un ejercicio etnográfico al elaborar un Diario, que es una técnica empleada en la recogida de la información (Murillo, 2010:10). Las indicaciones en su elaboración fueron que se narraran las experiencias más significativas del día y de cómo ha cambiado su dinámica familiar, personal y social. Representó un hecho inédito en ellos, alguno comentó que volvía a las aulas de primaria, nos parece que"[...]resulta un material que parece sostenerse a través del tiempo[...]al paso del cambio cultural”. (Chartier, 2016)

Enfatizamos que la autobiografía tendrá un remitente y en este caso será el estudiante próximo a ingresar a la Unidad académica. Por ello entonces cabrían algunas preguntas a ser resueltas en el camino:

¿qué me gustaría comentarle? ¿cómo decirselos de la manera más clara y comprensible? Con esta consignaapuntamos a despertar su imaginación, interpelarlos y convocarlos subjetivamente. (Finocchio, 2016) Unaspecto interesante fue cuando les explicamos que su trabajo llevaría un título y ellos serían los que lo construirían. Tomamos de base el escrito de Alexia Sanz Hernández "El método biográfico en investigación social: Potencialidades y limitaciones de las fuentes orales y los 
documentos personales", con el propósito de unificar criterios acerca de la autobiografía. Se les dieron las orientaciones necesariaspara que los trabajos finales fueran presentados impecables y su estructura cubriera los criterios de todo documento científico: tuviera cohesión y coherencia, además de aspectos de sintaxis, ortografía, redaccióny evitar hasta lo más posible el plagio de información conocido bajo el término "cortar y pegar" (cut andpaste) (CA White, 2009:2). Fue grata sorpresa que la totalidad de los estudiantes entregaran su trabajo final y cubrieran, en parte, las recomendaciones; aún siguieron presentándose problemas en la redacción, estructura interna, coherencia y cohesión, la ausencia de objetivos, y su poca relación con las conclusiones.

Los títulos fueron sugestivos: Un blanco caminar por mis años preuniversitarios; Hola mundo; Serendipia; Camino hacia la meta; Maktub; Recuerdos de una vida pasada; La vida no es perfecta por sí misma, lo que sucede en ella la hace perfecta; En camino al hospital; El tren de la vida; Vocación

¿sinónimo de amor?

\section{TESTIMONIOS}

"Este curso a pesar que solo nos toca los viernes me ha sido de interés, pues hemos aprendido[...]yo en lo particular, a escribir textos de una manera más formal y correcta”, "Uno de los trabajos que me costó bastante fue la autobiografía[...]", "[...] fue muy satisfactorio porque ya puedo hacer ensayos y trabajos siguiendo las normas APA que antes desconocía”, "Me pareció una clase muyenriquecedora[...]considero que mis hábitos de lectura han mejorado y soy un mejor redactor, gracias alos conocimientos que aprendí".

\section{CONCLUSIONES}

La composición de textos es una actividad actual, necesaria y fundamental para el ejercicio de la presente y futura práctica médica. La experiencia vivida con los estudiantes de recién ingreso nos muestraque a pesar de la afirmación anterior, el actual contexto académico se muestra adverso y árido para éste tipo de enseñanzas. Aún así, debemos insisitir en que los esfuerzos institucionales deberán de apoyar de manera decidida una formación profesional donde las habilidades para la compresión y composición de textos académico-científicos tenga un lugar preponderante a lo largo 
de la vida universitaria. Nuestra propuesta pedagógica deja la lección de que pueden realizarse un sinúmero de ejercicios de esta naturaleza y que los estudiantes responderán, como ha sido una constante, de manera extraordinaria; por lo que debemos continuar luchando por abrir nuevos espacios curriculares. 


\section{REFERENCIAS}

Aleza, Izquierdo Milagros. (2011). Signos ortográficos, ortotipografía y normas actuales. España: Departamento de Filología Española. Universidad de Valencia. Recuperado el 2 de Febrero de 2017, de https://www.uv.es/normas/2011/materiale s/Signos_2011.pdf

Alexopoulou, Angélica. (2010). Tipología textual y comprensión lectora en E/LE. Nebrija(9). Recuperadoel 14 de Diciembre de 2016, de http://www.nebrija.com/revistalingui stica/tipo logia-textual-y- comprension-lectora-en-e-le

Avilés, Fabila René. (1997). La autobiografía como género literario. Revista de la Universidad de México, 48-53. Recuperado el 14 de Noviembre de 2016, de http://www.revistadelauniversidad.unam.mx/ojs_rum/files/journals/1/articles/14586/ public/14586- 19984-1-PB.pdf

Carlino, P. (2005). Escribir, leer y aprender en la universidad. Una introduccion a la alfabetización académica. México: Fondo de Cultura Económica.

Culebras y Vives Cecilia. (2004). Taller de ortografía y redacción básicas. Cuernavaca, Morelos, México:Departamento de Desarrollo Académico e Idiomas. Seminario de investigación CE NIDET. Recuperado el 15 de Octubre de 2016, de http://ww w.cenidet.edu.mx/subaca/w eb-dda/docs/ortografia_basica.pdf

Cassany, Daniel. (1995). La cocina de la escritura. Barcelona, España: Anagrama.

Cassany, Daniel y Antonio García del Toro. (1999). Recetas para escribir. San Juan de Puerto Rico. Editorial Plaza Mayor.

Cassany, Daniel. (2006). Taller de textos. Leer, escribir y comentar en el aula. Barcelona, España: Paidós.

Cassany, Daniel. (2009). Enfoques didácticos para la enseñanza de la expresión escrita. Comunicación, Lenguaje y Educación, (6), 63-80. Recuperado el 13 de febrero de 2017, de https://ww w.upf.edu/pdi/dtt/daniel_cassany/enfoqes.htm

Cassany, Daniel (s/f)). Decálogo didáctico de la enseñanza de la composición. Recuperado el 22 de febrero de 2017, de https://www.upf.edu/pdi/dtf/daniel_cassany/decalogoco mposicion.pdf

Chartier, Anne-Marie (2016). Cierre. En el cuaderno de clase: las huellas del cotidiano leer y escribir.Flacso Virtual. Recuperadoel 28 de febrero de 2017, de http://virtual.fla cso.org.ar/mod /book/view.php?id=124221\&chapterid=187071

C A White Robin. (2009). Writing Guide 2: Writing a Research Paper. 7th Edition. School of Law. University of Leicester. Recuperado el 15 de febrero de 2017, de https://ww w2.le.ac.uk/departments/law/current/writingguide/Writing_Guide_Research_Paper_2009.pdf. 
De Garay Adrian (s/f). Mis estudios y propuestas sobre los jóvenes universitarios mexicanos. Recuperadoel 22 de febrero de 2017, de http://www.fundacionucol.org/ wp-content/uploads/2013/09/Estudios-y- propuestas-Adrian-de-Garay.pdf

Díaz-Barriga, Arceo Frida y Gerardo Hernández Rojas. (2002). Estrategias docentes para un aprendizajesignificativo. Una interpretación constructivista. México. 2ª . Ed. McGrawHill

Fernández, G. y Carlino Paula. (2015). Leer y escribir en los primeros años de la universidad: Un estudio en Ciencias Veterinarias y Humanas de la UNCPBA. Cuadernos de Educación, 277-289. Recuperado el 28 de diciembre de 2015, de w ww://www.aacademica.org/paula.carlino/54 .pdf

Finocchio, Ana María. (2016). Las consignas de escritura en la escuela. En Cuando las consignas invitana escribir. Recuperado el 20 de febrero de 2017, de http://virtual.f lacso.org.ar $/ \mathrm{mod} / \mathrm{book} / \mathrm{view}$. php?id=124261\&chapt erid=187511

Martínez, Ezquerro Aurora (2014). Talleres literarios. La Rioja. España: Universidad de la Rioja. Serviciode publicaciones. Recuperado el 15 de Febrero de 2017, de http: // biblioteca.unirioja.es/tfe_e/T FE000747.pdf

Martínez, M. J. (2010). Investigación etnográfica: Métodos de investigación en educación especial. México, México: Universidad Autónoma Metropolitana. Recuperado el 8 d e Febrero de 2017, de https://www.uam.es/personal_pdi/stmaria/jmurillo/Investiga

resentaciones/Curso_10/I_Etnografica_Trabajo.pdf

cionEE/P

Monzón, V. E. (2003). Estilo de citas y referencias de la American Psychological Association (APA). Caracas, Venezuela: Universidad Central de Venezuela. Recuperado el 22 de Diciembre de 2016, de http://documentslide.com/education/manual-del-apa-est ilo-de-citas-y-referenciasde-la-american-psychological-association.html

Rincón, Castellanos Carlos Alberto. (s.f.). Unidad 14: La escritura III. Recuperado el 3 de E nero de 2017, de

http://aprendeenlinea.udea.edu.co/boa/contenidos.php/cb10887 d 80142488399661377b684b60/511/estilo/pn_vino/1/contenido/capitulos/Unidad14L aEscritura3.PDF

Ruíz, Zavala Alma, Beatriz López y Cervantes, Elisa Aguilar Funes y Tatiana Sorókina (Coordinadora). (2012). Géneros discursivos. Breve guía universitaria. México: Un iversidad Autónoma Metropolitana- Xochimilco. Recuperado el 14 de Noviembre de 2016, de http://biblioteca.xoc.uam.mx/docs/ahistorico/generos_discursivos.pdf

Sanz, Hernández Alexia. (2005). El método biográfico en investigación social: Potencialidades ylimitaciones de las fuentes orales y los documentos personales. 
Asclepio, 99-115. Recuperado el 8 de Febrero de 2017, de https://flacso.unah.ed u.hn/gestordocumentos/297

Troglia, María José y Elena Stapich. (2008). El taller de lectura. Un espacio para la autoconstrucción delectores. En S. E. (Coordinadora), Textos, tejidos y tramas en el taller de lectura y escritura (pág. 163).Buenos Aires. Argentina: Ediciones Novedades Educativas. Recuperado el 15 de Febrero de 2017, de https://boo ks.google.com.mx/books?id=NarkaxgvT9QC\&pg=PA19\&lpg=PA19\&dq=talleres+clair e+boniface\&so urce=bl\&ots=RWjtqGwLTt\&sig=zM2TuAFD38ysgHxDrbiOYFiXUzA\&hl=es419\&sa $=X \& v e d=0 a h U K E w j l z N W j 6 p L S A h U H 92 M K H W S X A r Q Q 6 A E I H j A$

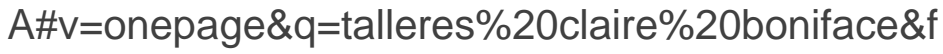

Troglia, María José. (2008). Un taller y otros talleres. Vallas y trampolines a la hora de animar un taller de lectura y escritura. En Textos, tejidos y tramas en el taller de lectura y escritura. Buenos Aires. Argentina: Ediciones Novedades Educativas. Recuperado el 15 de Febrero de 2017, de https://books.google.com.mx/books?id

$=$ NarkaxgvT9QC\&pg=PA19\&lpg=PA19\&dq=talleres+claire+boniface \&source=bl\& ots=RWjtqGwLTt\&sig=zM2TuAFD38ysgHxDrbiOYFiXUzA\&hl=es-

419\&sa=X\&ved=0ahUKEwjlzNWj6pLSAhUH92MKHWSXArQQ6AEIHjAA\#v=onepage $\& q=$ talleres $\%$ 20claire\%20boniface\&f

Trujillo, Sáez Fernando. (2002). Los modelos textuales en la enseñanza de la escritura y la lectura. Europhoros, 11-22. Recuperado el 12 de enero de 2017, de http://fernand otrujillo.es/wp-content/uploads/2010/05/modesclec.pdf

Universidad Autónoma de Nayarit. Programa de estudios de la licenciatura en Químico Farmacobiólogo. Recuperado el 8 de febrero de 2017, de http://www.uan.edu.mx/e s/quimico-farmacobiologo

Universidad Autónoma de Nayarit. Programa de estudios de la licenciatura en Médico Cirujano. Recuperado el 8 de febrero de 2017, de http://www.uan.edu.mx/es/licenc iatura-medico-cirujano

Universidad Autónoma de Nayarit. Programa de estudios de la licenciatura en Enfermería. Recuperado el 8 de febrero de 2017, de http://www.uan.edu.mx/es/licenciatura-en-enfermeria

Zavala, Díaz Ana L. (2013). La "autobiografía" como una de las bellas artes. Revista de la Universidadde México (114), 87-88. Recuperado el 2 de Febrero de 2017, de http ://www.revistadelauniversidad.unam.mx/ojs_rum/index.php/rum/article/view/687 
CHAPTER 03

ESTUDIO DE LOS FACTORES DE RIESGO PARA EL CANCER

DE MAMA EN MUJERES URUGUAYAS

\section{Natalia Camejo}

Prof. Adj. del Servicio de Oncología Clínica, Hospital de Clínicas, Facultad de Medicina, Universidad de la República. Uruguay.

Servicio de Oncología Clínica. Hospital de Clínicas Avda. Italia s/n. CP 11600.

Montevideo, Uruguay.

Correo electrónico: ncam3@yahoo.com

\section{Cecilia Castillo}

Ex Prof. Adj. del Servicio de Oncología Clínica, Hospital de Clínicas, Facultad de Medicina, Universidad de la República. Uruguay.

\section{Nora Artagaveytia}

Prof. Adj. del Departamento Básico de Medicina, Hospital de Clínicas, Facultad de Medicina, Universidad de la República. Uruguay.

\section{Ana Laura Hernandez}

Prof. Agda. del Departamento de Psicologia Medica, Hospital de Clínicas, Facultad de Medicina, Universidad de la República. Uruguay.

\section{Andrea Schiavone}

Ex Asistente del Servicio de Oncología Clínica, Hospital de Clínicas, Facultad de Medicina, Universidad de la República, Uruguay.

\section{Milans Soledad}

Prof. Adj.con Orientación en Imagenología Mamaria del Departamento de Imagenología, Hospital de Clínicas, Facultad de Medicina, Universidad de la República, Uruguay.

\section{Guillermo Laviña}

Ex Prof. Adj. Clinica Quirúrgica 1, Facultad de Medicina, Universidad de la República. Uruguay.

\section{Lucía Delgado}

Ex Prof. Directora del Servicio de Oncología Clínica, Hospital de Clínicas, Facultad de Medicina, Universidad de la República. Uruguay.

RESUMEN: En Uruguay el cáncer de mama ocupa el primer lugar en incidencia y mortalidad por cáncer en la mujer.El conocimiento de la distribución de los factores de riesgo relacionados con el desarrollo de la enfermedad facilita la incorporación de estrategias de prevención en la práctica clínica habitual, lo que podría contribuir a disminuir los índices de morbimortalidad. Objetivos: conocer el perfilepidemiológico 
para el cáncer de mama y la frecuencia del control mamográfico en la población encuestada.- Material y Métodos: Se aplicó una encuesta a mujeres uruguayas. Luego de realizada la misma, se les brindó información sobre los factores de riesgo y protectores y sobre la importancia de realizar el control mamográfico. Resultados: Se incluyeron 296 encuestadas, la mediana de edad fue 36 años (18-80 años). Excluyendo el sexo femenino (factor de riesgo presente en todas las encuestadas), 133 encuestadas (44,9\%) presentaban uno o más factores de riego. La mayoría de las mujeres mayoresde 50 años (117, $90 \%)$, realizaban control mamográfico al menos en forma bianual. Conclusiónes: Concordantemente con lo reportado por el Programa Nacional de Cáncer de Mama, 44,9\% de las encuestadas tuvieron algún factor de riesgo. La mayoría de las encuestadas mayores de 50 años realizaban control mamográfico y clínico al menos en forma bianual. Si bien, debido a las características del trabajo, solamente podemos sacar conclusiones sobre las mujeres incluidas, los datos recogidos nospermiten conocer mejor el perfil epidemiológico de la población uruguaya, lo que puede contribuir a lasprácticas de prevención.

PALABRAS CLAVE: Cáncer de mama; Factores de riesgo; Prevención. 


\section{INTRODUCCIÓN}

El cáncer es un problema de significativa importancia en el tablero epidemiológico del Uruguay. De hecho, tomando en cuenta ambos sexos en forma conjunta, el cáncer es la segunda causa de muerte,después de las enfermedades cardiovasculares, siendo causante de casi un cuarto $(24,6 \%)$ del total de los fallecimientos registrados en nuestro país cada año. Se registran anualmente casi 16.179 casos nuevosy mueren más de 7.995 uruguayos por esta causa $(1,2)$.

Al igual de lo que se observa a nivel mundial, el cáncer de mama (CM) en Uruguay es el más frecuente en el sexo femenino y también la principal causa de muerte por cáncer. Cada año se registran unos 1.926 casos nuevos y unas 670 mujeres mueren como consecuencia de esta enfermedad. En Uruguay, la probablidad de padecer CM a lo largo de la vida es de una cada 11 mujeres. La edad medianade las pacientes a las que se les diagnosticó su primer CM infiltrante en el período 20122016 fue 63 años (51-74 años). La gran mayoría (69,5\%) de los casos se diagnostican en estadios tempranos reafirmando la importancia de la prevención secundaria en esta patología $(3,4)$.

Si bien en los últimos años se ha comprobado una disminución de la mortalidad por esta causa, lo que podría estar vinculado a un incremento de la detección temprana, una mejora en los tratamientos y en la integración de equipos interdisciplinarios en esta patología (2), el CM continúa generando una gran carga, tanto a nivel social como económico, por el impacto que produce en la persona afectada y en su entorno. La carga económica para la sociedad se configura mediante costos directos e indirectos. A título de ejemplo, dentro de los costos directos se encuentran los de atención médica y, dentro de los costos indirectos, deben tenerse en cuenta el ausentismo laboral y las pensiones por invalidez, viudez yorfandad. Por estas razones enunciadas, entre otras, es importante desarrollar políticas y programas parala prevención y el control de tales enfermedades.

La prevención del CM puede desarrollarse en diferentes niveles. La prevención primaria tiene como objetivo evitar que el individuo desarrolle la enfermedad, y se basa en el conocimiento de los factores de riesgo y de los factores protectores. La prevención secundaria tiene como objetivo lograr la curación de la enfermedad y se centra en la detección precoz y el tratamiento oportuno, en etapas dondela curabilidad es alta, con secuelas mínimas o directamente sin ellas (5). 


\section{PREVENCIÓN PRIMARIA EN EL CM}

La prevención primaria del CM está orientada a la modificación de los factores de riesgo pasiblesde cambio y a fomentar los factores protectores. Desarrollar esta clase de prevención en la población general es complejo actualmente ya que, en la mayoría de las personas que desarrollan la enfermedad, únicamente se reconocen dos factores de riesgo y ellos no son modificables: el sexo femenino y la edad.

\section{FACTORES DE RIESGO}

Si bien la etiología del CM, al igual que acontece en la mayoría de los cánceres, es desconocida,se reconocen diversos factores de riesgo involucrados en su génesis. Estos se pueden clasificar en: modificables y no modificables (tabla 1). Conocer la distribución de los factores de riesgo es esencial para efectuar intervenciones de promoción de salud en la comunidad, con el fin de promover el bienestary la salud de las mujeres.

Aproximadamente en la mitad de las pacientes diagnosticadas de CM se detecta algún factor deriesgo conocido, diferente al sexo femenino y la edad. Entre de los factores de riesgo es de vital interésreconocer aquellos que son modificables, entre los cuales se destacan el sobrepeso u obesidad, consumonocivo de bebidas alcohólicas y uso de terapia de reemplazo hormonal. Además, existen factores protectores como la práctica regular de ejercicio (6). El entendimiento de estos factores nos permite planificar acciones de prevención primaria en nuestro entorno acordes con las características de la población destinataria.

\section{PREVENCIÓN SECUNDARIA}

Las tasas de mortalidad por CM han descendido en los últimos años, debido al aumento de la detección temprana mediante el uso de mamografía de tamizaje. Hasta el momento la mamografía constituye el mejor método para el diagnóstico oportuno y está demostrado que es efectiva a fin de reducir la mortalidad por esta enfermedad (7). De acuerdo a las Guías de Práctica Clínica de Detección Temprana del Cáncer de Mama del Ministerio de Salud Pública (MSP), se recomienda realizar tamizaje mamográfico sistemático cada dos años a las mujeres con edad comprendida entre 50-69 años, intervaloetario en el cual el beneficio del tamizaje 
con mamografía es mayor y los riesgos (sobrediagnóstico, falsos positivos, etc) menores. En el caso de las mujeres con edades comprendidas entre 40-49 años y 70-74 años, se sugiere individualizar, analizando con la paciente los potenciales beneficios y riesgos derealizar dicho estudio.

b. OBJETIVO:

Conocer el perfil epidemiológico para el CM y la frecuencia del control clínico y mamográfico en la población encuestada

c. OBJETIVOS ESPECÍFICOS:

ii. Conocer la prevalencia de los principales factores de riesgo para CM en la población encuestada;

iii. Medir la frecuencia con que se realiza el control clínico y el estudio mamográfico;

iv. Comparar los resultados con las bases de datos a nivel nacional.

\section{MATERIAL Y MÉTODOS}

Se trata de un estudio observacional y prospectivo, en el que se incluyeron las mujeres que concurrieron a las jornadas de prevención del CM realizadas en conjunto por la Comisión Honoraria de Lucha contra el Cáncer (CHLC) y el Servicio de Oncología Clínica del Hospital de Clínicas desde el 2012 hasta el 2019 inclusive. El cuestionario fue respondido de forma individual por cada participante y de manera anónima.

La encuesta fue respondida de forma individual por cada participante y de manera anónima, dándole tiempo suficiente para responder a todas las preguntas. Dicha encuesta fue diseñada ad hoc paraindagar sobre los principales factores de riesgo para desarrollar la enfermedad, la realización del examen mamario y mamografía de screening, en forma comprensible (anexo 1). Consistió en 12 preguntas la mayoría cerradas, ya fueren dicotómicas o con múltiples alternativas. Las mismas estaban destinadas a conocer el comportamiento de la población en relación a los factores de riesgo para el CM y medir la frecuencia con que se realiza el examen mamario y el estudio mamográfico.

Las variables incluidas fueron: antecedentes familiares de CM; antecedentes 
personales de cáncery enfermedades proliferativas de la mama; elevada densidad mamaria; factores hormonales; consumo de alcohol; y ejercicio físico.

Los datos fueron recopilados, analizados y comparados con los datos uruguayos disponibles. Losmismos fueron procesados en una hoja de cálculo (Microsoft Excel) y como medidas de resumen se utilizaron las frecuencias relativas y absolutas.

El estudio propuesto se realizó de acuerdo con las normas éticas internacionales para las investigaciones biomédicas: "Normas del MERCOSUR sobre regulación de los estudios clínicos" y la "Declaración de Helsinski", y con el reglamento de investigación aprobado por la Comisión Nacionalde Ética en 2019.

\section{RESULTADOS}

Se incluyeron 296 encuestadas, 91 procedentes de Montevideo, 37 de Paysandú, 18 de Rocha, 36 de Tacuarembó, 35 de Maldonado y 79 de Soriano.

La integridad de las personas encuestadas fue de sexo femenino, y la mediana de edad fue 36 años (18-80 años).

Descartando como factor de riesgo el sexo femenino (pues se halla presente en todas las encuestadas), 133 encuestadas (44,9 \%) presentaban uno o más factores de riesgo para CM. Treinta y siete encuestadas tenían un sólo factor de riesgo, 30 (10 \%) tenían dos factores, y únicamente 8 (2,7\%) de las encuestadas tuvieron tres o más factores de riesgo.

La mayor parte de las encuestadas (192, 64,8 \%) fueron premenopáusicas, 102 (34,4 \%) posmenopáusicas y el resto (2 encuestadas) perimenopáusicas.

Ciento ochenta encuestadas $(60,8 \%)$ tenían hijos, de éstas ciento cuarenta y cuatro (80 \%) tuvieron hijos antes de los 30 años, y la mayoría (151 pacientes, o sea el $83,8 \%$ ) dieron de mamar durantemás de 6 meses.

Treinta y seis encuestadas (12,1\%) tenían antecedentes personales de CM, y veintisiete de ellas (75\%) desarrolló la enfermedad luego de los 50 años.

Setenta y siete encuestadas (26 \%) tenían antecedentes familiares de cáncer, 20 (7\%) tenían dos o más familiares afectados, 18 (6,1 \%) tenían un familiar de primer grado afectado, y 11 (3,7 \%) tenían dos o más familiares afectados y uno de estos era de primer grado.

Entre las encuestadas posmenopáusicas, 67 (65,6 \%) tuvieron su menopausia entre los 45 y 55 años, 21 (20,5\%) tuvieron menopausia tardía (luego de los 55 años) 
y 14 (13,7 \%) temprana (antes de los 45 años). La mayoría (92 encuestadas, 90,1\%) no recibió THR, el resto sí la recibió. De las 10 encuestadas que recibieron THR, 3 recibieron THR combinada, 2 con progestágenos y en 5 casos no secontaba con el dato.

Ciento noventa y siete encuestadas $(66,5 \%)$ realizaban ejercicio en forma regular, la mayor parte(138 o sea el $70 \%$ ) caminaba al menos 30 minutos 3 veces a la semana, y las demás realizaban otras formas de ejercicio (28 bicicleta, 15 yoga, 5 taichi, 5 aparatos, 2 gimnasia, 2 pileta y 2 pilates). El restode las encuestadas (34 \%) eran sedentarias.

Más de la mitad (180 encuestadas, 60,8 \%) no consumía alcohol. Del total de consumidoras de alcohol, 104 (89,6 \%) consumían menos de tres copas a la semana. La mayoría de las mujeres mayores de 50 años (117, $90 \%$ ), realizan control mamográfico y clínico al menos en forma bianual; el resto no realizan control mamográfico ni examen mamario en forma regular.

\section{DISCUSIÓN}

Como fue mencionado previamente la etiología del CM es desconocida, si bien múltiples estudios indagan sobre factores de riesgo que permitan predecir y cuantificar el riesgo de desarrollar la enfermedad, la mayoría de las veces se trata de un CM esporádico, no siendo posible identificar factoresde riesgo implicados en su génesis más allá del sexo y la edad

De las 296 encuestadas, 133 (que equivalen al 44,9 \%) presentaban uno o más factores de riesgopara CM. Esta frecuencia es similar a la identificada a nivel nacional por el Programa Nacional de Cáncerde Mama (PRONACAM), que fue del $43 \%$ (8) y a la identificada previamente por nuestro equipo de trabajo (40\%) (9).

De la totalidad de las encuestadas, 77 (26\%) presentaban antecedentes familiares; sin embargo, únicamente 18 encuestadas $(6,1 \%)$ tenían un familiar de primer grado afectado. Si bien esta proporciónes similar a la evidenciada por nuestro equipo de trabajo en un estudio previo (7,6 \%) (9); es inferior al porcentaje que emerge de la evaluación efectuada por el PRONACAM (13,6 \%) (8).

La diferencia podría explicarse porque la población analizada en nuestro estudio es una poblaciónmás joven, con una mediana de 36 años en el presente estudio y de 34 años en el estudio publicado previamente, es decir se trata de mujeres jóvenes 
cuyos familiares de primer grado quizá no han alcanzado aún la edad de los picos de incidencia del CM. Entretanto, la población evaluada por el PRONACAM incluye mujeres con una mediana de 52 años de edad (8).

Con respecto a los factores protectores, la mayor parte de las encuestadas (197 encuestadas, 66,5\%) realizaban ejercicio, y únicamente el 33,3\% era sedentaria. Este porcentaje de sedentarismo es inferior al evidenciado en la Primera Encuesta Nacional de Factores de Riesgo de Enfermedades Crónicas No Transmisibles (ECNT), en la cual se reporta un $40,7 \%$ de personas sedentarias dentro del sexo femenino (10). Es presumible que esta diferencia se deba a la distinta edad promedio de las poblaciones respectivamente consideradas.

Es de amplio conocimiento que el parto antes de los 30 años y la lactancia son considerados comofactores protectores en la génesis del CM, la mayor parte de las encuestadas tuvieron hijos antes de los 30 años (144, que representan el $80 \%$ de este subgrupo, y la mayoría (151 pacientes, o sea el 83,8 \% dieron de mamar durante más de 6 meses.

Ciento dieciséis encuestadas (39,1\%) consumía alcohol, siendo esta cifra algo inferior a la reportada en la Primera Encuesta Nacional de Factores de Riesgo de Enfermedades Crónicas no Transmisibles (ECNT), que fue del 63,7\% (10) y la mayoría de las que ingerían alcohol (104, equivalenteal 89,6 \%) lo hacían menos de tres veces a la semana.

Si bien entre los factores de riesgo indagados no se encontraba el tabaquismo y múltiples estudiossugieren que existe un riesgo más elevado de desarrollar CM en la población fumadora, la relación entreel tabaquismo y el desarrollo del CM es difícil de analizar, dado que hasta el $50 \%$ de las mujeres fumadores consumen alcohol, un factor de riesgo conocido para el desarrollo de la enfermedad (11).

Por otra parte, la asociación entre un índice de masa corporal alto y el riesgo de desarrollar CM en las mujeres postmenopáusicas también es conocido (12) y tampoco fue indagado en el cuestionario, por lo que queda pendiente la evaluación de estos factores en un futuro.

La mayoría de las mujeres mayores de 50 años realizaban control mamográfico y clínico al menosen forma bianual (117, esto es un $90 \%$ de dicho subgrupo).

Según los datos aportados por la CHLC, durante el año 2014 se realizaron a nivel nacional 95.935 mamografías. Si tenemos en cuenta los datos aportados por el Instituto Nacional de las Mujeres, en nuestro país viven 248.367 mujeres de entre 50 
y 64 años. Tomando en consideración que la gran mayoría de exámenes mamográficos se efectúan a mujeres de entre 50 a 70 años, podríamos realizar una extrapolación de los datos, y presumir que más la mitad de las mujeres de entre 50 a 64 años se realiza mamografía en forma bianual. Tal porcentaje, relativamente elevado, traduciría sin duda el impacto de las campañas de prevención realizadas con la CHLC y el Ministerio de Salud Publica

Empero al analizar los resultados conseguidos debemos considerar que la encuesta fue efectuadaen el ámbito de las jornadas de prevención de CM; vale decir que la totalidad de las encuestadas asisitiópor inquietud en una conferencia de prevención de la enfermedad, lo que acarrea un sesgo muy importante y restringe la posibilidad de extrapolar los resultados a la población general. En este sentido debemos tener en consideración que el $12,1 \%$ de las encuestadas tenían antecedentes personales y el $26 \%$ tenían antecedentes familiares de CM, lo cual podría conllevar un interés de base por parte de las asistentes y eventualmente generar una alteración en el análisis de los resultados.

Igualmente debemos tener en cuenta que la edad media de las encuestadas fue de 36 años (es decir que se trata de una población joven), lo que también podría ser una limitación significativa para extrapolar o proyectar estos resultados en mujeres uruguayas de otras franjas etarias.

Así queda pendiente para estudios venideros la valoración de los factores de riesgo yprotectores para el CM en una población más amplia.

\section{CONCLUSIONES}

Si bien, debido a las características de este trabajo, sólo nos es posible alcanzar conclusiones sobre las mujeres incluidas, los datos recogidos nos permiten conocer mejor el perfil epidemiológico de la población uruguaya, lo que puede contribuir a las prácticas de prevención. De manera semejante a loreportado por el PRONACAM, $44,9 \%$ de las encuestadas tuvieron algún factor de riesgo para desarrollar la enfermedad. El porcentaje de encuestadas con antecedentes familiares fue inferior a lo evidenciado anivel nacional y se halló menor porcentaje de sedentarismo, lo que podría explicarse por la edad de las mujeres encuestadas, con una mediana de 36 años. El porcentaje de consumidoras de alcohol fue inferiora la evidenciada en la primera ECNT, y la mayoría de las encuestadas consumía alcohol menos de tres 
veces a la semana. La mayoría de las encuestadas de más de 50 años realizaban control mamográfico yclínico al menos en forma bianual. Esto sin duda traduce el impacto de las campañas de prevención realizadas con la CHLC y el Ministerio de Salud Publica. 


\section{BIBLIOGRAFÍA}

1. Ministerio de Salud Pública. División Estadística. Estadísticas de mortalidad.

(Fecha de acceso:19 de abril 2019] Disponible en: http://www.msp.gub.uy/EstVitales/

2. CHLCC. Registro Nacional de Cáncer. Situación epidemiológica del cáncer en el Uruguay. Montevideo, mayo 2019. [citado: 21 de abril de 2020] Disponible en: $\quad$ https://www.comisioncancer.org.uy/Ocultas/Situacion-Epidemiologica-delUruguay-en-relacion-al-Cancer--Mayo-2019-uc108

3. Comisión Honoraria de Lucha contra el Cancer. Informe Anual. Periodo 2012-2016 (Fecha acceso: 20/04/2020). Disponible en: https://www.comisioncancer.org.uy/Ocultas/Cancer-de-MAMA- Mujeres--uc77

4. Barrios E.; Garau M. Cáncer: Magnitud del problema en el mundo y en Uruguay, aspectos epidemiológicos. Anales de la Facultad de Medicina 2017, 4, 9-46

5. Fletcher RH, Fletcher SW, Fletcher GS. Clinical epidemiology: The essentials. 5th ed. Philadelphia: Lippincott, 2013. 255 p.

6. Key TJ, Verkasalo PK, Banks E. Epidemiology of breast cancer. Lancet Oncol. 2001;2(3):133-40.

7. Nelson HD, Tyne K, Naik A, Bougatsos C, Chan B.K. Humphrey L. Screening for breast cancer:an update for the U.S. Preventive Services Task Force. Ann Intern Med 151 (10): 727-37, W237-42, 2009

8. Ministerio de Salud Pública (Uruguay). Programa Nacional de Detección Oportuna de Cáncer de Mama. Evaluación de sus avances a los 7 años de desarrollo. Montevideo: MSP 1998: 33 pp.

9. Camejo N, Castillo C, Artagaveytia N, Hernandez AL, Schiavone A, Milans S et al. Encuestas sobre prevención del cáncer de mama en una población de mujeres uruguayas. An Facultad Med (UnivRepúb Urug). 2018,5(2):63-74.

10. Ministerio de Salud Pública Dirección General de la Salud, División Epidemiología. 2aEncuesta Nacional de Factores de Riesgo de Enfermedades Crónicas No Transmisibles.

11. Gaudet MM, Gapstur SM, Sun J. Active smoking and breast cancer risk: original cohort data andmeta-analysis. J Natl Cancer Inst. 2013 Apr;105(8):515-25. Epub 2013 Feb 28.

12. Eliassen $\mathrm{AH}$, Colditz $\mathrm{GA}$, Rosner $\mathrm{B}$, et al. Adult weight change and risk of postmenopausalbreast cancer. JAMA. 2006;296(2):193. 
CHAPTER 04

CONOCIMIENTOS, ACTITUDES Y PRÁCTICAS DE LOS

PROFESIONALES DE LA SALUD ANTE ELVIH/SIDA EN EL

PRIMER NIVEL DE ATENCIÓN

\section{Liliana Aurora Carrillo Aguiar}

Higher academic background: Médico Familiar., Master en Ciencias Médicas., Profesor Titular de la Residencia en Medicina Familiar.

Current Institution: Unidad Médica Familiar 77, Madero Tamaulipas, Instituto Mexicano del Seguro Social, México.

Full address (can be institutional or personal, as you prefer): Blvd. Adolfo López Mateos S/N, Col. Las Conchitas, Madero Tamaulipas.

E-mail: lilifha@hotmail.com

\section{Oscar Alejandro Moreno Solís}

Higher academic background: Médico Familiar

Current Institution: Servicio de Atención Familiar. Unidad Médica Familiar 16, Altamira Tamaulipas, Instituto Mexicano del Seguro Social, México.

Full address (can be institutional or personal, as you prefer): Calle $2 \mathrm{~N} / \mathrm{A}$, Jardines de Altamira, Residencial Centro 1, 89600 Altamira, Tamaulipas.

E-mail: oams87@gmail.com

\section{Brian González Pérez}

Higher academic background: Médico Familiar., Doctor en Ciencias de la Salud., Master en Ciencias Médicas., Master en Innovación y Tecnología Educativa., Profesor Investigador.

Current Institution: Servicio de Atención Familiar. Unidad Médica Familiar 38, Tampico Tamaulipas, Instituto Mexicano del Seguro Social, México. Facultad de Medicina "Dr. Alberto Romo Caballero" Universidad Autónoma de Tamaulipas, Tampico, Tamaulipas, México.

Full address (can be institutional or personal, as you prefer): Calle Argentina y Canadá 107 Col. Infonavit C.P. 89310, Tampico, Tamaulipas.

E-mail: brian.gonzalez.perez@gmail.com

\section{Ricardo Salas Flores}

Higher academic background: Endocrinólogo Pediatra., Master en Ciencias Médicas., Profesor Investigador.

Current Institution: Coordinación de Educación en Salud e Investigación. Hospital General Regional No. 6, Madero, Tamaulipas, Instituto Mexicano del Seguro Social, México. Facultad de Medicina "Dr. Alberto Romo Caballero" Universidad Autónoma de Tamaulipas, Tampico, Tamaulipas, México.

Full address (can be institutional or personal, as you prefer): Blvd. Adolfo López Mateos S/N, Col. Las Conchitas, Madero Tamaulipas.

E-mail: risafl@yahoo.com

Jesús Javier Mejía Inglés

Higher academic background: Médico Familiar 
Current Institution: Jefatura de Departamento Clínico en Atención Familiar. Unidad Médica Familiar 77, Madero Tamaulipas, Instituto Mexicano del Seguro Social, México.

Full address (can be institutional or personal, as you prefer): Blvd. Adolfo López Mateos S/N, Col. Las Conchitas, Madero Tamaulipas.

E-mail: jesadry.28@gmail.com

\section{Verónica Olvera Mendoza}

Higher academic background. Doctora en Desarrollo Educativo., Master en Finanzas., Profesor Investigador.

Current Institution: Facultad de Medicina "Dr. Alberto Romo Caballero" Universidad Autónoma de Tamaulipas, Tampico, Tamaulipas, México.

Full address (can be institutional or personal, as you prefer): Centro Universitario Sur, Cto. Interior S/N CP 89337, Tampico, Tamaulipas

E-mail:volvera@docentes.uat.edu.mx

RESUMEN: INTRODUCCION: El Virus de inmunodeficiencia humana $(\mathrm{VIH})$ / Síndrome de inmunodeficiencia adquirida (SIDA) es una enfermedad infectocontagiosa que a pesar de ser prevenible, sigue siendo un importante problema de salud pública a nivel mundial y sus portadores padecen el riesgo de sufrir prejuicios y discriminación por parte de la sociedad e incluso del mismo personal de salud, lo cual obstaculiza la correcta atención médica. OBJETIVO: Evaluar los conocimientos, actitudes y prácticas ante el VIH/SIDA de los profesionales de la salud en el primer nivel de atención. METODOS: Se realizó un estudio observacional, transversal, descriptivo y prolectivo. Se incluyó a personal de la salud de las áreas de medicina familiar, enfermería, estomatología y laboratorista de la Unidad de Medicina Familiar No. 77 del Instituto Mexicano del Seguro Social que aceptaron contestar la encuesta CAP ante el VIH/SIDA, la cual tiene tres dominios: Conocimientos, que incluye ítems sobre infecciones de transmisión sexual, formas de prevención, vías y fuentes de transmisión; Actitudes, que indaga por conductas de estigma, discriminación, rechazo y Prácticas de riesgo para adquirir la infección. RESULTADOS: Se encuestaron un total de 81 trabajadores, 61 mujeres y 20 hombres; con rango de edades entre 23 a 60 años, con una media de $42.47+7.7$ años. Las categorías fueron: 50 médicos, 15 laboratoristas, 10 enfermeras y 6 estomatólogos. Se encontró que las enfermeras obtuvieron mayor porcentaje correcto de respuestas en el dominio de Conocimientos (83.6\%), los médicos en cuanto a Actitudes $(42.1 \%)$ y los estomatólogos en el dominio de las Prácticas $(61.1 \%)$. No hubo diferencias al comparar los porcentajes de respuestas correctas según el sexo $(p=0,25)$, ni edad ( $p=0,89)$, así como en la relación entre los tres dominios $(p=0.874)$. CONCLUSIONES: A pesar de que se tiene el conocimiento sobre el VIH/SIDA, aún se tiene cierto rechazo hacia la enfermedad, por lo que es importante reforzar los protocolos de atención médica.

PALABRAS-CLAVE: Prácticas profesionales; Actitudes; Virus de inmunodeficiencia humana; Personal de salud; Atención médica. 


\section{INTRODUCCION}

El Virus de inmunodeficiencia humana $(\mathrm{VIH}) /$ Síndrome de inmunodeficiencia adquirida (SIDA) es una infección prácticamente de reciente descubrimiento, siendo el año de 1983 cuando se descubría que un retrovirus provocaba una infección crónica que después de un periodo de latencia termina por evidenciar un grave deterioro inmunológico gestado a través de largos años (1).

El reporte de la Declaración del 2012 del programa conjunto de la Organización de las Naciones Unidas para el VIH/SIDA habla que, a finales del año 2011, 34 millones de personas vivían con el $\mathrm{VIH}$, durante el 2011 se produjeron 1.7 millones de muertes provocadas por causas relacionadas y se reportaron 2.5 millones de infecciones nuevas, incluyendo 330,000 niños (2). El Centro Nacional para la Prevención y el Control del VIH/SIDA (Censida) en el 2012 reportó 157529 casos acumulados de sida, afectando primordialmente a personas entre 15 y 44 años (3). En el Instituto Mexicano del Seguro Social se determinó en el año 2009 que el grupo más afectado son hombres de entre 25 y 44 años y que tienen una mortalidad de 12 por cada 100000 hombres (4).

Al hablar de $\mathrm{VIH}$ se debe tratar siempre todo lo referente a su forma de actuar, su morbilidad y mortalidad que actúan por tres vías: 1) inmunodeficiencia 2) daño directo a órganos blanco y 3) daño a estos órganos por la inflamación crónica producida por el mismo virus (5). Debido a las diversas complicaciones generadas de la infección, tan sólo en el año 2002 generó un gasto de \$98, 614,832 pesos mexicanos tan sólo en el IMSS (6).

EI VIH puede transmitirse a los individuos que reciben transfusiones de sangre contaminada con dicho virus, hemoderivados o trasplantes hísticos, así como los usuarios de drogas intravenosas expuestos al $\mathrm{VIH}$ (7). Existe un factor de riesgo que es la ventana serológica; ésta es el período inmediatamente después de ocurrir la infección, en el cual, el paciente está infectado, pero no presenta lasintomatología y no puede ser detectada por las pruebas de laboratorio (8).

Existe un riesgo laboral pequeño pero claro de transmisión del VIH entre los profesionales sanitarios, el personal de laboratorio y, posiblemente, de otras personas que manipulan las muestras de los pacientes con infección por el VIH. En Estados Unidos se calcula que entre 600000 y 800000 profesionales sanitarios sufren cada año pinchazos con las agujas $u$ otros instrumentos punzantes de uso médico. En la 
actualidad, todas las heridas por punción y las exposiciones mucosas en los trabajadores de la salud reciben tratamiento antirretroviral profiláctico (9).

La estrategia mundial del Sector de la Salud contra el VIH (2016-2021) describe diversasmedidas de acción acelerada para agilizar e intensificar la respuesta frente al VIH y así cumplir el ambicioso objetivo de la ONU de poner fin al SIDA para el 2030 (10). Sin embargo el lograr un objetivo tan grande requiere de realizar muchos cambios en cuanto a infraestructura, aplicación de programas de prevención, generar cambios tangibles en la sociedad y también el redoblar esfuerzos del personal de salud, el tener un personal capaz, actualizado en el tema y que rija su práctica diaria encaminado hacia una correcta aplicación de las directrices marcadas por la ONU, las guías de práctica clínica (guía de prevención y tratamiento de ITS y Diagnóstico y Referencia oportuna del paciente con infección por el VIH en el primer nivel) y organizaciones de la salud de cada país; todo esto para que al final del día tengan disponible la misma información los médicos de cualquier parte del mundo.

\section{ENCUESTA CAP}

Partiendo del hecho que debemos evaluarnos como profesional de salud con respecto a un tema en específico podemos utilizar el instrumento llamado CAP (Conocimiento, Actitudes y Prácticas) el cual puede ser utilizado en prácticamente cualquier tema de interés. Las preguntas CAP tienden a evidenciar rasgos característicos de los saberes, actitudes y comportamientos en materia de sanidad asociados a factores religiosos, sociales o tradicionales, pero también la concepción que cada persona toma acerca de su cuerpo o de la enfermedad investigada; esto nos puede dar la respuesta para conocer los frenos encontrados para el cambio que estamos buscando generar. Además, nos permite conocer la congruencia entre el conocimiento, la opinión y el actuar del entrevistado (11).

Es fundamental que el personal de salud tenga conocimiento acerca de la enfermedad VIH/SIDApara enfocarse en la prevención y diagnóstico de personas que se encuentren en riesgo de contraerla. Es preciso contar con un conocimiento basado en guías actualizadas para tener la seguridad de transmitir información valiosa al paciente y tener un resultado favorable en la lucha contra la transmisión de la enfermedad (12). Hay que recordar que el conocimiento será siempre el que nos ayuda a su vez contra la desinformación e ignorancia que resultan en una actitud 
negativa al tratar con pacientes seropositivos. El presente trabajo tiene como objetivo evaluar los conocimientos, actitudes y prácticas ante el VIH/SIDA de los profesionales de la salud de la Unidad Médica Familiar N 77 del IMSS. Esto a su vez permitirá conocer las áreas a reforzar del personal hacia la enfermedad y mejorar así la atención a este sector de la población afectado por la enfermedad y marginado por la sociedad.

\section{METODOS}

Se realizó un estudio observacional, transversal, descriptivo y prolectivo autorizado por elComité Local de Investigación en Salud 2804 del Instituto Mexicano del Seguro Social durante el periodo comprendido de enero a marzo 2019. Se incluyó al personal de la salud de cualquier edad, sexoy turno laboral de las áreas de medicina familiar, enfermería, odontología y laboratorista adscritos a la Unidad de Medicina Familiar No. 77 del IMSS, que tengan contacto con pacientes y manipulen líquidos, fluidos corporales o excretas de pacientes portadores de VIH/SIDA. En caso de cumplir conlos requisitos, se le solicitó su participación voluntaria explicando de manera inteligible el concepto, objetivos y requerimientos de la investigación, junto a las dudas que pudieran surgir. Los que aceptaron participar en el estudio se les solicitó firmar un consentimiento informado estandarizado para losproyectos de investigación con clave 2810-009-013, en el cual, se exponen los puntos de ética y confidencialidad de los datos proporcionados. Una vez terminado el proceso de selección, se recolectaron los parámetros necesarios por medio de una encuesta CAP ante el VIH/SIDA, la cual tiene tres dominios: Conocimientos, que incluye ítems sobre infecciones de transmisión sexual, formas de prevención, vías y fuentes de transmisión; Actitudes, que indaga por conductas de estigma, discriminación, rechazo y Prácticas de riesgo para adquirir la infección.

Los datos recolectados se codificaron para protección de la información de los pacientes y tuvieron acceso a la base de datos solamente los propios investigadores. La base de datos y el análisis se hicieron con ayuda del paquete estadístico Statistical Package for Social Sciences para Windows (versión 19; SPSS Inc., Chicago IL, USA). Para el análisis de los resultados se utilizó estadística descriptiva (medidas de tendencia central y de dispersión), estadística inferencial (pruebas paramétricasy no paramétricas, según la normalidad o no normalidad de los resultados, con prueba de Kolmogorov Smirnov; análisis de varianza o Kruskal Wallis, Coeficiente de correlación 
de Pearson o Spearman, así como T de Student para muestras independientes o Wilcoxon), considerando significancia estadística con valores de $p<0.05$.

\section{RESULTADOS}

Se encuestaron un total de 81 trabajadores, 61 mujeres y 20 hombres; con rango de edades entre 23 a 60 años, con una media de $42.47+7.7$ años. Las categorías fueron: 50 médicos, 15 laboratoristas, 10 enfermeras y 6 odontólogos. Se encontró que las enfermeras obtuvieron mayor porcentaje correcto derespuestas en el dominio de Conocimientos (83.6\%), los médicos en cuanto a Actitudes (42.1\%) y los estomatólogos en el dominio de las Prácticas (61.1\%) (Gráfico 1).

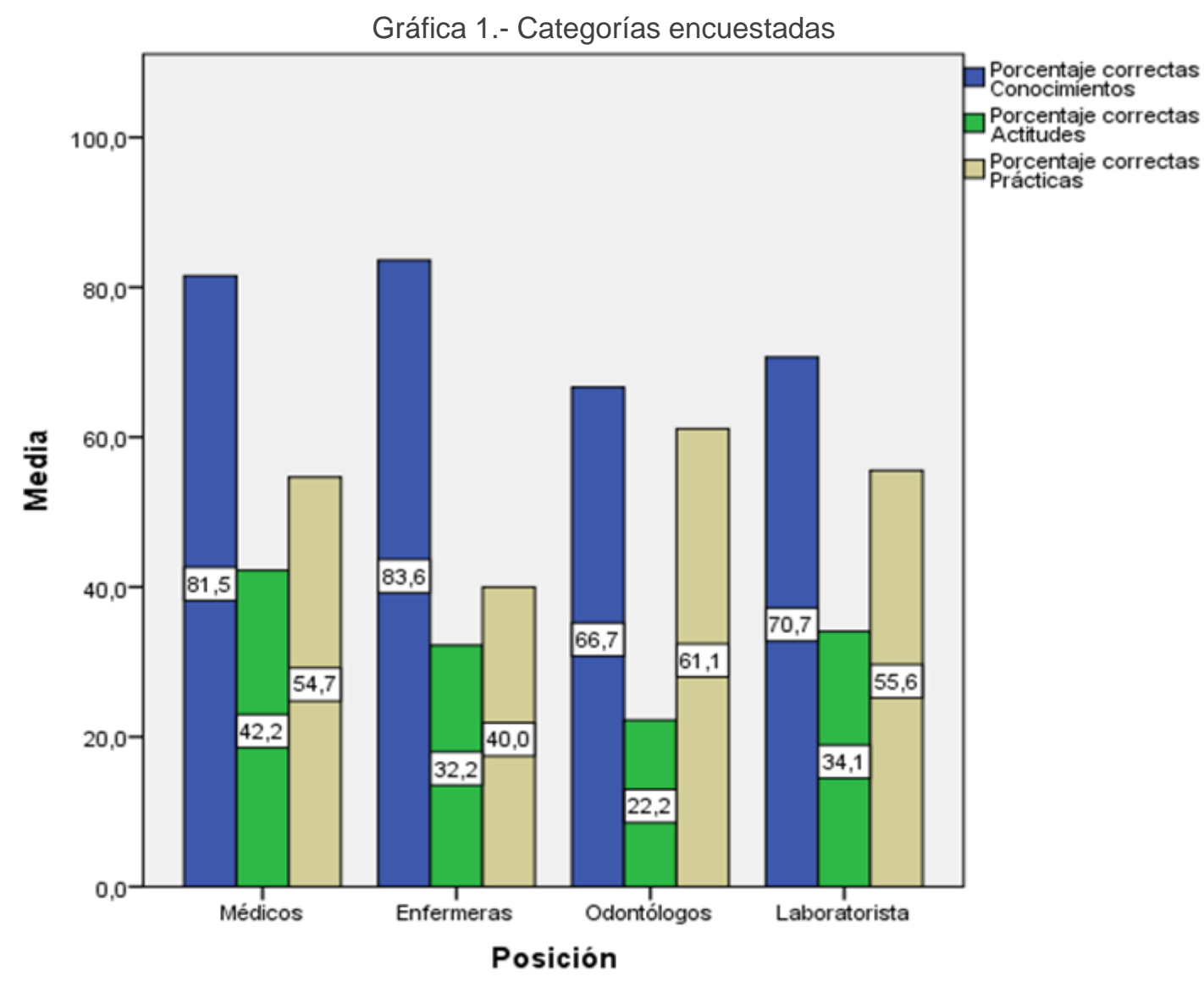

No hubo diferencias al comparar los porcentajes de respuestas correctas según el sexo $(p=0,25)$, ni edad $(p=0,89)$, así comoen la relación entre los tres dominios $(p=0.874)$, (Gráfico 2$)$.

Fuente: Los autores. 
Gráfica 2.- Diferencias por sexo.

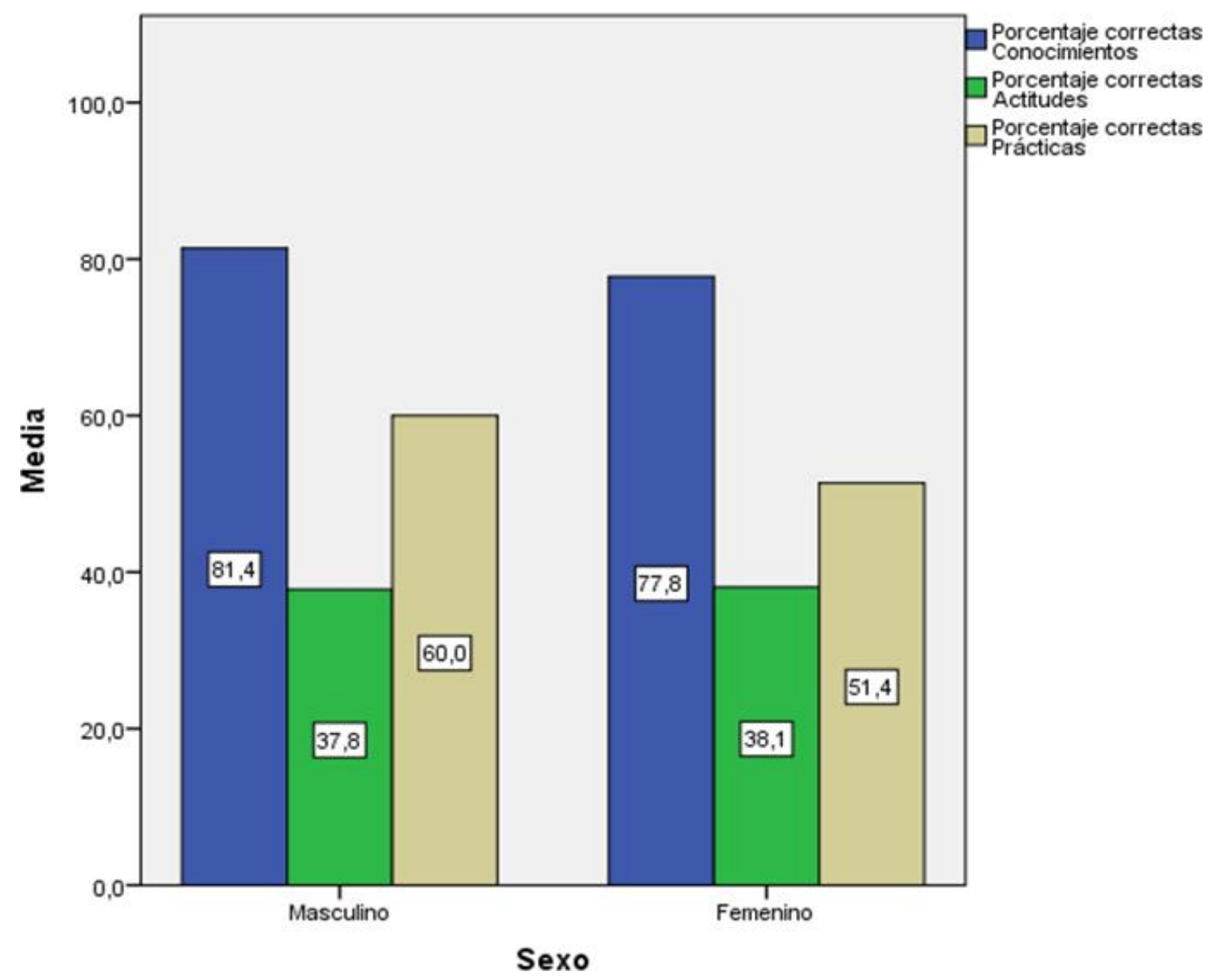

Fuente: Los autores.

\section{DISCUSIÓN}

Las investigaciones utilizando un instrumento tipo CAP aunque no son nuevas, aún no se obtieneun máximo aprovechamiento de este valioso recurso, por lo cual en nuestro país aún tenemos pocas de investigaciones de este tipo acerca del VIH para profesionales de la salud. Sería interesante realizar estetipo de investigación en nuestro primer nivel de atención antes y posterior a un curso de actualización acerca del paciente y enfermedad VIH/SIDA, lo cual nos ayudaría a realizar actualizaciones del tema mucho mejor orientadas de lo que se podría obtener con las limitantes de un estudio meramentetransversal. Muestra de esto queda plasmado en un estudio ESTVIH español realizado a profesionales de medicina y enfermería de atención primaria de la comunidad en Madrid donde mediante una encuestaCAP online pre y post-implementación de nuevas estrategias se logró mejorar la detección precoz de VIH/SIDA (13).

En el presente estudio obtuvimos un $78.66 \%$ de respuestas correctas del 
personal encuestado en el ámbito de conocimientos, lo cual es un indicador de que se tienen buenos conceptos clave acerca de la enfermedad, de su prevención y diagnóstico oportuno, contrario a lo que naturalmente se pensaría, las enfermeras fueron las que tuvieron una puntuación promedio mayor (83,6\%) que incluso los médicos y fueron los odontólogos los que tuvieron un desempeño menor con 66,7 \%.

En un estudio CAP sobre el VIH/SIDA realizado a médicos docentes de la Facultad de medicina, Universidad Mayor de San Simón, se obtuvo un promedio de respuestas correctas de 61,6\% lo cual mostró que en el primer nivel de atención analizado se tenía un mejor nivel de conocimientos que entre los profesores de la facultad (14).

En el global de la sección de actitudes se obtuvo un 37,99\% siendo ésta la sección de la encuesta en la que se obtuvo un menor aprovechamiento, la categoría con el promedio más alto fue la de los médicos con un $42,2 \%$ y la que obtuvo el menor desempeño fue la de odontología con 22,2\%. Este resultado sugiere que nuestro personal de salud aún presenta cierta resistencia hacia este tipo depacientes o la enfermedad en sí.

Haciendo la comparativa con el mismo estudio anterior nuestro primer nivel se queda muydebajo de su $92 \%$ de respuestas correctas en esta sección, sin embargo, podríamos hacer énfasis a que desconocemos qué porcentaje de los docentes encuestados tienen una práctica profesional que los relacione con pacientes seropositivos.

En la sección de prácticas se obtuvo una media de 53,49\% siendo los odontólogos los que obtuvieron un promedio mayor con $61,1 \%$ y las enfermeras las que obtuvieron el menor con 40,0\%. Este resultado sería una razón para promover cursos de actualización en el tema y el proceder del personal ante la detección de casos o la sospecha de estos. Nuestro estudio tiene una puntuación similar al obtenido por un estudio CAP colombiano el cual obtuvo un puntaje de 58,8 \% en el apartado de prácticas, lo cual nos pone en un mismo nivel que los profesionales de salud evaluados en éste estudio (15).

Se debe dar a conocer a la población las vías y mecanismos de transmisión, formas de prevención y servicios de información, detección oportuna y atención integral. El sistema interactivo deWandersman tiene como bases para la transferencia del conocimiento: la síntesis y sistema de transferencia, un sistema de apoyo y un sistema de entrega (16). En países que son mayormente afectados por el VIH/SIDA, 
como Nigeria, ven hoy en día a las escuelas y los sistemas de salud como una oportunidad para llevar a los jóvenes educación de prevención antes de que sean sexualmente activos (17). Se debe fomentar en los pacientes con VIH/SIDA el auto cuidado de la salud incluyendo medidas de prevención como sexo seguro y sexo protegido para romper la cadena de infección y re- infección (18).

\section{CONCLUSIONES}

Del personal encuestado podemos concluir que estamos ante un personal que tiene conocimientos clave de la enfermedad, el área de conocimientos es lo que nos arroja. Sin embargo, éste conocimiento no se observa a la par en cuanto a las actitudes y prácticas que debe tener el personal de salud que está en interacción con este tipo de pacientes.

Como personal de salud de primer nivel aún tenemos rechazo a la enfermedad y al paciente portador de VIH/SIDA cuando al ser una enfermedad bien conocida y estudiada a través de décadas, tendríamos que poder hablarla más abiertamente con el paciente y no mostrar ningún tipo de diferencias en nuestro trato. Es importante que el personal de salud conozca el protocolo de estudio de un paciente con diagnóstico de VIH para que así en su práctica diaria sepa cómo actuar ante un caso detectado. El llevar cursos de actualización sería una buena manera de reforzar el conocimiento y fomentar una buena práctica con el paciente, asimismo sería interesante continuar realizando investigaciones futuras de este tema para valorar el progreso que tenga el personal en su práctica diaria. 


\section{REFERENCIAS}

1.-Iglesias CM, Reyes G, Terán RM, Ortiz MM. Treinta años del VIH-SIDA: perspectivas desdeMéxico. 2015. México D.F.: Histórica.

2.-Organización Pan Americana de la Salud. Protocolo Integrado de VIH e ITS en Atención Primaria.Recuperado de

http://www.paho.org/par/index.php?option=com_docman\&view=download\&category_ slug=epidemiolo gia-y-control-de-enfermedades\&alias=492-protocolo-8-manual-deaps-para-el-manejo-de-vih-e- its\&ltemid=253

3.-Rodríguez CD, Magis RC, Bravo GE. Barreras que afectan el uso de datos de vigilanciaepidemiológica del VIH/sida en México. Sal Pub Mex, 2013; 55(4):408-415.

4.-José Luis Vázquez-Martínez, María Guadalupe Mercadillo-Pérez, Juan Germán Celis-Quintal. (2011). Mortalidad por VIH/SIDA en el Instituto Mexicano del Seguro Social. Rev Med Inst Mex Seguro Soc, 49 (1), 109-115

5.-Censida/Secretaría de Salud Guía de manejo antirretroviral de las personas con VIH. México, Sexta edición. 2014. Recuperado de www.censida.salud.gob.mx/descargas/principal/Guia_ARV_2014V8.pdf

6.-Zambrana MB, Ramírez TJ, Coria I. Gasto hospitalario de cinco patologías de alto impacto económico. Rev Med Inst Mex Seguro Soc, 2008;46(1):43-50.

7.- Longo DL, Kasper DL, Jameson J, Fauci AS, Hauser SL, Loscalzo J. (2012). Harrison Principios de Medicina Interna. México: McGraw-Hill; 2012.

8.- Suárez G, Eranilde L, De Freitas F, Henry A, Hannaoui R, Erika J, Gómez A. Prevalencia de enfermedades infecciosas de transmisión sanguínea en donantes que asisten al Banco de Sangre del Hospital Universitario "Antonio Patricio de Alcalá, Cumaná, Estado Sucre. Kasmera [Internet]. 2007;35(1): 56-64. Disponible en: http://www.scielo.org.ve/scielo.php?script=sci_arttext\&pid=S0075-

$52222007000100007 \&$ Ing=es.

9.- Gopar NR, Juárez PC, Cabello LA, Haro GL, Aguilar MG. Panorama de heridas por objetos punzocortantes en trabajadores intrahospitalarios. Rev Med Inst Mex Seguro Soc 2014;53(3):356-61.

10.- World Health Organization. Estrategia mundial del sector de la salud contra el VIH, 2016-2021:OMS [Internet]. [Consultado 2016]. Disponible en:

http://apps.who.int/iris/bitstream/handle/10665/250574/WHO-HIV-2016.05spa.pdf;jsessionid=0B21C2E4F227B0DC9176173453EB8151 ?sequence $=1$

11.- Gumucio. S. Recogida de Datos. Métodos cuantitativos. Ejemplos de encuestas CAP: Medicins du Monde. [Internet]. [Consultado 2001]. Disponible en: https://issuu.com/medecinsdumonde/docs/mdm_guia_encuesta_cap_2011

12.- Dirección General de Epidemiología/Secretaría de Salud. Manual de Procedimientos Estandarizados para la Vigilancia Epidemiológica del VIH-SIDA.2012. 
Obtenido

http://www.censida.salud.gob.mx/descargas/biblioteca/documentos/Manual_VIHSID A_vFinal_1nov12.pdf.

13.- Dirección General de Salud Pública Madrid (2017). Conocimientos, actitudes y prácticas de profesionales de atención primaria sobre diagnóstico precoz de $\mathrm{VIH}$ : encuesta pre-post intervención ESTVIH.

14.- Valdéz E., Avilés J. \& Saudán A. Conocimientos, actitudes y práctica sobre el VIH/sida endocentes de la Facultad de Medicina, Universidad Mayor de San Simón. Gac Med Bol 2012; 35 (1): 22- 26.

15.- Uribe AF, Orcasita LT. Evaluación de conocimientos, actitudes, susceptibilidad y autoeficacia frente al VIH/sida en profesionales de la salud. Av Enferm $2011 ; 29(2): 271-284$.

16.- Olvera BM, Moreno MM, Garza SS. Transferencia del conocimiento para la prevención de ITS/VIH/SIDA en adolescentes. Rev Med Inst Mex Seguro Soc, 2014;53(6):742-748.

17.- Abdu M, Umar A, Hj B, Faisal I, Syed H, Syed Ty cols. Effectiveness of HIV/AIDS educational intervention in increasing knowledge, attitude and practices for primary school teachers in some part of Africa, HIV \& AIDS Review, 2016; 15:17-25.

18.- NORMA Oficial Mexicana NOM-010-SSA2-2010, Para la prevención y el control de la infección por Virus de la Inmunodeficiencia Humana. México. 2010. 


\section{CHAPTER 05}

ACTITUDES PROAMBIENTALISTAS EN ESTUDIANTES MIEMBROS Y NO MIEMBROS DE LAS BRIGADES ACADEMIC OF VIGILANCIA, EDUCACIÓN Y FISCALIZACIÓN AMBIENTAL LA ESCUELAPROFESIONAL DE LA PSICOLOGÍA UNIVERSIDAD ANDINA DEL CUSCO, 2017

\section{Yanet Castro Vargas}

Doctora en Ciencias de la Salud

Current Institution: Universidad Andina del Cusco

Full address (personal): Jr. Ricardo Palma N-14 (Dpto. 702)

E-mail: ycastro@uandina.edu.pe

\section{Gareth Del Castillo Estrada}

Doctor en Ciencias de la Educación Current Institution: Universidad Andina del Cusco

Full address (personal): Urb. Mariscal Gamarra 14-H

E-mail: gdelcastillo@uandina.edu.pe

\section{Martha González Pilares}

Maestra en Gestión de los Servicios de la Salud Current Institution: Psique Cusco Full address (personal): Rafael Mariscal Quintanilla J-1

E-mail: mgonzalezpilares@gmail.com

\section{Katherine Calderón Cordova}

Psicóloga

Current Institution: Universidad Andina del Cusco

Full address (personal): Parque Amauta №210 (Dpto. 303)/Urb. Magisterio

E-mail: kcalderon@uandina.edu.pe

RESUMEN: La presente investigación se genera en el marco de la respuesta dada por la Escuela Profesional de Psicología de la Universidad Andina del Cusco a los escenarios propios del cambio climático, en el marco de la segunda advertencia de los científicos del mundo a la humanidad, la misma que poner de manifiesto la vulnerabilidad de los ecosistemas de la tierra. Como propuesta se busca identificar un cambio de actitudes en estudiantes integrantes de brigadas universitarias de vigilancia, educación y fiscalización ambiental, requisito del curso de Psicología Ambiental de la Escuela Profesional de Psicología. Para dicho fin se compararon alumnos pertenecientes a dichas brigadas, con aquellos no participantes de las mismas, que desarrollaran labores académicas en semestres contiguos. El enfoque de investigación fue mixto, bajo un diseño explicativo secuencial DEXPLIS, creándose una escala de tipo Likert para la recolección de datos en la parte cuantitativa y entrevistas semi-estructuradas para la parte siguiente. Entre los resultados principales se pudo identificar una mayor agrupación de evaluadosen niveles favorables de la actitud pro-ambientalista, manteniéndose dicho hallazgo en las dimensiones del 
constructo, por último, se determinó la diferencia estadística entre integrantes y no integrantes de brigadas respecto a la actitud evaluada.

PALABRAS-CLAVE: Actitud; Pro-ambiental; Brigadas; Medio ambiente.

ABSTRACT: This research is elaborated within the framework of the response given by the Professional School of Psychology of the Universidad Andina del Cusco to the scenarios of climate change, based on the secondwarning made by scientists from all over the world to humanity, the same that highlight the vulnerability of the earth's ecosystems. The proposal of this investigation seeks to identify changes on the students attitudes, specially on the ones that are members of the university brigades of surveillance, education and environmental control, which is a requirement for the course of Environmental Psychology of the Professional School of Psychology. For this purpose, students who are part of this brigades mentioned before were compared with those who did not participate in them, who will develop academic tasks in adjoining semesters. The research approach was mixed, under a sequential explanatory DEXPLIS design, creating a Likert-type scale for data recollection in the quantitative part and semi-structured interviews for the next part. Among the main results, it was possible to identify a greater group of evaluated students with favorable levels of the proenvironmental attitude. Keeping this findings in the dimensions of the construct, finally, the statistical difference between members and non-members of theuniversity brigades was determined by the attitude evaluated.

KEY WORDS: Attitude; Pro-environmental; Brigades; Environment. 


\section{INTRODUCCIÓN}

Hoy en día experimentamos el cambio climático en nuestra vida cotidiana, es usual percibir el aumento de la temperatura medio ambiental, el calor, la escasez de agua, el efecto invernadero, entre otras situaciones alarmantes. Esta realidad ha sido informada hace décadas, en el 1992 la unión de científicos preocupados advirtieron el curso de colisión para los seres humanos y el mundo natural, cartaque fue respaldada por más de 1700 científicos, ahora 26 años después se vuelve a publicar la advertencia de los científicos a la humanidad, como segundo aviso, con la diferencia que dicha comunicación se verespaldada por más de 17000 científicos, incluyendo la mayoría ganadores del Premio Novel de la Ciencia, dicho escenario nos hace tomar conciencia de la vulnerabilidad en la que se encuentra la humanidad y su cercanía a una catástrofe ambiental, frente a ello hace falta comprender "la unión planetaria, que es la exigencia racional mínima de un mundo limitado e interdependiente. Esta unión necesita de una conciencia y de un sentido de pertenencia mutuo que nos ligue a nuestra Tierra, considerada como primera y última Patria, idea que debe ser transversal a la enseñanza universitaria Morin (2005)

Las diferentes facetas del entorno, que incluyen ambientes naturales, construidos socioculturalesy digitales influyen en la conducta y afectan a nuestras emociones, comportamiento y salud en diferentesformas y niveles. (Stokols, 2018). Diversos son los retos en los que las ciencias sociales ambientales, yespecíficamente la Psicología Ambiental, debe afrontar en relación al conocimiento profundo sobre las actitudes proambientales y su evolución en el tiempo y en los diferentes marcos socioculturales; el papelde la conducta humana en los cambios globales y sus dimensiones psicológicas, sin dejar de lado los aspectos culturales y contextuales; además de colaborar en el diseño de estrategias eficientes de comunicación, formación y participación para la extensión de acciones proambientales a favor del sistema global del planeta (Castro, 2011)

El cambio climático fue un activador en la conciencia ciudadana, con el aumento de la temperatura medio ambiental, el calor, exceso o escasez de agua, el efecto invernadero, entre otras situaciones alarmantes la sociedad en su conjunto evidencio la consecuencia de un sostenido abuso y desinterés por el medio ambiente, con la certeza de que la actividad humana ha permitido la concentración de gases de efecto invernadero en la atmosfera, intensificándose por tanto el efecto invernadero 
natural, lo mismo que da por resultado el calentamiento adicional de la superficie y la atmosfera de la tierra, situación que puede afectar los ecosistemas naturales y por consiguiente a la humanidad (ONU, 1992).

En un escenario poco provisorio como el descrito, se hace importante la participación indiscriminada de distintos actores económicos y sociales que tengan como fin la generación de actividades, de distinta índole, las mismas que al articulase puedan evidenciar su impacto en el cuidadodel medio ambiente, tal es el caso de la resiente promulgación de la Ley Marco sobre Cambio Climático, la misma que tiene como objetivo establecer los principios, enfoques y disposiciones vinculadas a la adaptación y mitigación de efectos del cambio climático, mediante políticas públicas, las mismas que deberían guiar las acciones específicas desarrolladas por organizaciones de distinta índole en bien del medio ambiente, garantizando un mayor impacto.

En este contexto la Escuela Profesional de Psicología de la Universidad Andina del Cusco buscadentro de la formación integral de sus estudiantes formar ciudadanos con conciencia y cultura ambiental, quienes demuestren un claro compromiso con el ambiente, más aun teniendo en cuenta la conexión de los valores institucionales con la auténtica moral y valores del Tawantinsuyo (Góngora, 2015), ampliándose los espacios de justificación, para las practicas pro-ambientalistas, incluso a la generación de una identidad andina trascendental. Es de esta manera que la demanda ambiental encuentra asidero en el diseño de la malla curricular de la Escuela Profesional en el curso de psicología ambiental, aún antes de contemplarse el espíritu de la Ley Marco sobre Cambio Climático, en relación a su impacto educativo.

El presente proyecto busca identificar el impacto de prácticas que responden a una situación problema dada por las limitaciones de la educación ambiental y la tardía preocupación del Estado en laformación de ciudadanos interesados por el medio ambiente, además de la importancia de ampliar el número de actores vinculados a la gestión ambiental responsable, considerando el ámbito universidad un entorno preciso dada su misión de formar profesionales integrales que respondan a las necesidades sociales. Como propuesta se busca un cambio de actitudes en estudiantes de la Escuela Profesional de Psicología de la Universidad Andina del Cusco, los mismos que al integrar de brigadas universitarias devigilancia, educación y fiscalización ambiental, como requisito del curso de Psicología Ambiental, muestren cambios en los ámbitos cognitivo, emotivo y volitivo relacionados al cuidado del medio 
ambiente.

Para la investigación se establece como objetivo general el conocer la diferencia entre las actitudes proambientalistas de estudiantes integrantes y no integrantes de las brigadas universitarias de vigilancia, educación y fiscalización ambiental de la Escuela Profesional de Psicología de la UniversidadAndina del Cusco, 2017 y como objetivos específicos aquellos vinculados a conocer las dimensiones cognitiva, emotiva y volitiva de las actitudes pro-ambientalistas en los estudiantes integrantes y no integrantes de las brigadas universitarias de vigilancia, educación y fiscalización ambiental de la EscuelaProfesional, además de los estudiantes de octavo semestre, los mismos que por su proximidad al grupo evaluado presentan idoneidad para la comparación de actitudes.

Las actitudes ambientales son los sentimientos favorables o desfavorables que se tiene hacia alguna característica del ambiente o hacia algún problema relacionado con él (Holahan, 2012), esta apreciación permite además desarrollar una valoración ambiental personal, ambas operan conjuntamente para el desarrollo de los comportamientos proambientalistas.

Los comportamientos proambientalistas en relación a la mitigación del fenómeno pueden ser dedos tipos principalmente: directos e indirectos. Las acciones directas se orientan al desarrollo de prácticas de reducción del impacto de la acción humana en el ambiente, y las acciones indirectas están dirigidas a otras personas (familiares, compañeros de trabajo, amigos...) o instituciones (administración, empresas...) para que adopten prácticas sostenibles (Castro 2010)

La universidad es una entidad orientada a la generación de consciencia crítica con la responsabilidad de brindar una formación integral, los aspectos ambientales, sociales y de investigaciónson aspectos sustanciales de la enseñanza superior, y se deben abordar de forma global y transversal, tomando en cuenta que los profesores son generadores de paradigmas conceptuales y metodológicos y los estudiantes los receptores y agentes de cambio. (Peña, 2017)

\section{MATERIAL Y MÉTODOS}

El enfoque de la investigación es mixto puesto que se utilizará la recolección y análisis de los datos para afinar las preguntas de investigación o identificar nuevas interrogantes en el proceso de interpretación. (Hernandez, Fernandez, \& Baptista, 
2014), de esta manera las actitudes pro ambientalistas en la población de estudio son abordadas mediante procedimientos científicos propios delpositivismos lógico, para llegar a conocer una realidad in situ y el con un enfoque de base constructivista buscando profundizar en características o particularidades del fenómeno.

Se presenta bajo un enfoque descriptivo - compativo, el mismo que permitirá especificar las propiedades, las características y los perfiles de personas, grupos, comunidades, procesos, objetos o fenómenos que se someten a análisis (Hernandez, Fernandez, \& Baptista, 2014), para proceder a su comparación entre grupos encuestados. Midiéndose y recogiéndose información en los estudiantes de laEscuela Profesional de Psicología, integrantes y no integrantes de las brigadas universitarias de vigilancia, educación y fiscalización ambiental.

En cuanto al diseño de investigación es Explicativo Secuencial (DEXPLIS), este diseño se caracteriza por una primera etapa en la cual se recaban y analizan datos cuantitativos, seguida de otra donde se recogen y evalúan datos cualitativos. La mezcla mixta ocurre cuando los resultados cuantitativos iniciales constituyen insumo a la recolección de datos cualitativos, ambas etapas se integranen la interpretación de los resultados. (Hernandez, Fernandez, \& Baptista, 2014). Así las actitudes pro ambientalistas en estudiantes integrantes de las brigadas universitarias de vigilancia, educación y fiscalización ambiental, serán analizadas mediante las respuestas dadas al cuestionario diseñado específicamente para la evaluación cualitativa, siendo dichos datos insumo para el desarrollo defocusgroup (grupo de enfoque) que permitirá un mayor conocimiento de las actitudes pro-ambientalistasen los estudiantes parte de la población de estudio.

\section{PARTICIPANTES}

El estudio se desarrolló en la Escuela Profesional de Psicología de la universidad Andina del Cusco, la población de estuvo constituida por la totalidad de alumnos matriculados la curso de psicología ambiental, los mismos que imperantemente son integrantes de las brigadas universitarias de vigilancia, educación y fiscalización ambiental, en el periodo 2017 y un grupo homogéneo de comparación con estudiantes que no son parte de dichas brigadas, siendo los primeros 42 alumnos de noveno semestre y los segundos 47 alumnos matriculados al octavo semestre. 


\section{INSTRUMENTO}

En su parte cuantitativa se utilizó el cuestionario para la recolección de datos, estando constituidoel mismo por una serie de preguntas respecto de una o más variables a medir (Hernández, Fernández y Batista, 2014), bajo un diseño tipo Likert de cinco opciones, con valoraciones por ítemque se orientan amedir frecuencias que fluctúan entre nunca a siempre.En su parte cualitativa, se desarrollaron sesiones en profundidad o grupos de enfoque, al existir interés por determinar la forma en que los estudiantes que conforman las brigadas, estructuran sus actitudes interpretación respecto al problema generando una serie de percepciones, actitudes, motivaciones, sentimientos y pensamientos al respecto.

\section{PROCEDIMIENTO}

Para poder ejecutar la evaluación se solicitó los permisos respectivos a los estamentos universitarios pertinentes, autorizando los mismos la evaluación a estudiantes matriculados al curso depsicología ambiental, del noveno semestre, los mismos que de manera automática forman parte de las brigadas universitarias de vigilancia, educación y fiscalización ambiental, así como a los estantes matriculados al octavo semestre, quienes no forman parte de las brigadas.

Los datos recabados fueron codificados y analizados estadísticamente mediante procedimientosdescriptivos e inferenciales, respetándose en todas etapas aspectos éticos propios de la investigación.

Una vez obtenidos los resultados cuantitativos se procedió al diseño de la guía de tópicos a tratarse en el grupo de enfoque, la misma que permitiría establecer con mayor profundidad los cambiospresentados en las dimensiones emocional, cognitiva y volitiva vinculadas a las actitudes pro- ambientalistas.

\section{RESULTADOS}

\section{a. DIMENSIÓN EMOCIONAL}

La dimensión emocional de las actitudes se presenta predominantemente como muy favorable en los estudiantes pertenecientes a brigadas universitarias de vigilancia, educación y fiscalización ambiental, con un $73.8 \%$ de evaluados en dicho 
nivel, mientras un $26.2 \%$ se ubican en un nivel favorable, de esta manera no existen evaluados que se ubique en niveles medio, ni desfavorables. Es así que los estudiantes evaluados presentan sentimiento acentuados de agrado respecto al desarrollo de actividadespro-ambientalistas programadas por la brigada.

Tabla 1 - Dimensión emocional de las actitudes pro-ambientalistas en estudiantes integrantes y no integrantes de las brigadas.

\begin{tabular}{ccccc}
\hline & \multicolumn{2}{c}{ Integrantes de la brigada } & No integrantes de la brigada \\
\cline { 2 - 5 } Nivel & $\boldsymbol{f}$ & $\%$ & $\boldsymbol{f}$ & $\%$ \\
\hline Muy favorable & 31 & 73.8 & 32 & 68,1 \\
Favorable & 11 & 26.2 & 12 & 25,5 \\
Ni favorable, ni desfavorable & - & - & 2 & 4,3 \\
Desfavorable & - & - & 1 & 2,1 \\
\hline Total & 42 & 100,0 & 47 & 100 \\
\hline
\end{tabular}

Fuente: Los autores.

Los resultado analizados muestran la distribución de los estudiantes, no pertenecientes a las brigadas, en cuatro niveles valorativos de la dimensión emocional, estando mayormente agrupados en elnivel muy favorable, con $68,1 \%$ de evaluados, seguido del nivel favorable, con 25,5 \% de evaluados, agrupando los niveles negativos $6,4 \%$ de evaluados, sin presentarse ninguno en la categoría media. Si bien se puede observar una situación parecida a la presentada por los estudiantes que pertenecen a las brigadas de vigilancia, educación y fiscalización ambiental, veremos que los resultados nos permiten identificar una mayor dispersión de evaluados en los niveles de análisis, con la ubicación de casos en niveles negativos de valoración.

En relación a las emociones y su identificación con el desarrollo de prácticas pro-ambientalistaspor miembros de las brigadas,se logró identificar, mediante grupo de enfoque, sentimientos de agrado yalegría con la culminación de la acción, como por ejemplo aquellos generados por la cosecha del bio- huerto, manifestándose dicha condición en expresiones como:

Mi experiencia personal [...] Mis padres son agricultores, aman mucho la tierra [...] Cuando vineacá y desarrolle el proyecto me apareció una experiencia nueva [...] Aparte de que si se un poco de lo que es la agricultura, colaborar y trabajar con mis compañeros también fue una experiencia muy bonita. Nosotros hemos tenido que trabajar, informarnos porque nadie sabia como hacer [...] El esfuerzo cuentamucho, nos motivo y gusto bastante [...] Los primeros frutos, la cosecha fue bastante grata" . Por otro lado, se evidencia la generación de un vínculo afectivo con las prácticas y 
espacios que permitieronsu desarrollo de labores de cuidado del bio-huerto: "Me da felicidad, cuando bajo a la universidad, siempre visito el bio-huerto [...] Es muy grato.

\section{b. DIMENSIÓN COGNITIVA}

Los estudiantes, pertenecen a las brigadas de vigilancia, educación y fiscalización ambiental, se muestran agrupados mayormente en niveles positivos dentro de la dimensión cognitiva, con 59,5\% de evaluados en el nivel favorable, $35,7 \%$ en el nivel muy favorable y tan solo un $4,8 \%$ en el nivel medio,no existiendo estudiantes en niveles negativos. Por tanto, se puede apreciar creencias y opiniones positivas de los estudiantes respecto al cuidado del medio ambiente, las mismas que tendrían asidero enconocimientos y practicas previamente desarrollados.

Tabla 2: Dimensión cognitiva de las actitudes pro-ambientalistas en estudiantes integrantes y no integrantes de las brigadas.

\begin{tabular}{ccccc}
\hline & \multicolumn{2}{c}{ Integrantes de la brigada } & \multicolumn{2}{c}{ No integrantes de la brigada } \\
\cline { 2 - 5 } Nivel & $\boldsymbol{f}$ & $\%$ & $\boldsymbol{f}$ & $\%$ \\
\hline Muy favorable & 15 & 35,7 & 8 & 17,0 \\
Favorable & 25 & 59,5 & 25 & 53,2 \\
Ni favorable, ni desfavorable & 2 & 4,8 & 11 & 23,4 \\
Desfavorable & - & - & 3 & 6,4 \\
\hline Total & 42 & 100,0 & 47 & 100,0 \\
\hline
\end{tabular}

Fuente: Los autores.

Los estudiantes, no pertenecen a las brigadas de vigilancia, educación y fiscalización ambiental, se muestran agrupados mayormente en niveles positivos dentro de la dimensión cognitiva, con 53,2\% de evaluados en el nivel favorable, $23,4 \%$ en el nivel medio, $17,0 \%$ en el nivel muy favorable y tan soloun $6,4 \%$ en el nivel desfavorable. Dicha situación muestra una mayor dispersión en niveles que la encontrada en estudiantes integrantes de brigadas, agrupando el nivel medio aproximadamente la cuartaparte de evaluados y presentándose además algunos estudiantes con opiniones y creencias negativas respeto al cuidado del medio ambiente.

En la dimensión cognitiva, son muchas intervenciones de los miembros de la brigada devigilancia, educación y fiscalización ambiental, las que hacen referencia a la importancia de la información recibida para la racionalización futura vinculada a actitudes pro-ambientalistas, durante el desarrollo del grupo de enfoque tales como:

Primero desarrollados actividades para familiarizarnos [...] Para toda actividad a favor del ambiente creo que lo básico es la información, la profesora nos sensibilizo 
[...] Puedes hacer grandes aportes con pequeñas acciones. Además, otra estudiantes consideraron [...] Hemos debido informarnos[...] fue un proceso de aprendizaje para valorar el medio ambiente. De esta manera la mayoría de experiencias comentadas, por los miembros de las brigadas, vinculan en su etapa inicial conla búsqueda y recepción de información sobre el medio ambiente y su cuidado, así como con la importancia de conocer las actividades a realizar y organizar las mismas. Mostrándose además una claraidea sobre su acción de apoyo, la ansían que sería valorada en razón al esfuerzo involucrado en la tarea[...]Ya eres consciente de que puedes ayudar,fue incomodo, era muy trabajoso hacer todo.

\section{c. DIMENSIÓN VOLITIVA}

Por último, el componente comportamental (conativo) de las actitudes proambientalistas, muestra una mayor agrupación de estudiantes, pertenecientes a las brigadas, en el nivel favorable, con $45,2 \%$ de evaluados, seguido por un $42,9 \%$ de evaluados en el nivel muy favorable, un $9,5 \%$ en un nivelpromedio y tan solo un $2,4 \%$ en un nivel desfavorable, quedando claramente identificada una disposiciónpositiva respecto a intensiones conductuales ante el desarrollo de actividades proambientalistas.

Tabla 3: Dimensión comportamental de las actitudes pro-ambientalistas en estudiantes integrantes y no integrantes de las brigadas.

\begin{tabular}{ccccc}
\hline & \multicolumn{2}{c}{ Integrantes de la brigada } & \multicolumn{2}{c}{ No integrantes de la brigada } \\
\cline { 2 - 5 } Nivel & $\boldsymbol{f}$ & $\%$ & $\boldsymbol{f}$ & $\%$ \\
\hline Muy favorable & 18 & 42,9 & 9 & 19,1 \\
Favorable & 19 & 45,2 & 17 & 36,2 \\
Ni favorable, ni desfavorable & 4 & 9,5 & 15 & 31,9 \\
Desfavorable & 1 & 2,4 & 6 & 12,8 \\
\hline Total & 42 & 100,0 & 47 & 100,0 \\
\hline
\end{tabular}

Fuente: Los autores.

El componente comportamental (conativo) de las actitudes pro-ambientalistas, muestra una mayor agrupación de estudiantes, no pertenecientes a las brigadas, en el nivel favorable, con $36,2 \%$ de evaluados, seguido por un $31,9 \%$ de evaluados en el nivel promedio, un $19,1 \%$ en un nivel muy favorable y un $12,8 \%$ en un nivel desfavorable, encontrándose cierta disposición de trabajadores a desarrollar conductas favorables, sin embargo, a diferencia de los estudiantes pertenecientes a brigadas, aproximadamente un tercio de evaluados se ubica en el nivel medio con disposiciones conductuales ambiguas respecto al desarrollo de conductas proambientalistas, presentándose además un grupo importante de evaluados en niveles 
inferiores. En el caso de la dimensión conativa, varios de los entrevistados, participantes del grupo de enfoque, dan muestra de la importancia que representa el desarrollo de actividades prácticas, las mismasque permitan ejecutar lo aprendido:

Al comienzo no sabíamos nada, la formación se dio en grupos tubo que informarse y colaborar con algo [...] Puedes conocer en la teoría pero en la práctica se palpa [...] Una cosa es saber y otra hacer. Es importante considerar que los participantes de las brigadas además evidenciaron interés por aspectosambientales y el desarrollo de conductas vinculadas, pudieron identificar dicha predisposición para actuar con prácticas ancestrales, propias del quehacer del poblador andino, situación reflejada en comentarios tales como: El hecho de valorar a los que producen la tierra también te cambia [...] No lo había visto de esa forma [...] De alguna manera todos concibieron la visión de la cosmovisión andina [...] La pachamama, como la conocemos, nos da el fruto, nos da el vivir.

Por último, se pudo comprobar la existencia de diferencias estadísticamente significativas, másallá del error estándar, en el grupo de estudiantes perteneciente a las brigadas de vigilancia, educación y fiscalización ambiental, respecto al grupo de estudiantes no pertenecientes a dichas brigadas.

Tabla 4 Diferencia entre las actitudes proambientalistas de estudiantes integrantes y no integrantes de las brigadas.

\begin{tabular}{|c|c|c|c|c|c|c|}
\hline \multirow[b]{3}{*}{ Grupo } & \multirow[b]{3}{*}{ Frecuencia } & \multicolumn{4}{|c|}{ Actitud Pro-ambientalista } & \multirow{3}{*}{ Total } \\
\hline & & Desfavorable & $\begin{array}{l}\text { Ni favora- } \\
\text { ble, ni desfavo- } \\
\text { rable }\end{array}$ & Favorab & favorable & \\
\hline & & & & & & \\
\hline \multirow[t]{2}{*}{ Brigada } & Recuento & 0 & 1 & 17 & 24 & 42 \\
\hline & Frecuencia esperada &, 5 & 5,2 & 20,8 & 15,6 & 42,0 \\
\hline \multirow[t]{2}{*}{ No brigada } & Recuento & 1 & 10 & 27 & 9 & 47 \\
\hline & Frecuencia esperada &, 5 & 5,8 & 23,2 & 17,4 & 47,0 \\
\hline \multirow[t]{2}{*}{ Total } & Recuento & 1 & 11 & 44 & 33 & 89 \\
\hline & Frecuencia esperada & 1,0 & 11,0 & 44,0 & 33,0 & 89,0 \\
\hline \multicolumn{2}{|c|}{ Chi cuadrado $=17,228$} & p-valo & $r=0.001$ & & & \\
\hline
\end{tabular}

Fuente: Los autores.

Utilizando la prueba chi cuadrado de homogeneidad, con un p valor de 0.001 , se pudo refutar lahipótesis nula, y de esta manera comprobar la diferencia de grupos, hallazgo que condice con los resultados a nivel descriptivo, donde se identificó mayor agrupación de estudiantes pertenecientes a lasbrigadas en niveles positivos, en las tres dimensiones de la variable de estudio. 
La investigación desarrollada por Contreras (2012), intitulada: "Actitudes ambientales de los estudiantes de secundaria en Baja California: características personales y académicas asociadas", el mismo que vincula con la incorporó de manera formal, en los planes y programas de estudio mexicanos, del curso educación ambiental, muestra entre sus resultados descriptivos una actitud positiva de los estudiantes evaluados hacia el cuidado del medio ambiente, esta situación es también identificada en elestudio presente, teniendo en cuenta los niveles favorables y muy favorables encontrado mayormente enel estudio, encontrándose mayor frecuencia ene estudiantes parte de las brigadas universitarias de vigilancia, educación y fiscalización ambiental, además dicho resultado mayormente favorable y muy favorables se pueden encontrar también en las dimensiones parte del constructo evaluado. En relación a las diferencias en la población según factores de división poblacional, no se analizan dichos resultados al no encontrarse paralelo con el presente estudio.

En referencia a lo planteado por Castro (2014), se encuentra paralelo entre el interés del autor y las consideraciones sustento del presente estudio, teniendo en cuenta el interés por el análisis de las actitudes al momento de valorar compórtamelos en favor del medio ambiente, en un intento por generarteorías generales para la identificación, comprensión y acción frente al ambiente. Por otro lado, existe coincidencia en el interés por operacionalizar el constructo de actitudes ambientales, desde la óptica deCastro y de actitudes pro-ambientalistas, desde el presente estudio, dada la importancia asignada a la objetividad, como condición implícita del manejo científico.

Por último, al considerar la novedad del tema de estudio en nuestra localidad vemos trascendentela identificación de instrumentos propios de otro contexto, pero que por su naturaleza se orienten a la medición de las actitudes ambientales, en ese entender se analizó el estudio de Aragonés y Amérigo (1991), intitulado: "Un estudio empírico sobre las actitudes ambientales", el mismo que estudia la validez de la escala Environmental Concern Scale - ECS, dando luces de posibles relaciones de la variable de estudio con otras variables como la ideología política, a raíz de los datos aportados por el estudio analizado se entendió la importancia de comenzar el presente estudio operacionalizando la variable de una manera convencional, para en futuras investigaciones aportar al desarrollo de escalas precisas y enfocadas en la normativa y regulaciones vigentes. 


\section{REFERENCIAS}

Aragonés, J., \& Amérigo, M. (1991). Un estudio empírico sobre las actitudes ambientales . Revista de psicología social , 223-240.

Contreras, S. (2012). Actitudes ambientales de los estudiantes de secundaria en Baja California:características personales y académicas asociadas (tesis de maestría). Universidad Autónoma de Baja California, México.

De Castro, R. (2011). Dimensiones Humanas del Cambio Global. En Psicología Ambiental 2011: Entre los estudios urbanos y el análisis de la sostenibilidad. IX Congreso de Psicología Ambiental. Almería. España 2011.

De Castro, R. (2014). Naturaleza y funciones de las actitudes ambientales. Estudios de psicología, 11- 22.

Góngora, M. (2002) Llankay, yachay, sonqoy: valores históricos del pueblo en el tawantinsuyo.

UNMSM.

Hernández, R.; Fernández, C. \& Baptista, P. (2014) Metodología de la Investigación, México D.F.: McGraw-Hill

Holahan, Ch. (2012). Psicología Ambiental, un enfoque general. México: LIMUSA.

Morin, E. (1999). Los siete saberes necesarios para la educación del futuro . Paris: UNESCO.

Moser, G. (2014). Psicología Ambiental: Aspectos de las relaciones individuo - medio ambiente. Bogotá: ECOE Ediciones.

Naciones Unidas . (1992). Convención marco de las Naciones Unidas sobre el cambio climático. Paris:ONU.

Peña, D. (2017). Creencias y Comportamientos Proambientales en Estudiantes de Administración en Universidades Mexicanas en Función del Grado de Implementación del Sistema de Gestión Ambiental (SGA). (tesis de doctorado). Universidad de Barcelona

Stokols, D. (2018). Social Ecology in the digital age, Londres: Elsevier. 
CHAPTER 06

GIMNÁSTICA DEL TALENTO, DESARROLLO DE COMPETENCIAS Y HABILIDADES EN ENTORNO LABORAL

\section{Luis Poveda Crespo}

povedacrp@outlook.com

https://luispoveda.blogspot.com/

\section{María Jesus Vitón de Antonio}

RESUMEN : El presente artículo ofrece un acercamiento y una visión general de la investigación realizada sobre el aprendizaje y desarrollo de competencias que configuran "talento" en entornos sociolaborales denominada "Gimnástica del Talento". La metodología de aprendizaje propuesta en el modelo permite una transformación y mejora progresiva de las habilidades asociadas a la actividad profesional que se desarrolla en las Familias Profesionales de Comercio y Marketing y Gestión Comercial y de Ventas, desplegadas por el Instituto Nacional de Cualificación profesional(INCUAL). Se presenta una innovación conceptual; primero al desagregar las actividades y tareas que se realizan en el desempeño de la profesión "Modelo de los Nueve Pasos", segundo; asociar las competencias críticas y prioritarias en cada uno de los pasos propuestos en el modelo y tercero; diseñar un programa de ejercicios para el entrenamiento de cada una de las competencias asociadas. Los resultados de la investigación nos indican que el enfoque de ejercicios propuesto y la triangulación realiza entre las actividades y tareas a desempeñar, las competencias y el conocimiento de las técnicas de entrenamiento son altamente satisfactorios al proporcionar una reducción en el tiempo de aprendizaje por la propia experiencia y mejorar los indicadores de resultados pre y post.

PALABRAS-CLAVE: Talento; Competencias críticas; Desarrollo de habilidades; Modelo de aprendizaje. 


\section{INTRODUCCIÓN}

En ocasiones, a veces, más de las que pensamos, los docentes encontramos cierto "divorcio" entre lo que enseñamos y las competencias que una persona necesitará emplear en su vida profesional. Elegir las competencias como principio organizador del curriculum es una forma de trasladar la vida real al aula, el enfoque de formación por competencias integra elementos de aprendizaje que van más allá de convertir al alumno en meros reproductores del conocimiento teórico memorístico.

La noción de competencia, tal como es usada con relación al entorno sociolaboral, se sitúa a mitad de camino entre los saberes, los conocimientos y las habilidades; el camino del conocimiento y el camino de las habilidades, así, entendida, la competencia exige a la vez conocimiento para hacer y un hacer con habilidad. La definición de las competencias, y obviamente su aprendizaje, exigen entonces acuerdo y colaboración entre el mundo de la educación y el mundo del trabajo, se adquieren en trayectorias que implican una combinación de educación formal, aprendizaje en el trabajo y, eventualmente, educación no formal. (Gallart y Jacinto, 1995)

La competencia no proviene de la aprobación de un currículum escolar formal, sino de un ejercicio de aplicación de conocimientos en circunstancias críticas. En los entornos socio laborales, este conocimiento es necesario para la resolución de problemas $y$, no es mecánicamente transmisible; es una mezcla de conocimientos previos y de experiencia concreta que proviene fundamentalmente del trabajo en el mundo real.

Una competencia implica un saber hacer (habilidades) con saber (conocimiento), así como la valoración de las consecuencias de ese hacer (valores y actitudes). La manifestación de una competencia revela la puesta en práctica de conocimientos, habilidades, actitudes y valores para el logro de propósitos en contextos y situaciones diversas, inteligencia aplicada, talento para la acción. (Marina J.A., 2010).

La pregunta que nos surge es ¿podemos acelerar o mejorar esa experiencia adquirida en el trabajo real con el fin de mejorar las competencias? ¿es posible diseñar un programa de entrenamiento para este fin? Este es nuestro objetivo y es la propuesta de la Gimnástica del Talento. 


\section{OBJETIVOS}

La investigación realizada proporciona respuestas a las actuales disposiciones y prospectivas definidas por el Instituto Nacional para las Cualificaciones Profesionales (INCUAL) y en concreto, para las Familias Profesionales de Comercio y Marketing y Gestión Comercial y de Ventas.

Las cuestiones previas más significativas para planificar las actividades de desarrollo competencial:

- Primera cuestión; ¿es posible que se pueda definir, construir y materializar una estructura sistemática para entrenar las competencias y habilidades asociadas a las familias Profesionales descritas?

- Segunda cuestión; ¿por qué medio o instrumento se puede identificar de manera pertinente el perfil actual de competencias del individuo en ese entorno sociolaboral concreto?

- Tercera cuestión; ¿el modelo propuesto GIMNÁSTICA DEL TALENTO (GT) puede capacitar más positivamente y mejorar los indicadores de rendimiento en los individuos objeto de investigación, puede aportar una mejor respuesta a las demandas y requerimientos del entorno sociolaboral?

La investigación, concreta dos objetivos generales:

- Analizar y diseñar una herramienta de medición e identificación de las competencias críticas para el desempeño efectivo de la actividad recogida en las Familias Profesionales elegidas.

- Contrastar, estudiar y evaluar la efectividad del entrenamiento al desarrollo de las competencias y habilidades necesarias para desempeñar la actividad profesional de manera efectiva en entornos laborales.

\section{MÉTODO}

El enfoque metodológico del estudio se plantea de tipo analítico y cuasi-experimental, un proceso exploratorio con el fin de concertar en instrumentos operativos y de concreción material, un control de constancia sobre todas aquellas variables extrañas o contaminadoras que pudieran actuar conjuntamente con la variable independiente, produciendo un resultado sesgado en la variable dependiente, aunque sin aleatorización ni grupo control ya que el grupo estaba previamente formado.

Se utiliza una triangulación de diferentes métodos de carácter cualitativo, como 
el estudio Delphi, el Panel de Expertos y de carácter cuantitativo como la construcción del cuestionario competencial habilidades básicas comerciales.

- En un primer paso, se identificaron desde un punto de vista teórico las competencias clave para el éxito en las Familias Profesionales elegidas, ya que tienen una alta demanda de profesionales.

- El segundo paso, es la integración de esas competencias en la propia actividad profesional (desempeño), mediante Focus Group y panel de expertos, y se concretan indicadores de rendimiento cuantitativos y cualitativos.

- El tercer paso, es identificar el nivel o grado de competencia actual en los sujetos objeto de investigación mediante el diseño de un cuestionario (HABACO).

- El cuarto paso, es el entrenamiento operativo. Aplicación de GIMNÁSTICA DEL TALENTO como modelo de entrenamiento, en función de los niveles de competencia.

- El quinto, y último paso, es volver aplicar el cuestionario para validar pre y post.

A continuación, se presenta de forma gráfica.

Figura 1 - Metodología general.

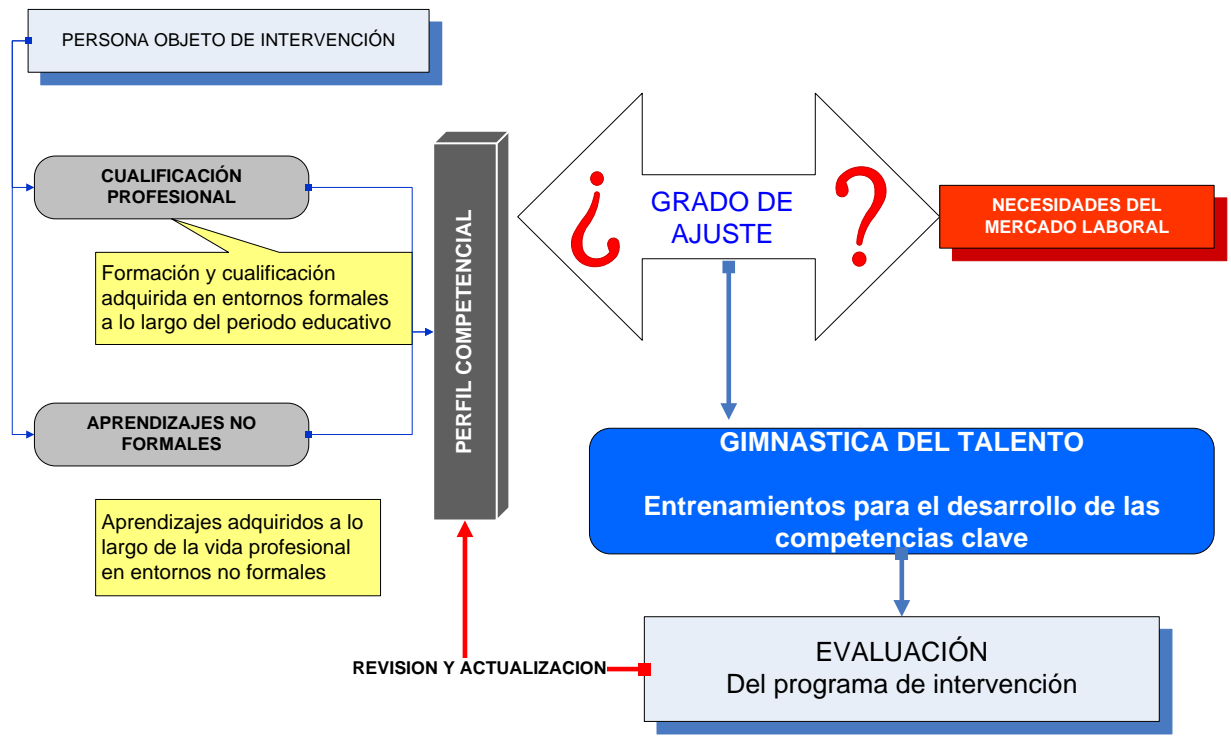

Fuente: Elaboración propia.

Se considera imprescindible contrastar lo enunciado en los diversos textos consultados, con entrevistas a fuentes directas de diversa procedencia, para garantizar la confiabilidad de la información. Se realizan entrevistas estructuradas y técnicas 
cualitativas grupales con responsables de Recursos Humanos para identificar la demanda del mercado sociolaboral de estos perfiles profesionales.

Dentro de las metodologías cualitativas destacar la utilización de Panel de Expertos (basado en focus group). Esta metodología constituye una técnica de investigación cualitativa ampliamente difundida en diversos ámbitos de la investigación en psicología, pedagogía, sociología y campos del marketing.

\section{RESULTADOS}

La Gimnastica del Talento como metodología para desarrollar competencias presenta como innovación la creación del Mapa de Competencias que realiza una triangulación entre actividades, las competencias en cada una de las actividades y la propuesta de desarrollo para cada actividad/competencia.

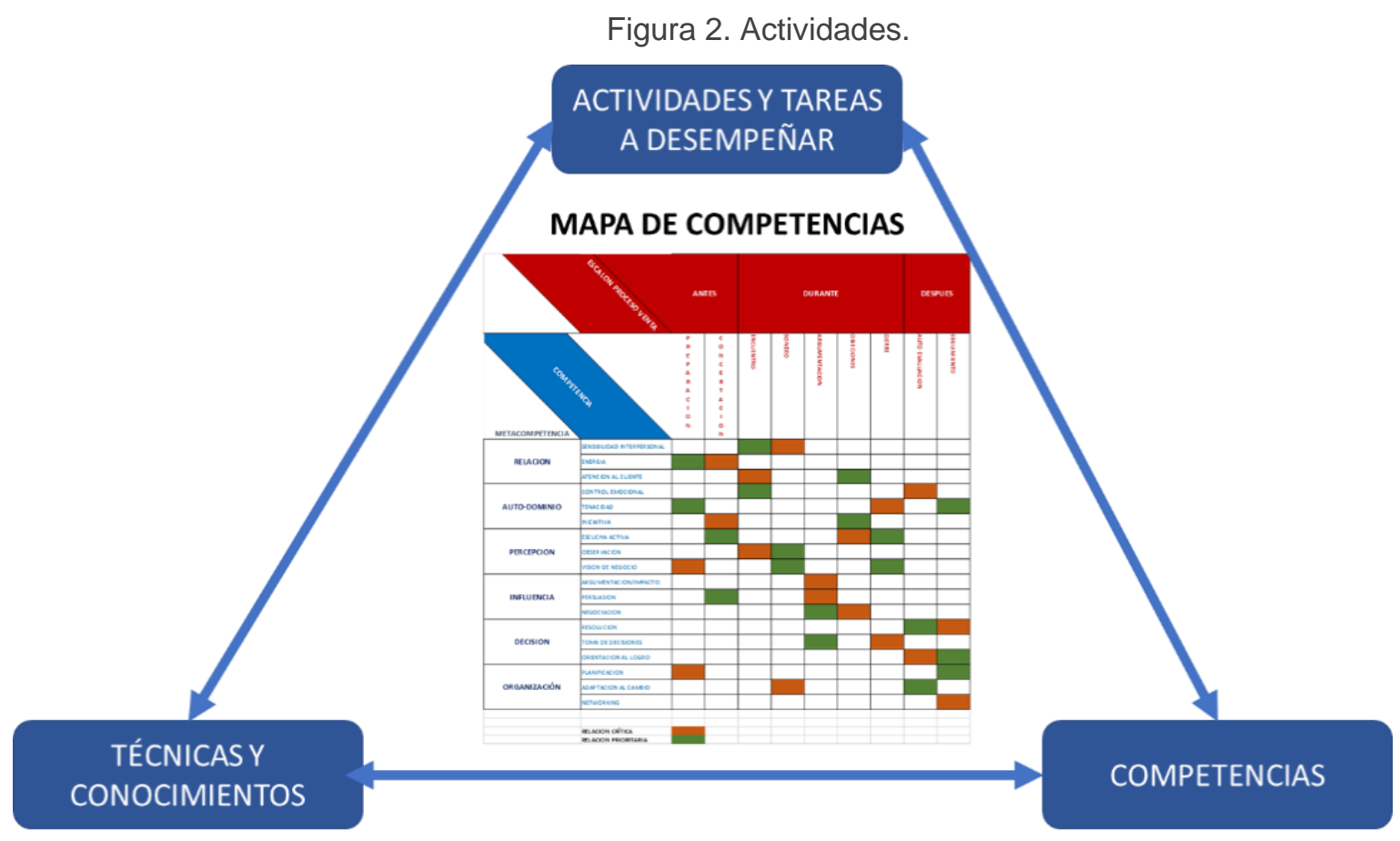

Fuente: Adaptación propia.

Los resultados obtenidos en la investigación podemos resumirlos en:

- Conseguir diseñar, implantar y evaluar un modelo de entrenamiento y desarrollo de 18 Competencias necesarias para el desempeño efectivo de la actividad socio laboral analizada. Estas competencias son: 
- Competencia 1. Sensibilidad interpersonal

- Competencia 2. Energía

- Competencia 3. Atención al Cliente

- Competencia 4. Control Emocional

- Competencia 5. Tenacidad

- Competencia 6. Iniciativa

- Competencia 7. Escucha Activa

- Competencia 8. Observación

- Competencia 9. Visión de Negocio

- Competencia 10. Argumentación e Impacto

- Competencia 11. Persuasión

- Competencia 12. Negociación

- Competencia 13. Resolución

- Competencia 14. Toma de Decisiones

- Competencia 15. Orientación al Logro

- Competencia 16. Planificación y Organización

- Competencia 17. Adaptación al Cambio

o Competencia 18. Networking

- Los resultados apuntan que el modelo de intervención Gimnástica del Talento van en la línea propuesta por el panel de expertos mostrando mejorías tras la intervención entre el grupo pre y el grupo post claramente significativas;

- La propuesta de intervención Gimnastica del Talento, afecta a los componentes básicos de las competencias;

o El saber; al incorporar nuevos constructos y conocimientos relacionados con cada competencia;

- La habilidad, al repetir y aplicar ejercicios de entrenamiento que permiten un reforzamiento y adquisición temprana de las mismas;

- La actitud, al mejorar la autoestima y la confianza en sí mismos por las mejorías en indicadores de rendimiento.

\subsection{Diseño de ejercicios en la Gimnástica del Talento}

Para cada una de las 18 competencias analizadas se construye un programa de entrenamiento secuencial y contextual de los contenidos de manera que los participantes puedan aprenderlos de manera significativa. 
La secuenciación está constituida por una serie de diversos elementos que se relacionan mediante una acción recíproca característica, dando lugar a una sucesión lineal dotada de constancia interna y de especificidad de actuación, es decir, una serie lineal de componentes que tienen que ir presentándose en orden coherente para conseguir la finalidad que persiguen (Eigenmann. 1981).

La secuenciación propuesta en la "tabla de ejercicios" para cada competencia tiene la siguiente estructura:

- Evaluación del nivel de competencia actual, mediante cuestionario auto-aplicado.

- Definición del significado de la competencia. Conductas más significativas de la misma, en nivel bajo, medio y alto.

- Contenidos conceptuales. Desarrollo del concepto de la competencia, importancia en el entorno socio laboral, relaciones con otras competencias, marco teórico explicativo.

- Contenidos procedimentales. Constituyen un conjunto de acciones que facilitan el logro del fin propuesto abracando la ejecución de habilidades, técnicas y métodos. Para ello, se crea un caso o lectura sobre el que se reflexiona en cada una de las competencias.

En cuanto a la contextualización requiere un conocimiento profundo de las características del contexto en el que se va a realizar la acción educativa y como los participantes van a relacionar sus conocimientos previos y los contenidos que son objeto de aprendizaje.

Cada competencia termina el entrenamiento con la contextualización y aplicabilidad de transferencia al entorno socio laboral mediante la generación de una nueva forma de reaccionar a los hechos, objetos y circunstancias percibidas.

\subsection{Modelo de los Nueve Pasos}

Durante 2017 se llevó a cabo la implantación de Gimnástica del Talento a una población objeto de estudio, el grupo para el análisis de los resultados se segmento en; Genero (hombre, mujer), experiencia profesional (menos de 1 año, de 1 a 3 años y más de 5 años), Formación (básica, estudios medios, estudios universitarios).

Los ejercicios que se aplicaron es la variable independiente del estudio (A), que está vinculada al desarrollo de las competencias y de las habilidades y el nivel de 
rendimiento profesional que realizan como la variable dependiente (B).

Se propone un modelo de intervención, el modelo de nueve pasos que parte del principio de que independientemente del producto o servicio que el individuo tenga en la organización en la que se encuentre, tiene que realizar nueve etapas o pasos, en mayor o menor medida para el desempeño de la actividad.

Debe hacer actividades ANTES de mantener la relación con su interlocutor, antes de relacionarse con él en el proceso de interacción comercial; Paso1 (Preparase) y Paso 2 (Concertar el encuentro). Las actividades que debe realizar DURANTE el proceso de interacción son; Paso 3 (Toma de Contacto o Encuentro) Paso 4 (Sondear, analizar necesidades), Paso 5 (Argumentar, captar el interés), Paso 6 (Negociar, solventar posibles diferencias) y Paso 7 (Cerrar el acuerdo, si es posible o posponer para otra ocasión). Las actividades que debe de realizar DESPUÉS de la interacción son; Paso 8 (Autoevaluación, identificación de puntos fuertes y áreas de mejora) y Paso 9 (definir un Seguimiento de la actividad).

Figura 3. Modelo de Nueve Pasos.
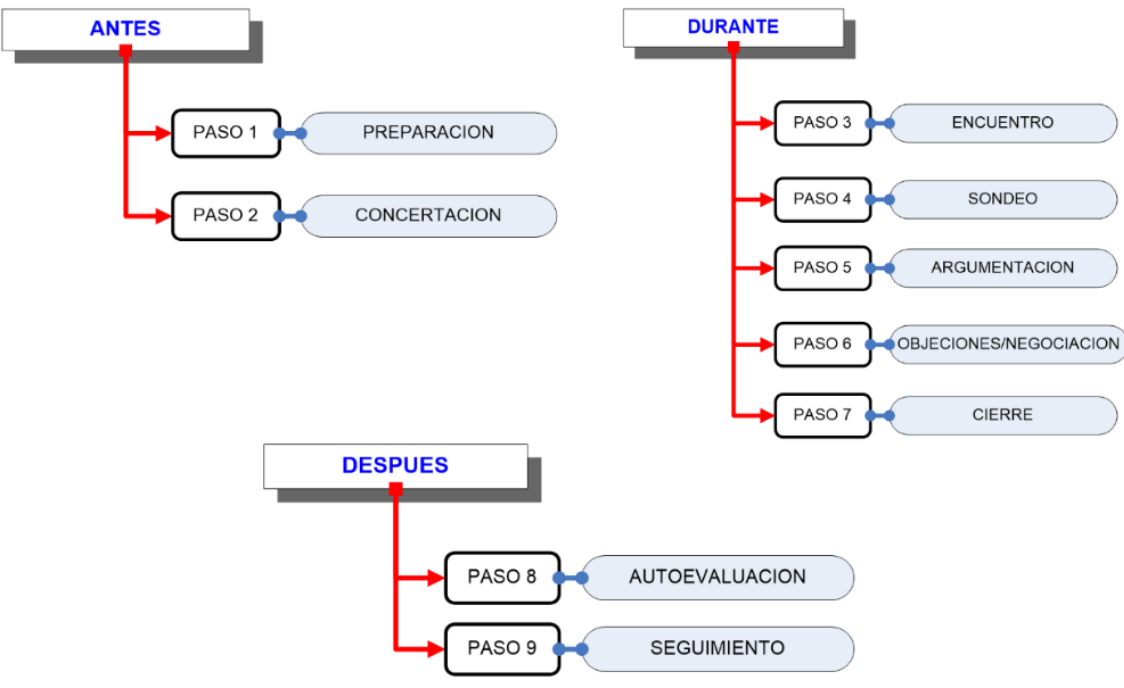

Fuente: Adaptación propia.

La organización final del Mapa de Competencias en relación con cada uno de los Nueve pasos es la siguiente; (se identifican las competencias críticas para la actividad y competencias prioritarias). Se desarrollan y aplican los ejercicios propuestos parta cada una de las competencias "Gimnastica del Talento" y se evalúan los resultados. 
Figura 4. Mapa de competencias.

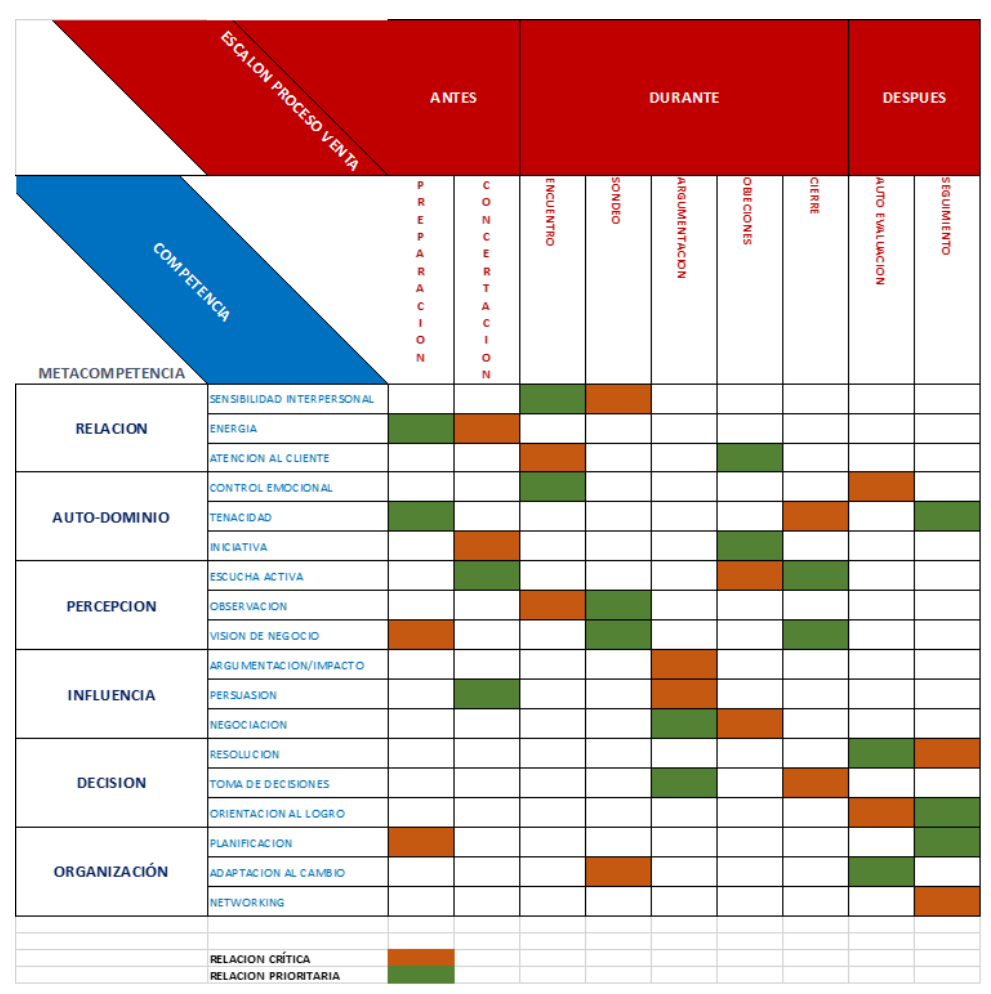

Fuente: Adaptación propia.

\section{CONCLUSIONES}

El trabajo se suma a los anteriores que (Guerrero, 1999) ofrecen los principales hallazgos sobre el papel que juegan las competencias profesionales como clave para la obtención de empleo estable y de calidad alcanzando los siguientes resultados:

1. El diseño combinado de Focus Group, Panel Expertos y Metodología Delphi nos ha permitido construir un escenario fortalecido con relación a los requerimientos competenciales actuales en el entorno sociolaboral objeto del estudio.

2. El Modelo de los nueve pasos aporta el Mapa de Competencias con una visión holística que ayuda a potenciar y dinamizar nuevas actuaciones en este ámbito de estudio.

3. Los ejercicios aportan una personalización del desarrollo competencial ajustado a los requerimientos del entorno y del propio individuo.

4. Los datos obtenidos indican que hay una reducción importante del tiempo de aprendizaje en sujetos con menos experiencia en el sector.

5. Se ha logrado la comprensión y descripción del estado actual en esta área, mediante un exhaustivo análisis de los modelos de formación continuada, certificación 
profesional y modelos actuales de entrenamiento y que convergen en la aplicación sistemática de ejercicios de desarrollo competencial y que se configura en uno de los componentes de innovación sobre otras investigaciones llevadas a cabo con anterioridad. La "Gimnástica del Talento" ha aportado mejoras entre el grupo pre y post intervención con diferencias en casi todas las competencias.

6. La Gimnástica del Talento puede capacitar mejor a los profesionales del sector y aportar respuestas a las demandas del mercado socio laboral. Los resultados son concluyentes en cuanto a la posibilidad de transferencia a otros entornos como la formación dual o certificados de profesionalidad al destacar la importante mejoría en el rendimiento en individuos con menos experiencia profesional.

La evidencia empírica indica claramente, que la "Gimnastica del Talento" como modelo incrementa la eficacia en el desempeño profesional. Los indicadores de rendimiento, la eficiencia en cuanto al incremento de satisfacción, el ahorro de tiempos y de recursos, son positivos tras la intervención, con todo lo que ello supone para las administraciones y organizaciones en general.

En formación continuada en entornos no formales, generalmente se considera que un programa de intervención es menos costoso si requiere de un menor número de sesiones formativas, que estas puedan ser en grupo o individuales, según la necesidad, y que para la propia organización y para el propio sujeto requiera un menor esfuerzo social de dedicación frente a la familia, ocio u otras actividades, es decir, que permita una mayor conciliación.

Todos estos criterios, basados en la valoración aditiva de las ventajas de la intervención de la Gimnástica del Talento, frente a otras intervenciones son fundamentales para el desarrollo adecuado de la actividad profesional según muestra los datos de la investigación realizada. 


\section{BIBLIOGRAFÍA}

Eigenmann J. (1981). El desarrollo secuencial de curriculum. Ed. Anaya. Madrid.

Gallart M.A.y Jacinto C., (1995). Competencias Laborales: Tema Clave En La Articulación Educación-Trabajo. Publicado con autorización de los editores. Tomado del Boletín de la Red Latinoamericana de Educación y Trabajo, CIID-CENEP, Año 6 № 2. Publicado en diciembre 1995 en Buenos Aires (Argentina).

Guerrero Serón A., (1999). El enfoque de las competencias profesionales: una solución conflictiva a la relación entre la formación y el empleo. Revista Complutense de Educación. Vol 10 nº 1 135-360.

Marina J.A., (2010). La Educación del Talento. Ed. Ariel. Barcelona. 
CHAPTER 07

REHABILITACIÓN PROTÉSICA EN PACIENTE CON

OSTEOPOROSIS BAJO TRATAMIENTO CON

BIFOSFONATOS

\section{Dra. Belinda Pérez Santa}

Universidad de Guadalajara, Centro Universitario de Ciencias de la Salud, Departamento de Clínicas Odontológicas Integrales, México.

\section{Dra. Luz Elena Napoles Salas}

Universidad de Guadalajara, Centro Universitario de Ciencias de la Salud, Departamento de Clínicas Odontológicas Integrales, México.

E-mail: luznapoles06@hotmail.com

Dra. Saralyn López y Taylor

Universidad de Guadalajara, Centro Universitario de Ciencias de la Salud, Departamento de Clínicas Odontológicas Integrales, México.

\section{Dra. Sabrina Del Rosario Pérez Santana}

Universidad de Guadalajara, Centro Universitario de Ciencias de la Salud, Departamento de Clínicas Odontológicas Integrales, México.

\section{Dra. Olga Rocío Manzo Palomera}

Universidad de Guadalajara, Centro Universitario de Ciencias de la Salud, Departamento de Clínicas Odontológicas Integrales, México.

\section{Dra. Ana Bertha Olmedo Sánchez}

Universidad de Guadalajara, Centro Universitario de Ciencias de la Salud, Departamento de Clínicas Odontológicas Integrales, México.

\section{Dr. Ricardo Sosa Pérez}

Universidad de Guadalajara, Centro Universitario de Ciencias de la Salud, Departamento de Clínicas Odontológicas Integrales, México.

\section{Dr. Carlos Eduardo Bracamontes Campoy}

Universidad de Guadalajara, Centro Universitario de Ciencias de la Salud, Departamento de Clínicas Odontológicas Integrales, México.

\section{Dra. Rosa Patricia Gómez Cobos}

Universidad de Guadalajara, Centro Universitario de Ciencias de la Salud, Departamento de Clínicas Odontológicas Integrales, México.

\section{Dra. Gabriela Gómez Gonzalez}

Universidad de Guadalajara, Centro Universitario de Ciencias de la Salud, Departamento de Clínicas Odontológicas Integrales, México. 


\section{INTRODUCCIÓN}

La condición de salud bucodental nos puede causar alteraciones en la alimentación, así como déficit nutricional, además de la percepción negativa de cómo los padecimientos óseos repercuten en la salud oral, así como en todo nuestro sistema orgánico y psicosocial. Con la edad, los procesos de reabsorción y formación ósea se desequilibran, hay un incremento en la pérdida del tejido óseo, ya sea por aumento en la actividad osteoclástica, la disminución de la actividad osteoblástica, o ambas (Castellanos, 2015). La osteonecrosis es la falta de cicatrización después de una extracción, la cual se manifiesta con dolor e infección. La enfermedad generalmente inicia con una alveolitis, que progresa hacia una osteomielitis, con secuestros óseos por lo cual se determinó no realizar la extracción de los terceros molares incluidos, ya que si se realizara se corre el riesgo de debilitar la estructura ósea de la rama mandibular, obsérvese radiografía panorámica Fig-1

PALABRAS-CLAVES: Osteoporosis; Osteonecrosis; Óseos; Bifosfonatos.

Figura 1. Rx Panorámica: OD 38 y 48 Retenidos

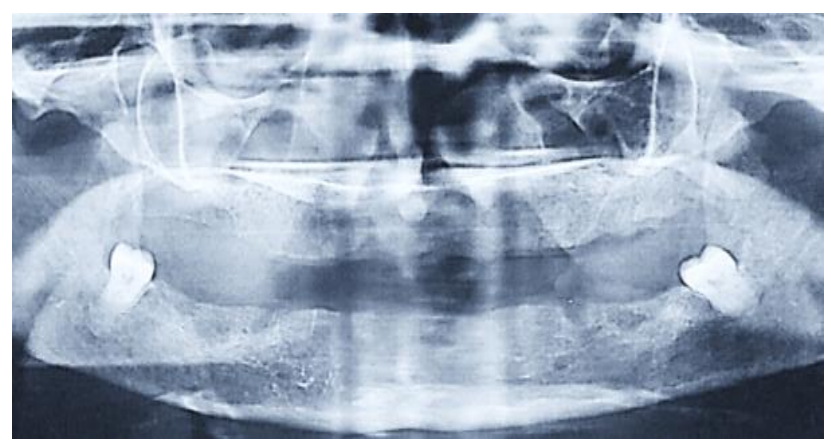

Fuente: Los autores.
Figura 2. Proceso Superior.

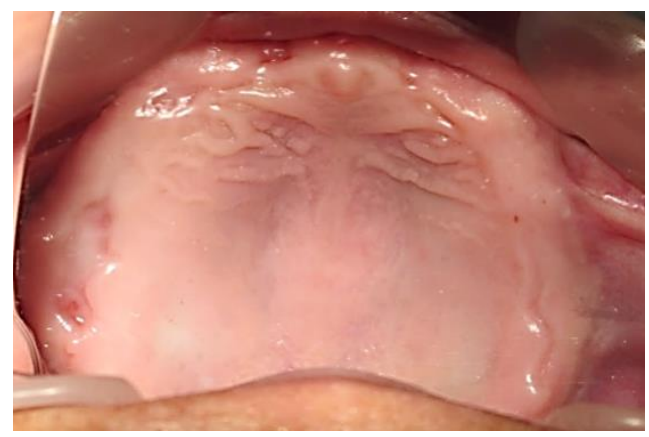

Fuente: Los autores.

\section{EXPOSICIÓN DEL CASO}

Se presenta paciente femenina de 60 años de edad, en Clínicas Odontológicas Integrales CUCS, motivo de consulta: "Quiero comer, baje mucho de peso" Dentro de la historia clínica indica diabetes e hipertensión controlada, adicionalmente refirió padecer osteoporosis desde los 40 años de edad, motivo por el cual desde hace tres años tiene prescripción médica controlada con medicamento. Radiográficamente se observan incluidas las piezas 38 y 48 respectivamente (FIG. 1). Clínicamente no presenta alteraciones en boca, ni molestia alguna por los órganos dentarios retenidos 
(FIG. 2; 3; 4). La paciente y su familiar fueron informados sobre las posibles complicaciones debido a su condición y los cuidados puntuales durante el tratamiento.

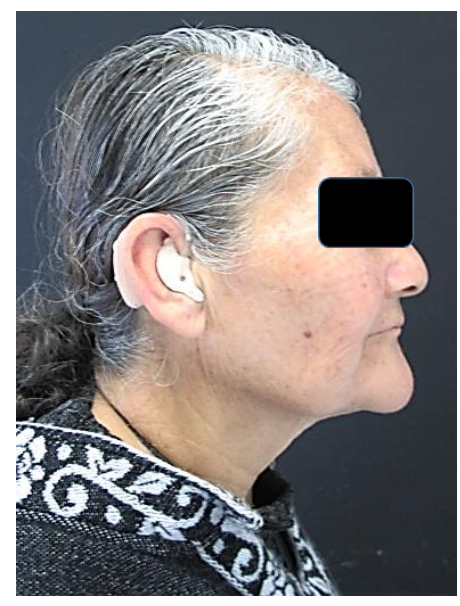

Figura 5. Estado Inicial del Paciente.
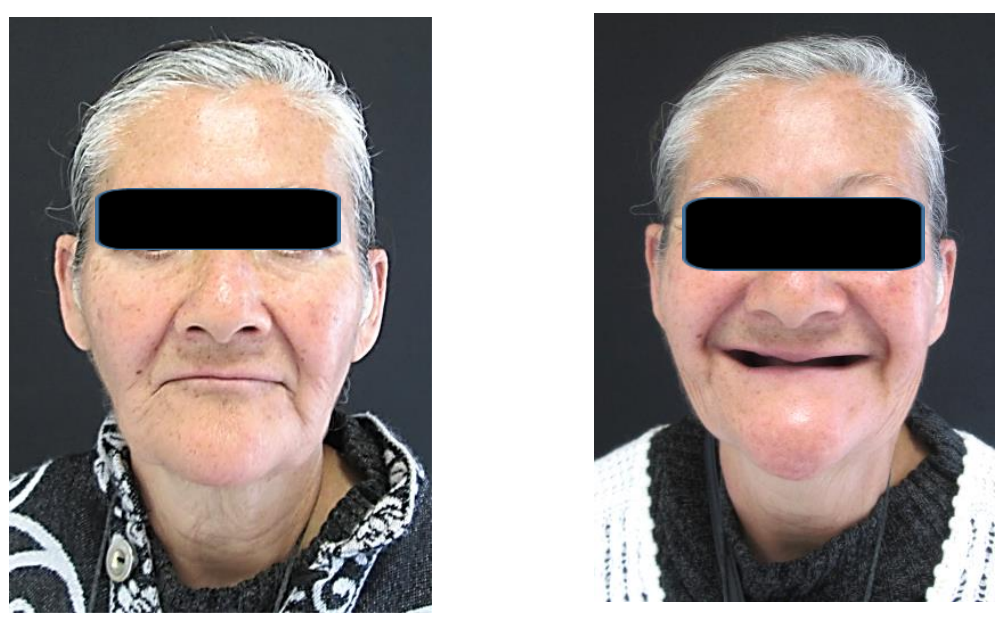

Fuente: Los autores

\section{CASO CLÍNICO}

Diagnóstico y revisión de la cavidad oral, estado inicial del paciente (FIG. 5). Se tomaron impresiones preliminares, obtención de modelo y fabricación cucharillas individuales de acrílico, se procedió con los registros miofuncionales(FIG.6), preparando las cucharillas para impresión final (FIG. 9) y llenado de modelos de trabajo (FIG. 7) Se fabricaron bases y rodillos en cera rosa extradura (FIG. 8), Relaciones maxilomandibulares, montado en articulador semiajustable(FIG. 10), selección de dientes de acuerdo al paciente, y toma de color. Prueba de dentadura en cera, para hacer ajustes en paciente (FIG.11). Se realiza el acrilado de la dentadura. Posteriormente los ajustes en boca (liberación de frenillos y ajustes en zonas presión), se entrega la dentadura a satisfacción del paciente confirmando estética, fonética y función. se dan indicaciones de uso, cuidados y mantenimiento, se toman fotografías finales (FIG. 12), se programa cita al paciente para control de 24, 48 y $72 \mathrm{hrs.}$ 
Figura 6. Cucharilla individual. Registros miofuncionales.
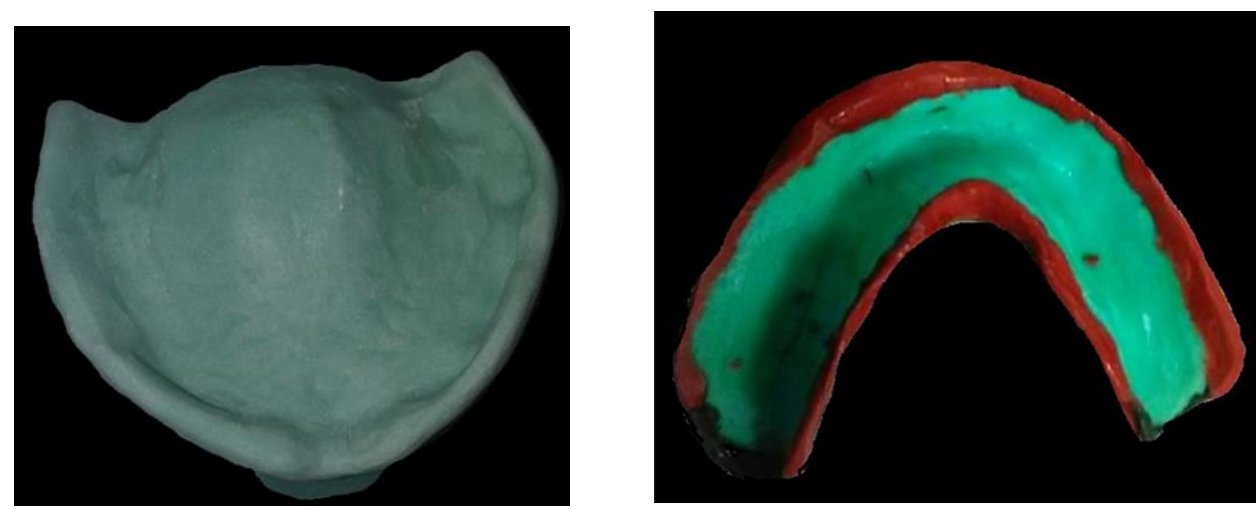

Fuente: Los autores.

Figura 7. Encajonado de Impresiones.
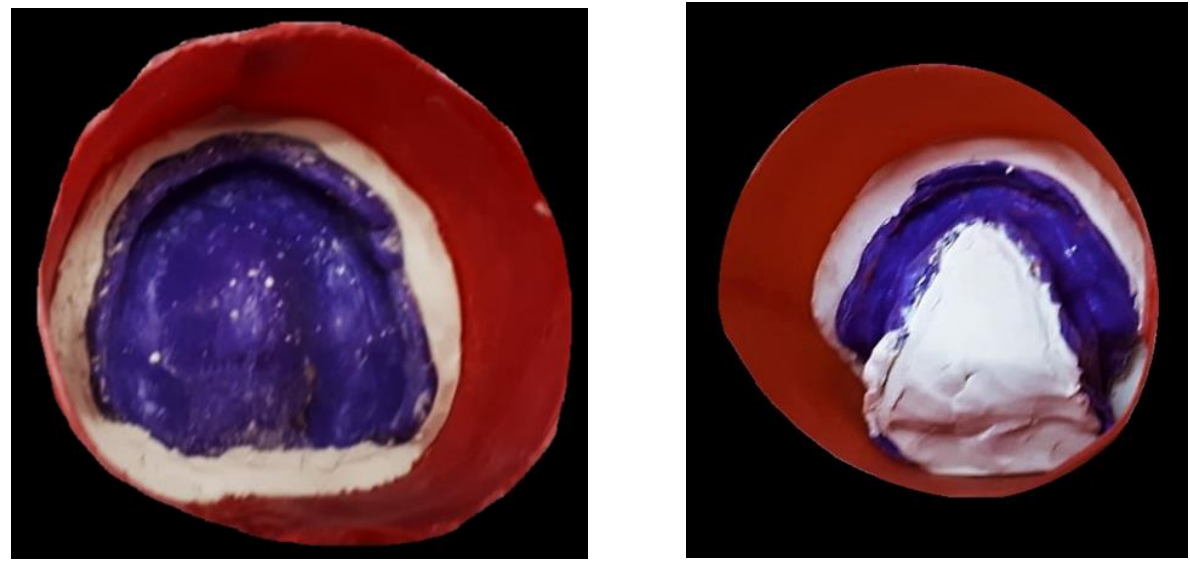

Fuente: Los autores.

Figura 8. Bases y rodillos. Registro interoclusal.
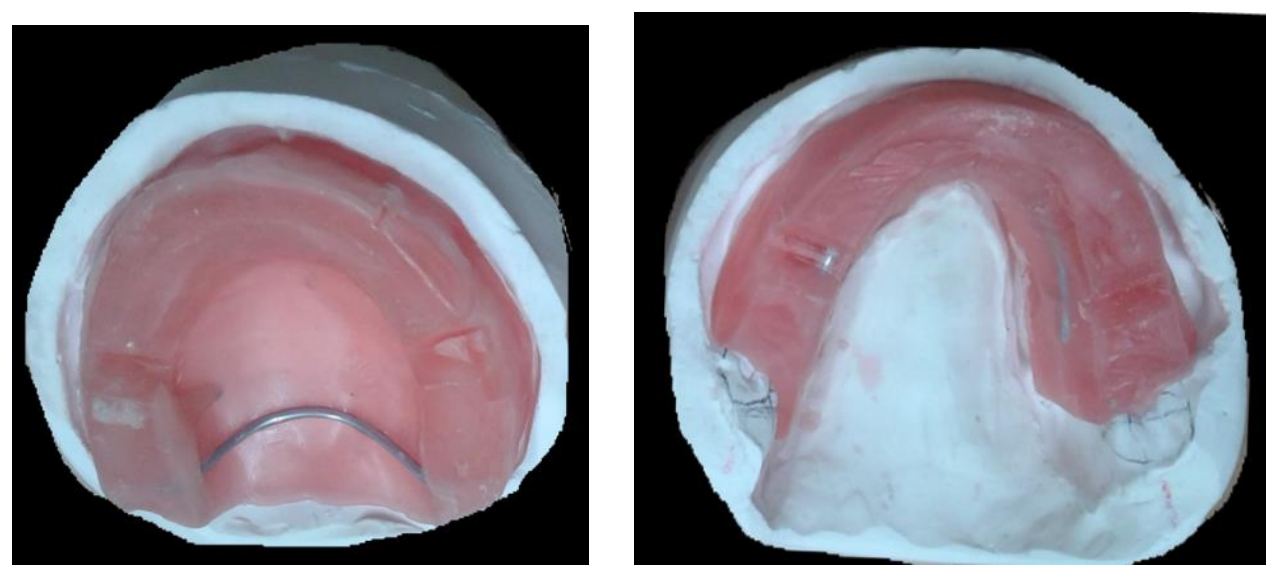

Fuente: Los autores. 
Figura 9. Impresión Final con Silicón regular.

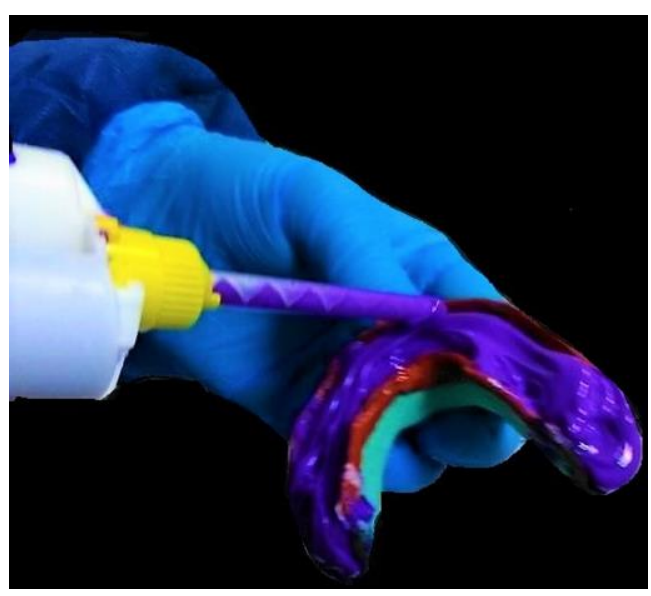

Figura 10. Montaje en cera.

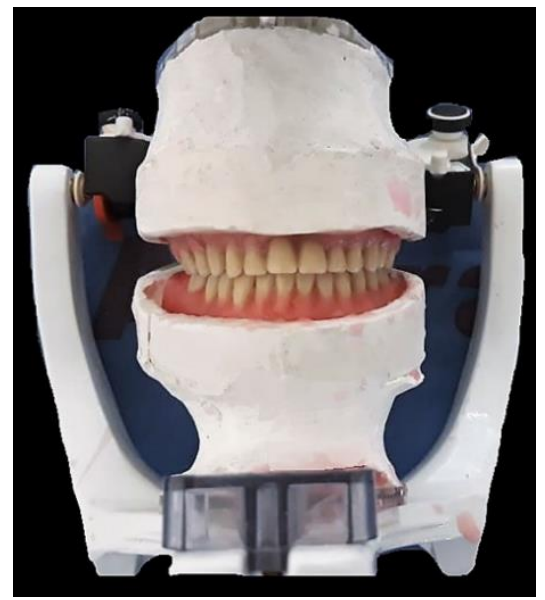

Fuente: Los autores.

Figura 11. Prótesis totales. Terminadas y entregadas

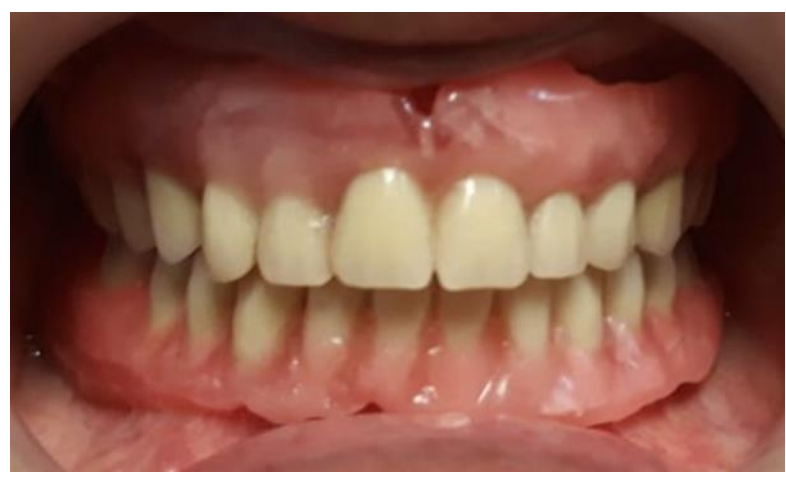

Fuente: Los autores.

Figura 12. Paciente después del tratamiento.
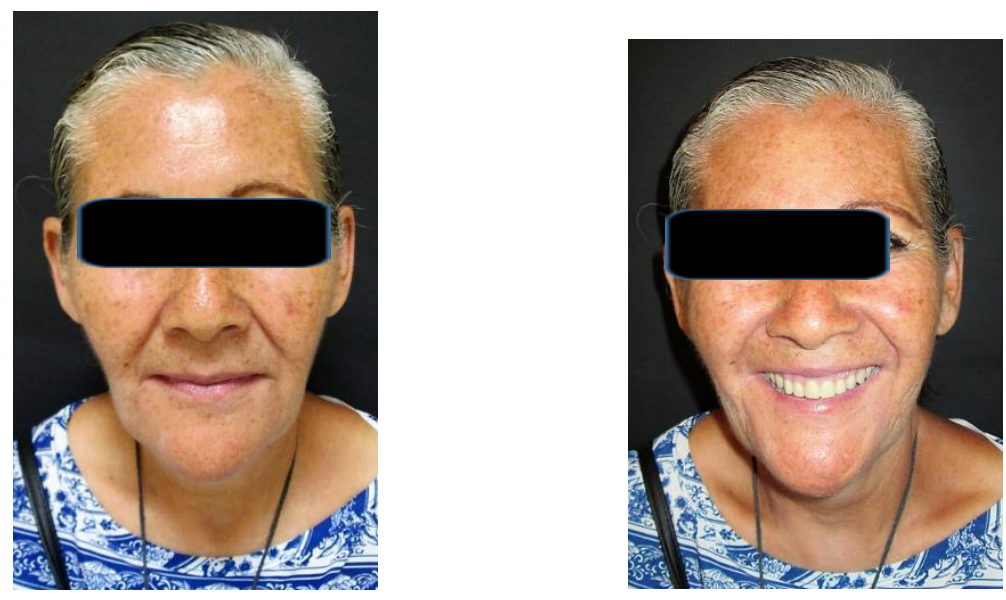

Fuente: Los autores. 


\section{DISCUSIÓN}

Como parte del tratamiento se tomó la decisión de preservar los órganos dentales incluidos por el riesgo de que, al realizar la cirugía, existe la posibilidad de presentar osteonecrosis, debido a que el paciente ha consumido el fármaco por su padecimiento durante los últimos tres años. El individuo deberá cumplir con el control para descartar cualquier molestia que pudiera repercutir en los tejidos, durante el uso de las prótesis. Se recomienda esperar un año para la cirugía de los OD.38 y 48 respectivamente.

\section{CONCLUSIÓN}

Se le devolvió a la paciente su sonrisa, siendo que ahora ya tiene correcta dimensión vertical, estética, y lo más importante: su seguridad integral. Para preservar la salud de los tejidos residuales, se decidió preservar los órganos dentarios incluidos, para prevenir lesiones irreversibles ocasionadas por los bifosfonatos, a su vez osteonecrosis: puesto que existe la posibilidad de que el paciente sea un Individuo susceptible. De suma importancia son las indicaciones a las citas subsecuentes de control cada 3 meses, una vez terminado el tratamiento con bifosfonatos, se considerará la extracción de terceros molares inferiores parcialmente erupcionados, y realizar un rebase de la dentadura a mediano plazo. 


\section{BIBLIOGRAFÍA}

Bumann, A. (2000). Atlas de diagnóstico funcional y principios terapéuticos en odontología. Barcelona, España: Ed. Masson.

JOSE ,L, DIAZ,L,(2015) MEDICINA EN ODONTOLOGÍA y Manejo dental de pacientes con enfermedades sistémicas. Tercera edición, Ed. El manual moderno, México D.F. Lindhe,J, Karting,T, (2017) Periodontología Clínica e Implantológica. Editorial Panamericana.

H.H. Horch;(2003) Cirugía Oral y Maxilofacial; Ed. Masson.

John J. Sharry (2005) Prostodoncia dental completa,Ed.Toray.

Cortés-Motta M, FernándezGrisales R. (2016) Osteonecrosis de los maxilares: fisiopatología, diagnóstico y tratamiento. Rev. CES Odont ; 29(2)

M. A. Vidal, C. Medina y L. M. Torres ${ }^{1}$ (2011) Seguridad de los bifosfonatos, Rev. Soc. Esp. Dolor vol.18 no.1 Madrid ene./feb.

Ruggiero SL, Mehrotra B, Rosenberg TJ, Engroff SL. (2004) Osteonecrosis of thejawsassociatedwiththe use of bisphosphonates: a review of 63 cases. J Oral MaxillofacSurg ; 62: 527-34

A.Eumann Mesas' S. Maffei' M. Aparecido' V. Ribeiro. 82010)Salud oral y déficit nutricional en adultos mayores no institucionalizados en Londrina, Paraná, Brasil,Rev.bras. epidemiol. vol.13 no.3 São Paulo Sept. 
CHAPTER 08

VALIDACIÓN APLICATIVO MÓVIL PARA DETECCIÓN DEL

BURNOUT EN DOCENTES BOGOTÁ-COLOMBIA

Edgardo Javier Muñoz Beltran

Educación superior: Doctor en Educación, Magister en salud pública.

Institución: Universidad Popular del Cesar. Habla a:

Universidad Popular del Cesar.

Correo electrónico: ejamub@yahoo.com.ar

Maria Ines Mantilla Pastrana

Educación superior: Doctor en Educación, Magister en Enfermería.

Institución: Red Latinoamericana de Enfermería informática,Habla

a: Red latinoamericana de enfermería Informática

Correo electrónico: mariainesmantilla@gmail.com

\section{Mery Gonzalez}

Educación superior: Magister salud pública.

Institución: Fundación Universitaria del área andina. Habla a:

Fundación universitaria del área andina

Correo electrónico: megonzalez2@areandina.edu.com

\section{Jhonny Walyt Cruz Riveros}

Educación superior: Magister en Enfermería.

Institución: Fundación Universitaria del área andina. Habla a:

Fundación universitaria del área andina

Correo electrónico: jhcruz@areandina.edu.com

\section{Deysy Rodriguez Araujo}

Educación superior: MAGISTER EN CALIDAD Institución:

Fundación Universitaria del área andina. Habla a: Fundación universitaria del área andina

Correo electrónico: drodriguez139@areandina.edu.com

RESUMEN: El estrés crónico laboral puede ser una de las características en la aparición de burnout, la población docente en particular está sometido a altas cargas de estrés, el uso de aplicativos móviles podría ser de gran ayuda para identificarlo, sin embargo, son escasos los desarrollados y validados en la población docente como eje en la identificación oportuna del burnout. Como objetivo se plantea determinar si hay burnout en docentes de escuelas públicas y privadas en la ciudad de Bogotá-Colombia, así como el desarrollo de un aplicativo móvil tipo App que promueva el conocimiento del síndrome de burnout. Los instrumentos utilizados para la medición fueron el test MBI (Maslach Burnout Inventory). La metodología consistió en una investigación cuantitativa, descriptiva y no experimental; la población objeto fueron 294 profesores de escuelas de la ciudad de Bogotá-Colombia. Dentro de los resultados encontrados se evidenció cansancio emocional en los grupos estudiados $p<0.02$. El hecho de ser especialista o tener una maestría en los profesores actuaba como protector de la enfermedad $\mathrm{P}<0.01$, Ic(-2.27, -0.52$)$.

PALABRAS-CLAVE: Burnout profesional; Prevención-control; Aplicaciones de la informática médica; Estréslaboral. 


\section{INTRODUCCIÓN}

Burnout es un tema de actualidad, porque cada día la sociedad se encuentra sometida a innumerables variables de adaptabilidad a un medio que genera estrés. Sin embargo algunas profesiones están más sometidas que otras a estrés, lo que podría representar que el efecto se visibilice de múltiples formas, aunque la situación radica en cómo se logra identificarlas de una manera correcta, y cómo el mismo individuo que se encuentra en proceso de padecerla, logra anclar y ajustarse al contexto para evitar llegar a las fases finales de burnout.

Muchos estudios evidencian la presencia de Burnout en diferentes profesiones de ayuda, entre ellas la docencia (Bambula, F. D., Sánchez, A. L., \& Arévalo, M. T. V. 2012, p.218), relacionada con altas cargas laborales, ejecución simultánea de varias actividades, sobreempoderamiento y déficit de la calidad educativa que genera estrés como forma de representar logros que no se cumplen.

La correcta identificación de los factores asociados al burnout es la pieza fundamental para encontrar su presencia en sus fases iniciales, en primer lugar, porque es el punto de inflexión para el inicio de acciones oportunas, y en segundo lugar porque al identificar los factores asociados al burnoutse lograría entender todo el proceso fisiopatológico, los factores asociados, las líneas de acción y la caracterización del burnout en la macroesfera educativa.

El síndrome de burnout consiste en una respuesta psicológica al estrés laboral crónico que compromete tres dimensiones: cansancio o agotamiento emocional, despersonalización y autorrealización, referidas a la relación entre el individuo y el ámbito laboral.

Según Llull, D. S., Martí, X., \& Brage, L. B. (2015) afirman:

El agotamiento laboral es la sensación de cansancio, fatiga, vacío y la persona se siente gastada y sin energías; la despersonalización consiste en una actitud de distanciamiento ycinismo en relación con los compañeros de trabajo y alumnos, mientras que la autorrealización consiste en un sentimiento de disminución de la competencia donde el profesional se siente cada día más ineficaz e inútil (p.247).

Tratándose de una necesidad imperiosa para determinar el manejo, identificación y diagnóstico del estrés proyectado a la presencia o ausencia de burnout en entidades educativas de la ciudad de Bogotá-Colombia, se encontró escasa información, ausencia de protocolos ajustables e instrumentos de medición permanente, razón por la cual se procedió con base en la problemática, al diseño 
del estudio con el objetivo de determinar la presencia o ausencia de burnout en los profesores de escuelas públicas y privadas de la ciudad de Bogotá-Colombia, mediante la aplicación del instrumento Maslach Burnout Inventory midiendo las características de cansancio emocional, despersonalización y autorrealización.

Como Hipótesis se propuso que no existían diferencias entre las escuelas públicas y privadas en relación a la presencia de burnout.

El uso de herramientas tecnológicas basadas en las TIC como soporte en actividades de promoción de la salud no son nuevas. En ese sentido autores como Wanden-Berghe, C., Sabucedo, L., \&Martínez de Victoria, I. (2011), manifiestan que "la incorporación de las tics al mundo sanitario está suponiendo un motor de cambio para mejora de la calidad de vida" p.30.

En ese sentido, es necesario mencionar que, a parte de la medición de las tres dimensiones descritas anteriormente, se procedió a diseñar y validar un aplicativo móvil como estrategia permanente de consulta, conocimiento y autogestión como actividades de promoción y prevención de la enfermedad.

\section{MÉTODO}

\subsection{Descripción del contexto y de los participantes}

Es un estudio descriptivo, de prevalencia y muestreo aleatorio, con la participación de docentes de escuelas públicas y privadas de la ciudad de Bogotá en el año 2018, con una población de 1257 docentes y una muestra de 294 docentes que cumpliesen con los criterios de inclusión.

\subsection{Instrumentos}

Para la medición del burnout en los docentes de escuelas públicas y privadas de la ciudad de Bogotá-Colombia se procedió a utilizar el instrumento denominado MBI (Maslach Burnout Inventory) (Bakker, A. B., Demerouti, E., \& Schaufeli, W. B. 2002, p.250), previo permiso de los autores, cuya principal característica es la medición de tres dimensiones de análisis: cansancio emocional, despersonalización y autorrealización. Por otra parte se diseñó un instrumento para la caracterización de las variables sociodemográficas.

Para la interpretación de los resultados del instrumento de acuerdo a Taris, T. 
W., Le Blanc, P. M., Schaufeli, W. B., \& Schreurs, P. J. (2005) se menciona que:

Agotamiento o cansancio emocional con niveles de 27 en adelante son resultados altos, niveles entre 19 a 26 niveles medios y por debajo de 19 niveles bajos; para despersonalización puntuaciones por encima de 10 serían un nivel alto, 6 a9 nivel medioy menor a 6 niveles bajos; para autorrealización es un sentido inverso de 0-30 baja realización personal, 34 a 39 intermedia y superior a 40 alto nivel de realización.

Se realizó una validación de contenido al instrumento para lograr la aplicación al conjunto de docentes, en ese sentido se invitaron a 10 docentes con trayectoria en el campo de la docencia para su ejecución con los siguientes resultados.

Tabla 1. Rango resultados jueces

\begin{tabular}{|c|c|}
\hline jueces & Rango promedio \\
\hline juez 1 & 5,33 \\
juez 2 & 5,48 \\
juez 3 & 4,72 \\
juez 4 & 5,33 \\
juez 5 & 6,08 \\
juez 6 & 5,40 \\
juez 7 & 5,86 \\
juez 8 & 6,08 \\
juez 9 & 5,55 \\
juez & 5,17 \\
invest & \\
\hline
\end{tabular}

Tabla 2. Estadísticos de prueba

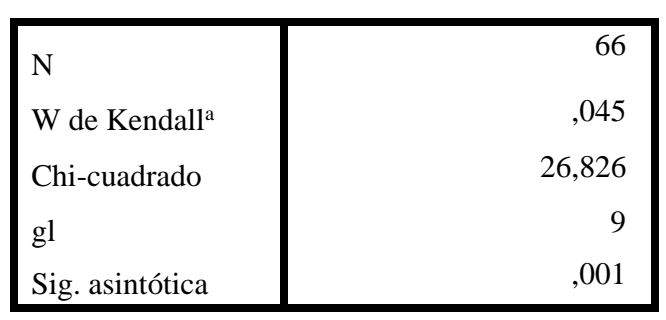

Fuente: Los autores.

Fuente: Los autores.

De acuerdo a la presente salida del estadístico Spss se observó que la concordancia de los evaluadores no se debe a las probabilidades, se logra rechazar la hipótesis nula, en ese sentido es concluyente decir que las clasificaciones de los evaluadores están asociadas entre sí.

Esta es una prueba importante porque logró evidenciar que es posible que existan asociaciones entre los resultados emitidos por los jueces, sin embargo, es necesario una prueba más robusta para establecer una acertada validación del contenido, y las que más se acercan en ese sentido son la prueba de la comunalidad, la medida de adecuación KMO y la prueba de esferidad de Bartlett en su grado de significancia.

Para interpretar las salidas provenientes del estadístico Spss es necesario conocer que la comunalidad debe ser mayor de 0.4, la medida de adecuación KMO debe ser mayor a 0.5 y la prueba de esfericidad en su grado de significancia debe ser menor de 0.05 . los resultados provenientes del estadístico se pueden observar a continuación. 
Tabla 3. Prueba de KMO y Bartlett.

\begin{tabular}{|c|c|c|}
\hline $\begin{array}{l}\text { Medida Kaiser-Meyer-Olk } \\
\text { treo } \\
\text { Prueba de esfericidad de } \\
\text { Bartlett }\end{array}$ & $\begin{array}{l}\text { adecuación de mues- } \\
\text { Aprox. Chi-cua- } \\
\text { drado } \\
\text { gl } \\
\text { Sig. }\end{array}$ & $\begin{array}{c}, 53 \\
109,025 \\
45 \\
, 000\end{array}$ \\
\hline
\end{tabular}

Fuente: Los autores.

Tabla 4. Comunalidades

\begin{tabular}{|l|r|r|}
\hline & \multicolumn{1}{|c|}{ Inicial } & Extracción \\
\hline juez 1 & 1,000 &, 622 \\
juez 2 & 1,000 &, 632 \\
juez 3 & 1,000 &, 670 \\
juez 4 & 1,000 &, 726 \\
juez 5 & 1,000 &, 413 \\
juez 6 & 1,000 &, 764 \\
juez 7 & 1,000 &, 617 \\
juez 8 & 1,000 &, 714 \\
juez 9 & 1,000 &, 495 \\
Juez inv. & 1,000 &, 775 \\
\hline
\end{tabular}

Fuente: Los autores.

De acuerdo a las salidas del estadístico Spss se cumplió con los criterios de validez de contenido para el instrumento evaluado, en este sentido las pruebas KMO y Bartlett cumplieron con los puntos fijos de referencia y la prueba de significancia resultó apropiada.

\section{PROCEDIMIENTO}

Para la recolección, aplicación y gestión de la información se procedió a aplicar los respectivos instrumentos con la muestra seleccionada de manera aleatoria y con carácter independiente, previa recolección de los consentimientos de cada uno de los participantes. Posteriormente se recolectó y procesó la información para la generación y análisis de los resultados.

\section{RESULTADOS}

Los resultados descriptivos se observan en la tabla 5 a continuación. 
Tabla 5. Descriptivos

\begin{tabular}{|c|c|c|}
\hline Variables & \multicolumn{2}{|c|}{ Frecuencia } \\
\hline Masculino & \multicolumn{2}{|l|}{122} \\
\hline femenino & \multicolumn{2}{|l|}{172} \\
\hline casados & \multicolumn{2}{|l|}{43} \\
\hline solteros & \multicolumn{2}{|l|}{205} \\
\hline Unión libre & \multicolumn{2}{|l|}{46} \\
\hline \multirow{3}{*}{ Tiempo en la institución } & $<5$ años & 122 \\
\hline & 5-10 años & 129 \\
\hline & > 10 años & 43 \\
\hline \multirow[b]{2}{*}{ Tipo de institución } & Publica & 148 \\
\hline & Privada & 146 \\
\hline \multirow{3}{*}{ Nivel de estudio } & Especialista & 40 \\
\hline & Maestría & 15 \\
\hline & Profesional & 239 \\
\hline
\end{tabular}

Fuente: Los autores.

Se observó un mayor porcentaje de mujeres (58.5 \%) en relación a la población masculina $(41.5 \%)$. Por otra parte el $81.3 \%$ de los profesores no tienen una especialidad o maestría en sus estudios.

Al hacer la comparación entre las diferentes dimensiones objeto de estudio se pudo determinar que la subdimensión cansancio emocional es estadísticamente significativa.

Tabla 6. Análisis de las dimensiones de estudio con Anova.

\begin{tabular}{|ccccccc|}
\hline & & $\begin{array}{c}\text { Suma de } \\
\text { cuadrados }\end{array}$ & gl & $\begin{array}{l}\text { Media } \\
\text { cuadrática }\end{array}$ & F & Sig. \\
\hline cansancio & Entre grupos & 85,454 & 3 & 28,485 & 5,206 &, 002 \\
emocional & $\begin{array}{c}\text { Dentro de } \\
\text { grupos }\end{array}$ & 1586,604 & 290 & 5,471 & \\
& Total & 1672,058 & 293 & & & \\
\hline $\begin{array}{c}\text { despersona- } \\
\text { lización }\end{array}$ & Entre grupos & 22,359 & 3 & 7,453 & 2,474 &, 062 \\
& $\begin{array}{c}\text { Dentro de } \\
\text { grupos }\end{array}$ & 873,709 & 290 & 3,013 & \\
\hline $\begin{array}{c}\text { Tutotal } \\
\text { ción }\end{array}$ & 896,068 & 293 & & & \\
& $\begin{array}{c}\text { Entre grupos } \\
\text { Dentro de } \\
\text { grupos }\end{array}$ & 3,770 & 3 & 1,257 &, 222 &, 881 \\
& Total & 1644,287 & 290 & 5,670 & & \\
\hline
\end{tabular}

Fuente: Os autores.

De acuerdo a la salida del estadístico Spss, es evidente que el cansancio emocional es una de las subdimensiones encontradas como significativas, sin embargo, al hacer la comparación con el estadocivil se pudo observar que los 
docentes que se encontraban casados podrían tener un factor mucho más sólido o protector, IC (-2.27. -0.52) $\mathrm{P}<0.01$ en relación con los grupos de soltero y en unión libre.(ver tabla 7 y figura 1$)$

Tabla 7. Variable dependiente: cansancio emocional.

\begin{tabular}{|c|c|c|c|c|c|c|c|}
\hline & \multirow[b]{2}{*}{$\begin{array}{l}\text { (l) es- } \\
\text { tado } \\
\text { civil }\end{array}$} & \multirow[b]{2}{*}{$\begin{array}{l}\text { (J) estadoci- } \\
\text { vil }\end{array}$} & \multirow{2}{*}{$\begin{array}{l}\text { Diferen- } \\
\text { ciade } \\
\text { medias } \\
(\mathrm{I}-\mathrm{J})\end{array}$} & \multirow[b]{2}{*}{$\begin{array}{l}\text { Error } \\
\text { estándar }\end{array}$} & \multirow[b]{2}{*}{ Sig. } & \multicolumn{2}{|c|}{$\begin{array}{c}\text { Intervalo de confianza al95 } \\
\%\end{array}$} \\
\hline & & & & & & $\begin{array}{l}\text { Límite } \\
\text { inferior }\end{array}$ & $\begin{array}{l}\text { Límite } \\
\text { superior }\end{array}$ \\
\hline \multirow[t]{3}{*}{$\begin{array}{l}\text { HSD } \\
\text { Tukey }\end{array}$} & casado & $\begin{array}{l}\text { soltero } \\
\text { unión libre }\end{array}$ & $\begin{array}{l}-1,39716^{*} \\
-1,79727^{\star}\end{array}$ & $\begin{array}{l}\text {,39166 } \\
, 49531\end{array}$ & $\begin{array}{l}, 001 \\
, 001\end{array}$ & $\begin{array}{l}-2,3198 \\
-2,9641\end{array}$ & $\begin{array}{l}-, 4745 \\
-, 6304\end{array}$ \\
\hline & soltero & $\begin{array}{c}\text { casado } \\
\text { unión libre }\end{array}$ & $\begin{array}{l}1,39716^{*} \\
-, 40011 \\
\end{array}$ & $\begin{array}{l}, 39166 \\
, 38096\end{array}$ & $\begin{array}{l}, 001 \\
, 546 \\
\end{array}$ & $\begin{array}{l}, 4745 \\
-1,2976 \\
\end{array}$ & $\begin{array}{l}2,3198 \\
, 4973\end{array}$ \\
\hline & $\begin{array}{l}\text { unión li- } \\
\text { bre }\end{array}$ & $\begin{array}{l}\text { casado } \\
\text { soltero }\end{array}$ & $\begin{array}{c}1,79727^{*} \\
, 40011\end{array}$ & $\begin{array}{l}49531 \\
\text { 38096 }\end{array}$ & $\begin{array}{l}, 001 \\
, 546\end{array}$ & $\begin{array}{l}, 6304 \\
-, 4973\end{array}$ & $\begin{array}{l}2,9641 \\
1,2976\end{array}$ \\
\hline \multirow[t]{3}{*}{$\begin{array}{l}\text { Tam- } \\
\text { hane }\end{array}$} & casado & $\begin{array}{c}\text { soltero } \\
\text { unión libre }\end{array}$ & $\begin{array}{l}-1,39716^{*} \\
-1,79727^{*}\end{array}$ & $\begin{array}{l}35730 \\
, 39102\end{array}$ & $\begin{array}{l}, 001 \\
, 000\end{array}$ & $\begin{array}{l}-2,2707 \\
-2,7509\end{array}$ & $\begin{array}{l}-, 5236 \\
-, 8436\end{array}$ \\
\hline & soltero & $\begin{array}{l}\text { casado } \\
\text { unión libre }\end{array}$ & $\begin{array}{l}1,39716^{*} \\
-, 40011\end{array}$ & $\begin{array}{l}\text {,35730 } \\
\text {,29530 }\end{array}$ & $\begin{array}{l}, 001 \\
, 445\end{array}$ & $\begin{array}{l}, 5236 \\
-1,1170\end{array}$ & $\begin{array}{l}2,2707 \\
, 3168\end{array}$ \\
\hline & $\begin{array}{l}\text { unión li- } \\
\text { bre }\end{array}$ & $\begin{array}{l}\text { casado } \\
\text { soltero }\end{array}$ & $\begin{array}{c}1,79727^{*} \\
, 40011\end{array}$ & $\begin{array}{l}\text { 39102 } \\
\text {,29530 } \\
\end{array}$ & $\begin{array}{l}, 000 \\
, 445 \\
\end{array}$ & $\begin{array}{l}, 8436 \\
-, 3168 \\
\end{array}$ & $\begin{array}{l}2,7509 \\
1,1170\end{array}$ \\
\hline
\end{tabular}

Fuente: Os autores.

Figura 1. Comparación estado civil y cansancio emocional

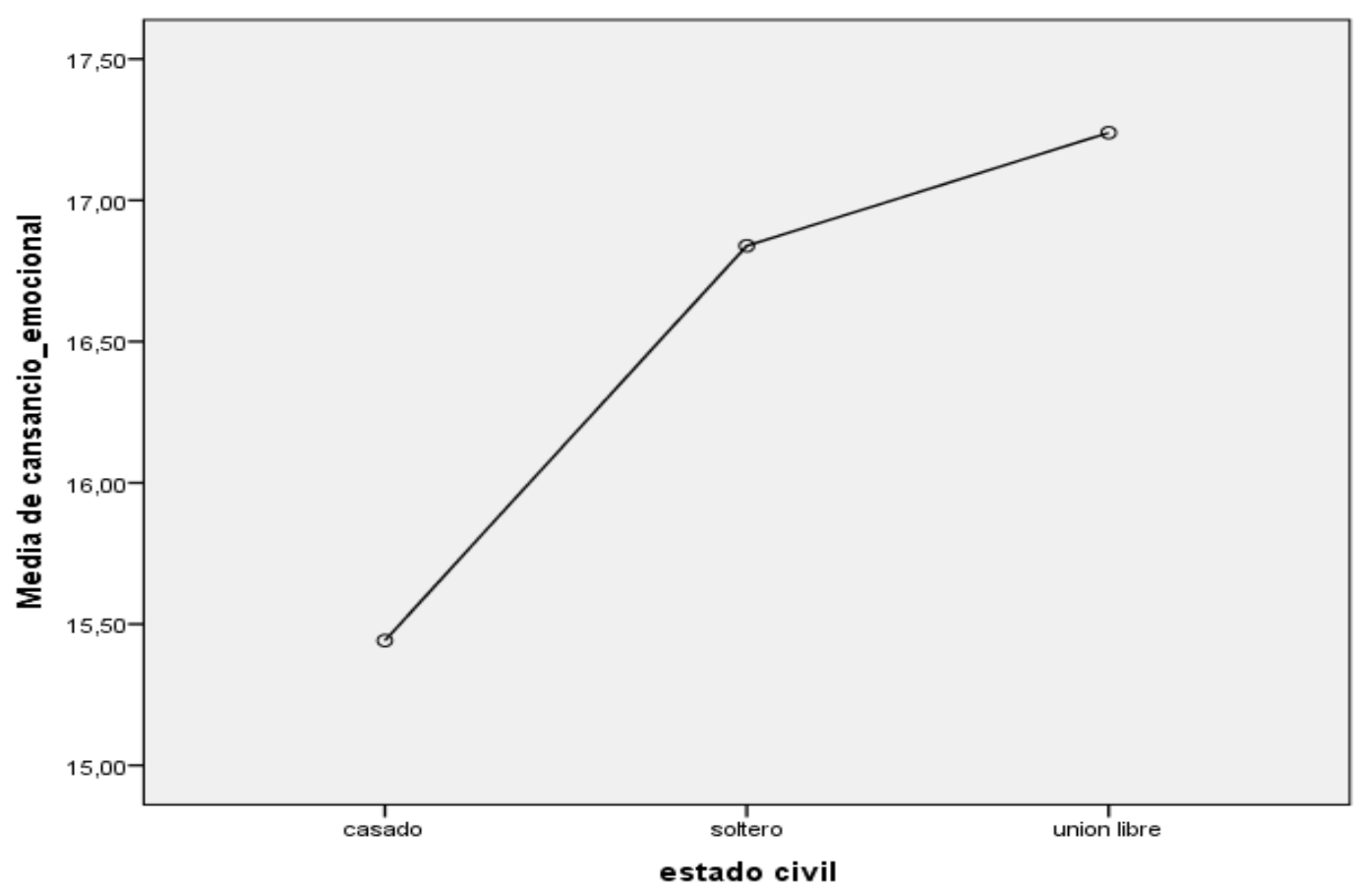

Fuente: Los autores. 
Se observa en la figura 1 que se aumentan los niveles de cansancio emocional cuando losdocentes son solteros o están en unión libre.

Al realizarse el análisis entre las tres dimensiones en relación al nivel de estudio de losdocentes, se encontraron los siguientes resultados. (Ver tabla 8)

Tabla 8. Dimensiones vs nivel de studio.

\begin{tabular}{|c|c|c|c|c|c|c|}
\hline & & $\begin{array}{l}\text { Suma de cua- } \\
\text { drados }\end{array}$ & gl & $\begin{array}{c}\text { Media } \\
\text { cuadrática }\end{array}$ & $\mathrm{F}$ & Sig. \\
\hline \multirow{3}{*}{$\begin{array}{l}\text { cansancio } \\
\text { emocional }\end{array}$} & Entre grupos & 9,646 & 2 & 4,823 & ,844 & ,431 \\
\hline & Dentro degru- & 1662,412 & 291 & 5,713 & & \\
\hline & Total & 1672,058 & 293 & & & \\
\hline \multirow{3}{*}{$\begin{array}{l}\text { desperso- } \\
\text { nalización }\end{array}$} & Entre grupos & ,007 & 2 & ,003 & 001 & ,999 \\
\hline & Dentro degru- & 896,061 & 291 & 3,079 & & \\
\hline & Total & 896,068 & 293 & & & \\
\hline \multirow{3}{*}{$\begin{array}{l}\text { Autorreali- } \\
\text { zación }\end{array}$} & Entre grupos & 125,957 & 2 & 62,979 & 12,040 &, 000 \\
\hline & $\begin{array}{l}\text { Dentro degru- } \\
\text { pos }\end{array}$ & 1522,101 & 291 & 5,231 & & \\
\hline & Total & 1648,058 & 293 & & & \\
\hline
\end{tabular}

Fuente: Los autores. estudio.

Se observó adecuada relación y significancia entre autorrealización y nivel de

Tabla 9. Prueba post hoc comparaciones múltiples dimensiones -profesiones

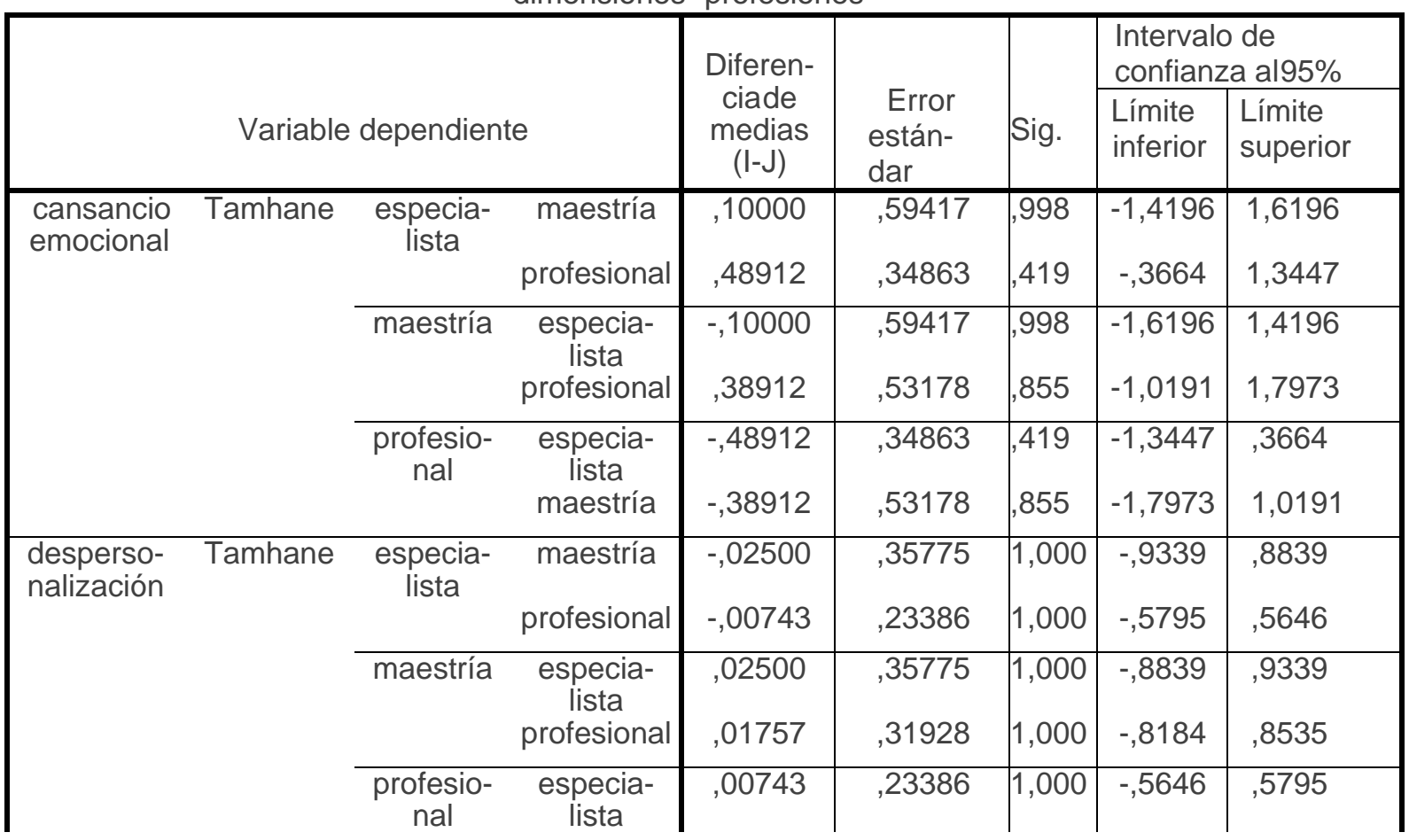




\begin{tabular}{|c|c|c|c|c|c|c|c|c|}
\hline & & & maestría &,- 01757 & 31928 & 1,000 &,- 8535 & ,8184 \\
\hline \multirow{6}{*}{$\begin{array}{c}\text { autorreali- } \\
\text { zación }\end{array}$} & \multirow[t]{6}{*}{ Tamhane } & \multirow{2}{*}{$\begin{array}{l}\text { especia- } \\
\text { lista }\end{array}$} & maestría & ,09167 & ,45547 &, 996 & $-1,0368$ & 1,2201 \\
\hline & & & profesional & 1,70282* & 37483 &, 000 & ,7801 & 2,6256 \\
\hline & & \multirow[t]{2}{*}{ maestría } & especia- &,- 09167 & 45547 &, 996 & $-1,2201$ & 1,0368 \\
\hline & & & profesional & $1,61116^{*}$ & 33670 & .000 &, 7414 & 2,4809 \\
\hline & & \multirow{2}{*}{$\begin{array}{c}\text { profesio- } \\
\text { nal }\end{array}$} & especia- & $-1,70282^{*}$ & 37483 &, 000 & $-2,6256$ &,- 7801 \\
\hline & & & maestría & $-1,61116^{*}$ & ,33670 &, 000 & $-2,4809$ &,- 7414 \\
\hline
\end{tabular}

Fuente: Los autores.

Al realizar el análisis post hoc se evidenciaron diferencias sustanciales con relación al nivel de estudio, sin embargo, es posible identificar que no se presentaron diferencias significativas entre las dimensiones cansancio emocional $y$ despersonalización cuando fueron contrastadas con la variable independiente nivel de estudio. Por otra parte, la dimensión autorrealización presentó diferencias cuandofue contrastada con la variable nivel de estudio hallándose resultados entre especialista y maestría con relación a los profesionales.

Se evidencia que los docentes con carreras de especialización y maestría están más realizados en comparación con los docentes que no tienen estudios de posgrado. Sin embargo se observó que los docentes que no tienen carreras de estudios posteriores a su estudio de base se sienten bien, en la actualidad $P<0.000$, Ic $(-2.62$, $-0.7801)$.

Por otra parte, al analizar mediante Anova $®$ las tres dimensiones con la variable tiempo, se pueden describir mayores niveles de cansancio emocional en el grupo de docentes con tiempo menor de cinco años $\mathrm{P}<0.000$ lc $(0.4677-1.9210)$.

Al realizar el análisis de las dimensiones de estudio en relación a la modalidad institucional, pública o privada, se encontraron diferencias entre el hecho de pertenecer a una institución pública vs una institución privada educativa. En ese sentido se presentaron puntajes más altos en la dimensión cansancio emocional en las instituciones públicas, menos niveles de despersonalización en las entidades públicas que en las privadas y en lo referente a la autorrealización se encontraron similitudes entre ambas modalidades educativas.

En cuanto al rechazo o aceptación de las hipótesis se evidenció que existían diferencias significativas entre las instituciones de carácter público y las privadas en relación a las dimensiones de estudio, en ese sentido se rechazó la hipótesis nula, aceptando la alternativa (ver tabla 10). 
Tabla 10. Testeo de la hipótesis de estudio.

\begin{tabular}{|c|c|c|c|}
\hline & $\begin{array}{c}\text { Cansancio emocio- } \\
\text { nal }\end{array}$ & $\begin{array}{c}\text { Despersonaliza- } \\
\text { ción }\end{array}$ & $\begin{array}{c}\text { Autorrealiza- } \\
\text { ción }\end{array}$ \\
\hline U de Mann-Whitney & 4086,500 & 7371,000 & 8261,000 \\
W de Wilcoxon & 14817,500 & 18397,000 & 18992,000 \\
$Z$ & $-9,304$ & $-4,947$ & $-3,566$ \\
Sig. asintótica (bilate- \\
ral)
\end{tabular}

Fuente: Los autores.

\subsection{Desarrollo de la herramienta de educación para la prevención delburnout}

Se procedió a desarrollar el aplicativo móvil dividiéndolo en tres partes: la primera tenía que ver con conocer el burnout, la segunda parte fue destinada al test y la tercera a un video explicativo. Mediante el apoyo de seis expertos y profesores, se validó el aplicativo desarrollado. En una primera fase de validación no se alcanzaron los resultados esperados: análisis factorial prueba KMO 0.539, Bartlett: Chi 0.234, gl 3 , sig. 0.508; en una segunda medición y luego de hacer los ajustes al instrumento, se evidenció KMO 0.585, Bartlett: Chi 1.853, gl 3, sig. 0.603. Se procedió a subir la app al play store link siguiente:

https://play.google.com/store/apps/details?id=brain.personal.brain\&hl=es_419.

Este aplicativo se puede subir a cualquier plataforma de intranet, es de fácil instalación y podríaser de apoyo sustancial para promover el conocimiento sobre el burnout.

\section{DISCUSIÓN Y CONCLUSIONES}

El síndrome de burnout puede evidenciarse en cualquier contexto donde las situaciones de estrés laboral no son atendidas adecuadamente, sin embargo, es evidente en muchos estudios que existen ciertas profesiones en donde las manifestaciones son más evidentes. En el caso particular de los profesores, este estudio encontró en la dimensión cansancio emocional claras diferencias con relación a las otras dos dimensiones.

La variable estado civil presenta valores significativos para determinar que existe una relación entre el cansancio emocional y dicha variable, se observó que el hecho de estar casado, solteroo vivir en unión libre podría tener un valor determinante como factor propiciador en la aparición de cansancio emocional. Sin duda el hecho de 
estar casado suponía mejores niveles de cansancio emocional en comparación con el hecho de estar soltero o vivir en unión libre, resultados que van de la mano con múltiples estudios al respecto, por ejemplo Grau (2009) comenta que "Ios factores personales son indicadores influenciadores y explicativos de burnout", sin embargo Rodríguez (2006) manifiesta que "los contextos familiares son factores predictivos en la contextualización del burnout", por otra parte es claro que es factible las relaciones entre los contextos, entre las situaciones personales y en general todo lo que conlleve a mecanismos no homeostáticos podrían influir como generadores de la conducta adversa de estrés y por consiguiente en la alta probabilidad de padecer de burnout.

El hecho de ser mujer, según diferentes estudios sobre el síndrome de burnout, es un factor fuerte en la explicación de dicha patología, en ese sentido autores como (Aranda ,2006; Moreno,2006;Extremera,2003; Maslach, 2009) llegan todos a la misma conclusión: el hecho de pertenecer al sexo femenino es un factor predictor en la aparición de burnout; sin embargo es adecuado mencionar que en la presente investigación no se encontró relación fuerte y el grado de significancia en la dimensión auto realización $(P>0.05)$ con la variable sexo; por otra parte el género masculino presentó mayor cansancio emocional que el género femenino, sin embargo al comparar la variable sexo con la dimensión despersonalización se encontraron mayores resultados en el género femenino.

Variables como el tiempo en la organización, el tipo de trabajo realizado, la modalidad de la institución, los niveles de estudios de sus trabajadores en relación al trabajo realizado, el salario que se devenga en contraprestación con las funciones específicas de trabajo, son en definitiva variables contextualizadoras y podrían ser objeto de análisis detallado para la explicación de eventos relacionados a la presencia de burnout en una organización.

Entre las variables estudiadas como el grado de estudios en relación a las dimensiones se pudo corroborar diferencias, sin embargo se puede detallar que no se encontraron diferencias significativas entre las dimensiones cansancio emocional y despersonalización cuando fueroncontrastadas con la variable independiente nivel de estudio, por otra parte la dimensión autorrealización está ampliamente relacionada con el nivel de estudio encontrándose que a mejor nivel de estudio mayor es la realización, esto va en concordancia con lo manifestado por avalos(2007) cuando manifiesta que "los niveles de realización profesional están relacionados íntimamente con los logros académicos y el medio ambiente donde se interactúa”(p.78). 
Es evidente que para definir la presencia de burnout en la muestra estudiada se necesitaba encontrar altos niveles de cansancio emocional, altos niveles de despersonalización y bajos niveles de autorrealización, sin embargo, es posible concluir que no se presentaron las tres características fundamentales para definir que existe burnout en los docentes de las escuelas públicas y privadas de la ciudad de Bogotá.

Por otro lado, se encontraron características relacionadas con el cansancio emocional $(p<0.02)$ en los grupos de estudio en ambas modalidades institucionales, en ese sentido es evidente la presencia de la dimensión cansancio emocional como un factor clave que debería ser tratado, gestionadoy fortalecido mediante acciones de promoción de la salud y el uso de herramientas de educación virtual como la herramienta desarrollada. 


\section{REFÊRENCIAS}

Aranda Beltrán, C. (2006). Diferencias por sexo, Síndrome de burnout y manifestaciones clínicas, en losmédicos familiares de dos instituciones de salud, Guadalajara, México. Revista costarricense de salud pública, 15(29), 1-7.

Ávalos, B. (2007). El desarrollo profesional continúo de los docentes: lo que nos dice la experiencia internacional y de la región latinoamericana. Revista Pensamiento Educativo, 41(2), 77-99.

Bambula, F. D., Sánchez, A. L., \& Arévalo, M. T. V. (2012). Factores asociados al síndrome de burnout en docentes de colegios de la ciudad de Cali, Colombia. Universitas Psychologica, 11(1), 217-227.

Bakker, A. B., Demerouti, E., \& Schaufeli, W. B. (2002). Validation of the Maslach burnout inventory-general survey: an-internet study. Anxiety, Stress \& Coping, 15(3), 245-260.

Extremera, N., Fernández-Berrocal, pablo, \& Durán, A. (2003). Inteligencia emocional y burnout enprofesores. Encuentros en psicología social, 1(5), 260-265.

Grau, A., Flichtentrei, D., Suñer, R., Prats, M., \& Braga, F. (2009). Influencia de factores personales, profesionales y transnacionales en el síndrome de Burnout en personal sanitario hispanoamericano y español (2007). Revista Española de Salud Pública, 83, 215-230.

Llull, D. S., Martí, X., \& Brage, L. B. (2015). Malestar social y malestar docente: una investigaciónsobre el síndrome de desgaste profesional burnout y su incidencia socioeducativa. Aula, 21, 245-257.

Maslach, C. (2009). Comprendiendo el burnout. Ciencia \& Trabajo, 11(32), 37-43.

Moreno, M., Aranda, C., Aldrete, M. G., Flores, E., \& Pozo, E. (2006). Factores psicosociales y burnouten docentes del centro universitario deficiencias de la salud. Investigación en salud, 7(3), 173-177.

Rodríguez, A. M. H. (2006). Satisfacción laboral y síndrome de" burnout" en profesores de educación primaria y secundaria. Revista Colombiana de Psicología, 15(1), 81-89.

Taris, T. W., Le Blanc, P. M., Schaufeli, W. B., \& Schreurs, P. J. (2005). ¿Are there causal relationshipsbetween the dimensions of the Maslach Burnout Inventory? A review and two longitudinal tests. Work\& Stress, 19(3), 238-255.

Wanden-Berghe, C., Sabucedo, L., \& Martínez de Victoria, I. (2011). Investigación virtual en salud: las tecnologías de la información y la comunicación como factor revolucionador en el modo de hacer ciencia. Salud colectiva, 7, S29-S38. 
CHAPTER 09

NURSING CARE IN COVID-19 PATIENTS

\section{Brian González Pérez}

Higher academic background: Médico Familiar., Doctor en Ciencias de la Salud., Master en Ciencias Médicas., Master en Innovación y Tecnología Educativa., Profesor Investigador.

Current Institution: Servicio de Atención Familiar. Unidad Médica Familiar 38, Tampico Tamaulipas, Instituto Mexicano del Seguro Social, México. Facultad de Medicina "Dr. Alberto Romo Caballero" Universidad Autónoma de Tamaulipas, Tampico, Tamaulipas, México.

Full address: Calle Argentina y Canadá 107 Col. Infonavit C.P. 89310, Tampico, Tamaulipas.

Email: brian.gonzalez.perez@gmail.com

\section{Ricardo Salas Flores}

Higher academic background: Endocrinólogo Pediatra., Master en Ciencias Médicas., Profesor Investigador.

Current Institution: Coordinación de Educación en Salud e Investigación. Hospital General Regional No. 6, Madero, Tamaulipas, Instituto Mexicano del Seguro Social, México. Facultad de Medicina "Dr. Alberto Romo Caballero" Universidad Autónoma de Tamaulipas, Tampico, Tamaulipas, México.

Full address: Blvd. Adolfo López Mateos S/N, Col. Las Conchitas, Madero Tamaulipas. Email: risafl@yahoo.com

\section{Roandy Gaspar Hernández Carranco}

Higher academic background: Doctorado en Ciencias de la Enfermería., Profesor Investigador.

Current Institution: Facultad de Enfermería de Tampico. Universidad Autónoma de Tamaulipas, Tampico, Tamaulipas, México.

Full address: Centro Universitario Sur, Cto. Interior S/N CP 89337, Tampico, Tamaulipas

Email: roandy.hernandez@docentes.uat.edu.mx

\section{Cecilia Jaqueline Martínez Garza}

Higher academic background: Estudiante de enfermería. Programa Delfín, XXVI Verano de la Investigación Científica y Tecnológica del Pacífico.

Current Institution: Facultad de Enfermería de Tampico. Universidad Autónoma de Tamaulipas, Tampico, Tamaulipas, México.

Full address: Centro Universitario Sur, Cto. Interior S/N CP 89337, Tampico, Tamaulipas

Email: martinezgarzacecilia@gmail.com

\section{Mabel Pérez Hernández}

Higher academic background: Estudiante de enfermería. Programa Delfín, XXVI Verano de la Investigación Científica y Tecnológica del Pacífico.

Current Institution: Facultad de Enfermería de Tampico. Universidad Autónoma de 
Tamaulipas, Tampico, Tamaulipas, México.

Full address: Centro Universitario Sur, Cto. Interior S/N CP 89337, Tampico, Tamaulipas

Email: perezhernandezmabel@gmail.com

\section{Adamari Yuliana Rivas Reyes}

Higher academic background: Estudiante de enfermería. Programa Delfín, XXVI Verano de la Investigación Científica y Tecnológica del Pacífico.

Current Institution: Facultad de Enfermería de Tampico. Universidad Autónoma de Tamaulipas, Tampico, Tamaulipas, México.

Full address: Centro Universitario Sur, Cto. Interior S/N CP 89337, Tampico, Tamaulipas

Email:yuliana.rivass@gmail.com

\section{Montserrat Zapata Carlos}

Higher academic background: Estudiante de enfermería. Programa Delfín, XXVI Verano de la Investigación Científica y Tecnológica del Pacífico.

Current Institution: Facultad de Enfermería de Tampico. Universidad Autónoma de Tamaulipas, Tampico, Tamaulipas, México.

Full address: Centro Universitario Sur, Cto. Interior S/N CP 89337, Tampico, Tamaulipas

Email: a2183380072@alumnos.uat.edu.mx

\section{Liliana Aurora Carrillo Aguiar}

Higher academic background: Médico Familiar., Master en Ciencias Médicas., Profesor Titular de la Residencia en Medicina Familiar.

Current Institution: Unidad Médica Familiar 77, Madero Tamaulipas, Instituto Mexicano del Seguro Social, México.

Full address: Blvd. Adolfo López Mateos S/N, Col. Las Conchitas, Madero Tamaulipas. Email: lilifha@hotmail.com

\section{Verónica Olvera Mendoza}

Higher academic background. Doctora en Desarrollo Educativo., Master en Finanzas., Profesor Investigador.

Current Institution: Facultad de Medicina "Dr. Alberto Romo Caballero" Universidad Autónoma de Tamaulipas, Tampico, Tamaulipas, México.

Full address: Centro Universitario Sur, Cto. Interior S/N CP 89337, Tampico, Tamaulipas

Email: volvera@docentes.uat.edu.mx

RESUMEN: Objetivo. Recopilar información sobre los cuidados asistenciales que realiza la unidad de enfermería a los pacientes con COVID-19 y de esta manera poder identificar las acciones de cuidado más concretas y eficaces que den resultados positivos. Métodos. Se realizó una revisión bibliográfica narrativa. Se ejecutó el análisis de artículos originales y revisiones sistemáticas que incluyeron información en relación con los cuidados de Enfermería en pacientes infectados de Covid-19 durante esta pandemia. La búsqueda se efectuó consultando las bases de datos Pubmed, Infomed, Google Académico y SciELO, sin restricción de fecha, en los idiomas español e inglés, también se utilizó Decs y Mesh, el código para la herramienta Mesh fue la siguiente (("NursingCare"[Mesh]) OR "CarrierState"[Mesh]). 
Resultados. Se obtuvieron más de 300 artículos, los cuales, se fueron descartado mediante los filtros (del año 2020-2021, texto completo y meta análisis) se obtuvieron 11 resultados, los cuales se revisaron según su contenido, se eligió 2 artículos. El total de artículos que se utilizaron para la realización de la monografía fueron en total 12 artículos. Conclusiones. Según los resultados encontrados se puede concluir que el personal de e enfermería se ha destacado por sus cuidados holísticos durante el tratamiento de los pacientes portadores de Covid-19, con la finalidad de la recuperación de los pacientes, la disminución de las complicaciones que conlleva esta enfermedad y la reducción del contagio.

PALABRAS-CLAVE: COVID-19; Intervenciones de enfermería; Signos y síntomas.

SUMMARY: Objective. Collect information on the care provided by the nursing unit to patients with COVID-19 and thus be able to identify the most concrete and effective care actions that give positive results. Methods. A narrative bibliographic review was carried out. The analysis of original articles and systematic reviews that included information in relation to Nursing care in patients infected with Covid-19 during this pandemic was carried out. The search was carried out consulting the databases Pubmed, Infomed, Google Academic and SciELO, without date restriction, in the Spanish and English languages, Decs and Mesh were also used, the code for the Mesh tool was as follows (("Nursing Care "[Mesh]) OR" Carrier State "[Mesh]). Results.More than 300 articles were obtained, which were discarded through the filters (from the year 2020-2021, full text and meta-analysis), 11 results were obtained, which they were reviewed according to their content, 2 articles were chosen. The total of articles that were used for the realization of the monograph were a total of 12 articles. Conclusions. According to the results found, it can be concluded that the nursing staff has stood out for their holistic care during the treatment of patients with Covid-19, in order to recover the patients, reduce the complications that this entails. disease and reduction of contagion.

KEYWORDS: COVID-19; Nursing interventions, Signs and symptoms. 


\section{INTRODUCCIÓN}

La detonación del COVID-19 en diciembre de 2019, China se convirtió rápidamente en una amenaza en todo el mundo y fue declarada pandemia por la Organización Mundial de la Salud el 11 de marzo 2020 e identificada por primera vez el 12 de diciembre de 2019 en Wuhan, provincia de China, causada por un nuevo virus que se denominó severeacuterespiratorysyndrome coronavirus-2 (SARS-CoV-2). Durante la pandemia SARS-CoV-2 la profesión de Enfermería ha adquirido un total protagonismo.

Begoña et al., (2020) Los profesionales de enfermería constituyen el principal elemento de los equipos de salud y en muchos lugares, son el primero y algunas veces el único recurso humano en contacto con los pacientes y las comunidades. Durante el periodo de la pandemia SARS-CoV-2 en todos los países, el liderazgo de los profesionales de enfermería ha resultado clave en el desarrollo de procesos asistenciales fundamentales para la respuesta. El personal de enfermería ha sido fundamental para aplicar los cuidados al paciente hospitalizado con COVID-19, al prevenir, detectar complicaciones de forma precoz y colaborar con el resto del equipo clínico del área de salud, para valorar la respuesta del paciente al tratamiento frente al coronavirus.

Maglio et al., (2020) Los pacientes con síntomas leves son hospitalizados en una habitación de aislamiento bien ventilada, preferiblemente con presión negativa, y se les administra y se tratan con intervenciones sintomáticas y de apoyo de apoyo, que pueden incluir antipiréticos, refrigeración externa, administración de oxígeno suplementos nutricionales y administración de fármacos antibacterianos. Sin embargo, los casos graves y críticos pueden requerir el ingreso en la $\mathrm{UCl}$, la administración de oxígeno de alto flujo ventilación mecánica. No existe ningún tratamiento ni vacuna definitivos para esta para esta enfermedad; por lo tanto, el resultado de la enfermedad depende de la calidad de los cuidados de apoyo proporcionados por las enfermeras para la recuperación y la prevención de complicaciones iatrogénicas.Maglio et al. (2020) Toda enfermedad epidémica da grandes retos a nivel sanitario, además de social y económico. Para dar una respuesta adecuada a esta urgencia por el SARS-CoV-2, es imprescindible disponer de protocolos que ayuden en la planificación, intervención y ejecución. Por lo anterior, es necesario brindar información sobre un referente teórico o una guía que facilite 
la práctica clínica del profesional de enfermería durante la pandemia COVID19, ayudando a la familiarización de esta pandemia.

Este proyecto está conformado por apartados de resumen, introducción, objetivos, métodos, el desarrollo que se constituye de 3 capítulos (Capítulo1. Covid19. 1.1. Definición, 1.2. Antecedentes, 1.3. Equipo de protección Capitulo 2. Cuidados de enfermería en portadores Covid-19. 2.1 Cuidados de enfermería, 2.2 Cuidados de enfermería en portadores con síntomas leves,2.3 Cuidados de enfermería en portadores con síntomas graves, 2.4 Cuidados de enfermería post-mortem. Capítulo 3. Enfermería en la promoción y prevención de Covid-19), conclusión y las referencias.

Justificación. La preocupación por riesgo de infección por el virus SARS-CoV2 se revela en diversos artículos publicados sobre el tema, sin embargo, no son suficientes los que aluden al papel del personal de enfermería y los cuidados enfermeros. Las enfermeras son fundamentales para aplicar los cuidados al paciente hospitalizado con COVID-19, prevenir y detectar complicaciones de forma precoz y colabora. (Savón, Y., Céspedes, V., \&Maslen, M. 2020). En este sentido dicho problema, este proyecto se justifica los cuidados de enfermería que se llevan a cabo de forma holística hacia los portadores de Covid-19 con síntomas leves y graves; así como las intervenciones que permiten, la disminución de la propagación del virus, previene y detecta complicaciones de forma precoz, y manejo del paciente fallecido. Buscamos a la interrogativa ¿Cuál son cuidados de enfermería en pacientes portadores de COVID-19

\section{DESARROLLO}

\subsection{Covid-19}

\subsubsection{Definición.}

La OMS (2020) define al coronavirus (COVID 19) como una enfermedad infecciosa causada por un coronavirus descubierto recientemente. Que se transmite a través de las gotículas de saliva o las secreciones nasales que se generan cuando una persona infectada tose o estornuda.

Deitrick et al., (2020) mencionaron en su artículo "Atención de enfermería de emergencia a pacientes con enfermedad del nuevo coronavirus 2019" que el síndrome respiratorio agudo severo coronavirus 2 (SARS-CoV-2) es un virus de ARN de sentido 
positivo y es la causa de COVID-19. Los coronavirus son causas comunes de enfermedades respiratorias leves en niños y adultos.

\subsubsection{Antecedentes}

La enfermedad por el coronavirus de 2019 (COVID-19) cómo se mencionó anteriormente es causado por coronavirus del síndrome respiratorio agudo grave de tipo 2 (SARS-CoV-2), un coronavirus de reciente aparición que se identificó por vez primera en Wuhan, Provincia de Hubei (China), en diciembre de 2019.

La OMS (2021) mencionó en su documento "Manejo clínico de la COVID-19" sobre los estudios epidemiológicos y virológicos permitieron suponer que son principalmente personas sintomáticas y asintomáticas quienes transmiten el virus a otras, ya sea por contacto estrecho y mediante gotículas respiratorias, o por contacto directo con personas infectadas.

Los pacientes que cursan con síntomas, la mayoría de las personas que presentan COVID-19 solo padecen el tipo leve (el $40 \%$ ) o moderado (el $40 \%$ ) de la enfermedad, aproximadamente el $15 \%$ presentaron un tipo grave de enfermedad para el que se requiere oxigenoterapia, y el $5 \%$ se encontraban en estado crítico que manifestaron complicaciones tales como insuficiencia respiratoria, SDRA, síndrome séptico y choque séptico, tromboembolia o insuficiencia multiorgánica, especialmente lesiones renales y cardíacas agudas (The novel coronavirus pneumoniaemergency response epidemiologyteam, p. 113-22, 2020, citado por OMS 2021 ).

Una vez que la OMS declaro la enfermedad pandémica por COVID19, se concluyeron varios puntos en los sistemas de salud a grado mundial, que pide actividades inmediatas y que pongan de manifiesto la coordinación intersectorial encaminadas a un fin en común: reducir la propagación para eludir colapsar los servicios de salud y de esta forma poder brindar actividades integrales. (Ramírez PM, 2020a).

Del mismo modo, permitió sacar a la luz las condiciones adversas de la atención en salud, referente a la carencia de recursos, a los recursos distribuidos inapropiadamente, la sobrecarga gremial, la sobresaturación del sistema, a las precarias condiciones de la gran mayor parte de trabajadores en salud, a la discriminación derivada de la ignorancia y el pánico generalizado, y de otro lado la 
carencia de conciencia relacionadas con la separación social y la cuarentena en los domicilios. (Calvo, C., 2020)

Más allá de la adversidad que se hace evidente con esta emergencia sanitaria, el denominado a los conjuntos en salud es brindar atención integral como continuamente se ha realizado, empero con las medidas de aislamiento establecidas a grado universal y evadir la automatización de los procesos que tienen la posibilidad de traducir en obviedades y errores en los procesos. Por lo anterior, según los lineamientos establecidos a grado mundial, se establecen rutas de atención para el funcionamiento poblacional afectada por Coronavirus 19 que requieran hospitalización. (Thomas P. et al. 2020)

En las indagaciones europeas y americanas «Se ha descubierto que el SARSCoV-2 es detectable en aerosoles a lo largo de hasta 3 horas, hasta 4 horas en cobre, hasta 24 horas en cartón y hasta 2 o 3 días en plástico y acero inoxidable», esto permitió detectar el porqué de la propagación exponencial del covid-19 y asimismo la alta proporción de personas que necesitan funcionamiento intrahospitalario. Del mismo modo, Se ha reconocido que la transmisión por gotas del covid-19 se da a una distancia de 1.8 metros por lo que, se ha predeterminado la definición de contacto estrecho como el producido a menos de 2 metros distancia por un intervalo de tiempo superior a 15 min como constituyente de alto peligro de contagio. (Thomas P. et al., 2020).

Los exámenes establecidos en los diferentes territorios han demostrado que del total de los individuos contagiadas, alrededor del $80 \%$ necesita funcionamiento ambulatorio u hospitalización en sala general para desempeño sintomático, el 5 al $16 \%$ muestra neumonía con complicaciones que necesita desempeño en una unidad de cuidado exhaustivo con ventilación mecánica invasiva, y del 2 al 7 \% restante está la tasa de letalidad 5, esto se convierte en un elemento de peligro por la alta transmisibilidad del virus por su permanencia en las zonas y la insuficiencia de los sistemas de salud para la proporción de población afectada. (Khal, G. 2020)

La OMS 2020 señaló como factores de riesgo para presentar un tipo grave de enfermedad y fallecer se han citado la edad avanzada, el tabaquismo y las enfermedades no transmisibles preexistentes, tales como la diabetes, la hipertensión, las cardiopatías, las neumopatías crónicas y el cáncer. El COVID-19 se asocia a manifestaciones psiquiátricas y neurológicas, entre las que se incluyen la ansiedad, la depresión, los trastornos del sueño, las cefaleas, los mareos, el deterioro del sentido 
del olfato o el gusto (Spinato, p.2089-2090, 2020, citado por OMS 2021), en ese mismo documento de la OMS menciona que hay otras manifestaciones como las mialgias, el delirio confusional o las encefalopatías, la excitación psicomotora, los accidentes cerebrovasculares, las lesiones cerebrales isquémicas hipóxicas, las convulsiones, el coma, las meningoencefalitis y el síndrome de Guillain-Barré. Parece ser que es frecuente que las personas hospitalizadas por COVID-19 presenten ansiedad y depresión. Sin embargo, también se ha notificado que los pacientes que no se hospitalizan (o aquellos que presentan COVID-19 leve o moderado) y los niños refieren un conjunto de síntomas crónicos y secuelas a medio y largo plazo.

\subsubsection{Equipo personal de protección}

La más importante función de la enfermera es protegerse de contraer o transmitir COVID-19. Se debe proporcionar equipo de protección personal (EPP) adecuado a todos los trabajadores de la salud, especialmente a las enfermeras de emergencia. Incluso cuando se atiende a pacientes críticamente enfermos, es importante protegerse y tomarse el tiempo para ponerse el EPP adecuado, a pesar de los instintos de querer prestar ayuda de inmediato. La educación y la capacitación sobre cómo ponerse (ponerse) y quitarse (quitarse) el equipo de protección personal de forma adecuada es esencial, ya que estos son momentos en los que los trabajadores de la salud corren un alto riesgo de contaminación accidental (Deitrik, Adam y Davis, p. 748-756. 2020).

El personal de enfermería debe cuidarse a sí mismas para estar sanas y disponibles para atender a futuros pacientes. Por ello es importa realizar las siguientes actividades para su protección personal y disminuir los contagios:

- Lavar las manos con agua y jabón o un desinfectante con base de alcohol durante por lo menos 20-30 segundos, previo al contacto con el paciente, con equipos instrumentos, y secarlas con papel desechable, preferentemente;

- Realizar los 5 minutos de lavado de manos, cambiar los guantes y desinfectar los estetoscopios con alcohol;

- Uso de los medios de protección personal, compuesto por la bata y la gorra, las gafas de seguridad, el protector facial y guantes, usar máscara facial o nasobucal durante el contacto con el paciente, y debe ser inmediatamente sustituida, al humedecerse; 
- Seguir rigurosamente las medidas de bioseguridad en los espacios de preparación de las soluciones, medicamentos, alimentos; desinfectar con alcohol, los equipos instrumentos, estetoscopios, bombas de infusión, utensilios del paciente después de cada uso;así como las superficies que se hayan tocado;

- Uso de los medios de protección personal, compuesto por la bata y la gorra, las gafas de seguridad, el protector facial y los guantes. (Lehite, Céspedes \&Maslen, 2020).

Se ha reconocido que las formas de inactivar al SARS-CoV2 más efectivas para inactivar al SARS-CoV2 es a temperaturas altas alrededor de 56 grados por una época no menor a $20 \mathrm{~min}$, se demostrado que su capa lipídica se puede romper con la utilización de solventes como el etanol al $70 \%$, resoluciones jabonosas, cloro orgánico entre otras; asimismo, se demostró que la clorhexidina al $4 \%$ en solución no es positiva. Lo anterior posibilita implantar medidas de sanitización efectivas de las zonas habituales, los recursos que logren tener contacto con el paciente, de las prendas que son lavables como el overol y la careta. (Andrés G. et al., 2020).

La utilización de dichos recursos por tiempos prolongados, las limitaciones que se proporcionan de forma precisa en el cuidado a esta población, aunado a la presión por miedo a contagio del trabajador de la salud, tanto como a sus parientes, está generando sobrecargas emocionales y llevando a afectaciones en la salud psicológica de los trabajadores. Por esta razón, se hace primordial impulsar la salud psicológica positiva, cuyo fin es «sentir y estar lo mejor viable en las situaciones en que se encuentre». Para que esto se produzca, se hace primordial a partir de la gestión de las entidades de salud, la construcción de espacios lúdicos en las entidades, con la intención de mejorar las interrelaciones sociales en este ámbito, y fomentar ocupaciones que liberen la tensión por el caso de hoy. (Ortega J, González JM. 2020)

\section{CUIDADOS DE ENFERMERÍA EN PORTADORES COVID-19}

\subsection{Cuidados de enfermería}

Las enfermeras deben ser muy conscientes de la gravedad y complejidad de la COVID-19, así como de la dificultad y el sufrimiento de los pacientes, para proteger la vida y la salud de los pacientes y hacer que se sientan cálidamente apoyados. Las enfermeras deben ser responsables y amables tratar a los pacientes como si fueran miembros de su familia, o incluso como si fueran miembros de la familia, o incluso 
asumir el papel de sus familiares si es necesario. Integrar el cuidado humano en todo el proceso de tratamiento y recuperación, satisfaciendo al mismo tiempo las necesidades de atención humana individualizadas del paciente. Proporcionar cuidados humanos con medidas profesionales y creativas. (ZHANG, et al., (2020))

El cuidado es la parte central de la actividad humana pues todas las personas se auto cuidan, en algún momento de sus vidas necesitaran que otros lo cuidan, es parte de las actitudes y valores humanos adquiridos por la influencia cultural de la sociedad, lo que se ha hecho más vivencial en este periodo donde todos contribuyen a prevenir la infección por el virus SAR-CoV-2 y con la finalidad de promover, mantener o recuperar su salud. Cuando los pacientes llegan al servicio de salud, el personal de enfermería debe indagar información sobre los síntomas y signos que presente y sobre sus antecedentes patológicos familiares y personales, además de precisar mediante la exploración física da información necesaria para la toma de decisiones médicas y de enfermería, por ejemplo, los signos vitales y la temperatura. Dentro de las intervenciones de enfermería, coadyuvar con la realización de las pruebas diagnósticas de la infección por el coronavirus y para la evaluación del paciente (Lehite, Céspedes \&Maslen, 2020).

\subsection{Cuidados de enfermería en portadores con síntomas leves}

En la vigilancia fundada para esta clase de población en el sector de hospitalización, está la necesidad de utilizar recursos biomédicos exclusivos para la atención individualizada, y la ejecución de la sanitización anterior a concluir con la atención, cabe decir que los conjuntos al ser de uso único, no salen de la unidad del paciente, asimismo, se hace hincapié en la restricción de visitas al paciente, por los cuidadores, y por parte del equipo de atención en salud, restringiendo las valoraciones según la necesidad imperativa de las mismas. Se hace primordial del mismo modo, la restricción de los traslados para toma de tests complementarios siguiente al traslado a hospitalización se indica en el tamaño de las modalidades tomarlos de manera portátil con la respectiva sanitización previamente y luego de la toma (Ramírez PM, 2020b).

Relacionadas con las normas establecidas por el personal médico, las intervenciones de enfermería se enfocarán en la vigilancia de las constantes vitales primordialmente la temperatura, frecuencia respiratoria, y necesidad de oxígeno 
suplementario, eludir las nebulizaciones que fomenten el flujo de aerosoles, por lo que se va a hacer primordial la utilización de inhaladores con cámara dispuesta para tal fin. Sin embargo, de consenso con el procedimiento sintomático, es de anotar la necesidad de llevar un control electrocardiográfico para detectar de forma precoz alteraciones del sistema de conducción del corazón secundarias al procedimiento. (Ortega J, González JM. 2020)

Las enfermeras, contribuyen en la atención y cuidados directos que han salvado vidas y limitado el sufrimiento, también al brindar apoyo emocional, educar a pacientes y sus familias, coordinar actividades de prevención y control de infecciones, como parte de un equipo de salud para dar atención positiva a los pacientes infectados. Conceptualizar los diagnósticos enfermeros y las intervenciones de enfermería según los indicios y signos que presente el paciente. Dar información al paciente sobre la patología, el autocuidado y la prevención de la infección a otros. Aislar al paciente según las sugerencias médicas, y afirmar que use los medios de defensa para evadir contagios. (Choi KR, Jeffers KS. 2020)

A lo largo de la atención la paciente usar máscaras N95 o N99. Para entrevistar o analizar al paciente conservar una distancia de 2 metros. Si el paciente muestra fiebre persistente con temperatura mayor a $38{ }^{\circ} \mathrm{C}$ se deberán regir los antitérmicos pautados y mantener el control de la efectividad del procedimiento. Dar apoyo emocional a los pacientes que presenten temor, malestar y un marcado estrés psicológico. (Choi KR, Jeffers KS. 2020)

Es importante el reconocimiento precoz de los signos y los indicios de mal pronóstico y agravamiento clínico con la finalidad de actuar de manera eficiente ejecutando las intervenciones que garanticen la estabilización de los pacientes según los protocolos existentes. Si se sitúa al paciente en decúbito prono, monitorizar de manera continua la $\mathrm{SaO} 2$ de oxígeno y hacer vigilancia clínica y garantizar la preparación del automóvil de parada cardiorrespiratoria, la movilización se realizará en bloque, evacuar la vejiga con sondaje vesical, evadir la broncoaspiración, eludir tironea miento de tubo endotraqueal y catéteres venosos profundo defender regiones de presión ósea para eludir las ulceras por presión. (Lane BE. 2020).

Es importante Ofrecer información al paciente sobre la enfermedad, el autocuidado y la prevención de la infección a otros. Aislar al paciente según las sugerencias médicas, y garantizar que utilice los medios de protección para disminuir contagios. Determinar y vigilar si tienen dificultades para respirar. En todo momento 
de la atención hacia el paciente utilizar máscaras N95 o N99, para entrevistar o examinar al paciente mantener una distancia de seis pies (1,82 metros). Medición, control y registro de las constantes vitales del paciente: temperatura, frecuencia respiratoria (FR), saturación de oxígeno (SaO2), presión arterial, frecuencia cardíaca y dolor, en función del estado clínico del paciente.

Si el paciente presenta fiebre persistente con temperatura superior a $38^{\circ} \mathrm{C}$ se deberán administrar los antitérmicos pautados y monitorear el tratamiento. Tomar las muestras biológicas para estudios complementarios según las indicaciones del médico responsable. Ofrecer apoyo emocional a los pacientes que presenten miedo, angustia y un marcado estrés psicológico. Monitorización de la saturación de oxígeno y administración de oxigenoterapia: iniciar la oxigenoterapia se la SaO2 baja de 90-92 \% en aire ambiente. Al inicio, administrar oxígeno mediante puntas nasales (2-5 I/min) evaluando la efectividad. Si persiste la hipoxemia, se valorará la posibilidad de usar la mascarilla facial simple (5-8 I/min) para que aporte $\mathrm{FiO} 2$ de 0,40-0,60. Si no se obtienen los resultados esperados, se podrá administrar oxígeno a flujos altos con una mascarilla equipada con bolsa reservorio (10-15 l/min para mantener el reservorio inflado) y FiO2 entre 0,60-0,95.

Observar los signos y los síntomas precoces de mal pronóstico y agravamiento clínico (cambios en el nivel de consciencia, progresión de la disnea, aparición de ortopnea o disnea Paroxística nocturna, disnea que no respondan a la oxigenoterapia convencional, habla entrecortada, respiración abdominal, dolor torácico, limitación funcional, escalofríos, cefalea, dolor faríngeo, tos, vómitos, diarrea) para actuar de forma eficiente ejecutando las intervenciones que garanticen la estabilización de los pacientes de acuerdo con los protocolos existentes. Si aparece un agravamiento brusco de la disnea, con incremento del trabajo respiratorio, frecuencia respiratoria 25 respiraciones por minuto, y $\mathrm{SaO} 2<90 \%$, se le comunicará de manera urgente al médico tratante, adoptando todas las medidas de permeabilización de las vías aéreas y oxigenoterapia. Al colocar al paciente en decúbito prono, se debe monitorizar de forma continua la $\mathrm{SaO} 2$ de oxígeno y realizar vigilancia clínica y asegurar la preparación del carro de parada cardiorrespiratoria, la movilización se realizará en bloque, evacuar la vejiga con sondaje vesical, impedir la broncoaspiración y el tironeamiento de tubo endotraqueal, así como de los catéteres venosos profundo

Proteger zonas de prominencia óseas que estén en constante presión con la superficie de la cama para evitar las ulceras por presión. Llamar al médico responsable 
la identificación temprana de aquellos casos con manifestaciones graves para la realización de tratamientos requeridos. Se colaboraron con el equipo interdisciplinar junto con los fisioterapeutas para la selección de pacientes que puedan beneficiarse de la realización de ejercicios de prevención primaria (respiratorios y musculo Esqueléticos). (Lehite, Céspedes \&Maslen, 2020).

Sharma, et al., (2020), mencionaron en el artículo "Clinical nursing care guidance for management of patient with COVID-19" sobre los pacientes con síntomas leves a moderados deben ser ingresados en una habitación aislada y tratados con cuidados sintomáticos y de apoyo. Las enfermeras tienen un papel importante en el cuidado de pacientes con síntomas leves-moderados, como se detalla a continuación:

- Proporcionar reposo absoluto en cama, promover un sueño profundo y monitorizar regularmente las constantes vitales, preferiblemente a través de un sistema de sistema de monitorización remota para reducir el riesgo de exposición y necesidad de EPP;

- Proporcionar fármacos antipiréticos (por ejemplo, paracetamol) para el tratamiento de la fiebre y las mialgias, pero deben evitarse los AINE. Las intervenciones no farmacológicas también pueden ser para la fiebre, como el nivel óptimo de temperatura ambiente, ropa ligera de algodón, refrigeración externa de enfriamiento externo, como esponjas tibias, uso de ventiladores y esponjas frías, pero recuerde enfriar gradualmente para evitar escalofríos;

- Anime a los pacientes a bañarse regularmente con agua y jabón, y a mantener una buena higiene personal;

- Proporcione abundantes líquidos, una dieta nutritiva y rica en proteínas con vitaminas;

- Los pacientes con dificultades respiratorias pueden necesitar la posición de Fowler, oxímetro de pulso para controlar la saturación de oxígeno y administración de oxígeno mediante puntas nasales o cánula para mantener una SpO2 > $90 \%$;

- Recoger muestras de sangre y enviarlas al laboratorio para el tiempo de protrombina, $\mathrm{LDH}$ (lactato deshidrogenasa), dímero $\mathrm{D}, \mathrm{ALT}$, proteína $\mathrm{C}$ reactiva $(\mathrm{PCR})$ y creatina quinasa, que pueden estar elevadas en estos pacientes;

- Se sabe que la hidroxicloroquina provoca bloqueos AV, cardiomiopatías y daños en los comercios; por lo tanto, las enfermeras deben vigilar de cerca estos efectos adversos. (Sharma, S., Nuttall, C., Kalyani, V., \& Hemlata, H. (2020). 
ZHANG, HU, et al., 2020 mencionaron en su artículo "ExpertConsensuson Nurses' Human Caringfor COVID-19 Patients in DifferentSite" en el apartado de cuidado humano en los pacientes hospitalizados sobre animar a los pacientes a participar en la rehabilitación y las actividades de recuperación, y expresar su agradecimiento por la cooperación de los pacientes; ofrecer un servicio de despertar a los pacientes en coma cuatro veces al día y música favorita de los pacientes, la bendición y palabras de ánimo de los pacientes, bendiciones y palabras de aliento de familiares, colegas y amigos., proporcionar orientación detallada sobre la medicación, el aislamiento, el estado de salud y el seguimiento de los pacientes dados de alta. Prestar atención al estado psicológico y emocional de los pacientes, la enfermera puede utilizar las escalas pertinentes para evaluar y encontrar anomalías durante este proceso, e intervenir oportunamente. Pedir al psicólogo que intervenga en caso de problemas psicológicos.

\subsection{Cuidados de enfermería en portadores con síntomas graves}

Los pacientes en estado crítico requieren el ingreso en la unidad de cuidados intensivos y pueden necesitar una vía aérea avanzada y ventilación mecánica. Pueden recibir oxigenación por membrana extracorpórea oxigenación por membrana extracorpórea (ECMO), terapia con glucocorticoides (pero su uso es controvertido), administración de plasma de convalecencia medicamentos antivirales, por ejemplo, remdesivir, favipiravir (están en Están en fase de prueba y son prometedores según los primeros informes) y fármacos antibacterianos para tratar las infecciones bacterianas asociadas.

Pueden administrarse vasopresores y fluidos para el tratamiento del shock y profilácticos y anticoagulantes para la prevención de la trombosis. Por lo tanto, es necesario seguir los protocolos de enfermería de cuidados críticos junto con precauciones específicas para la prevención de infecciones. Las intervenciones de enfermería de cuidados críticos más importantes son los siguientes:

- Monitorizar estrecha de la permeabilidad de la vía aérea, SpO2 > 90 \%, signos vitales, nivel de conciencia, equilibrio ácido-base, ECG, indicadores de infección, perfil de coagulación, funciones renal y hepática, signos de TVP y riesgo de úlceras por presión; 
- Colocar al paciente en posición de semifowler (30-45ํ de elevación de la cabeza) y cambiarlo cada dos semanas para prevenir úlceras por presión;

- Administrar oxigenoterapia para mantener una $\mathrm{SpO} 2$ > 90 \%; Inicialmente puede proporcionarse a través de puntas nasales o cánula o máscara. Si esto no consigue mantener la $\mathrm{SpO} 2$ deseada entonces el oxígeno nasal de alto flujo (HFNO), la ventilación no invasiva (VNI) o ventilación mecánica invasiva o ventilación mecánica invasive;

- El inicio temprano de la alimentación por sonda nasogástrica (dentro de las 48-horas) o nutrición parenteral con dieta rica en proteínas y vitaminas;

- Ayudar en la inserción de vías aéreas orofaríngeas e intubación endotraqueal con aerosoles y precauciones de contacto. La intubación endotraqueal se realiza tras cinco minutos de pre-oxigenación mediante el método de presión positiva continua en las vías respiratorias (CPAP). Entre la máscara y el circuito de balón de ventilación, que debe cambiarse regularmente (cada 5-7 días) o siempre que se ensucie;

- Utilizar un sistema de aspiración endotraqueal cerrado con baja presión de succión para evitar el riesgo de exposición a los aerosoles.

- El paciente con ventilación mecánica requiere el uso de circuito de ventilación separado, implementar la Neumonia Ventilator- Associated Pneumonia (VAP) preventionbundle, el paquete de prevención de las infecciones del tracto urinario relacionadas con el catéter (CAUTI), la sepsis relacionada con el catéter (CLEBSI), prevención de la trombosis venosa profunda (TVP), de la prevención de la trombosis venosa profunda (TVP) y la comprobación periódica de la preparación para el destete;

- Proporcionar regularmente cuidados bucales (cada 6 horas con clorhexidina al 0,12 \%), y Clorhexidina al 0,12\%), cuidado de la vía central (cambiar el apósito cada 72 horas con un apósito transparente), cuidado diario de los ojos, parches cuidado de la sonda urinaria, cuidado de la espalda, baño en la cama (con esponjas húmedas);

- Proporcionar compresión neumática intermitente y anticoagulante profiláctico para la prevención de la trombosis venosa trombosis venosa profunda y sus complicaciones. (Sharma, S., Nuttall, C., Kalyani, V., \& Hemlata, H. (2020));

- El paciente con ventilación mecánica requiere el uso de circuito de ventilación separado, implementar la neumonía Ventilator- AssociatedPneumonia (VAP) preventionbundle, el paquete de prevención de las infecciones del tracto urinario relacionadas con el catéter (CAUTI), la sepsis relacionada con el catéter (CLEBSI) prevención 
de la trombosis venosa profunda (TVP) de la prevención de la trombosis venosa profunda (TVP) y la comprobación periódica de la preparación para el destete;

- Proporcionar regularmente cuidados bucales (cada 6 horas con clorhexidina al 0,12\%), y clorhexidina al 0,12\%), cuidado de la vía central (cambiar el apósito cada 72 horas con un apósito transparente), cuidado diario de los ojos, parches, cuidado de la sonda urinaria, cuidado de la espalda, baño en la cama (con esponjas húmedas). Proporcionar compresión neumática intermitente y anticoagulante profiláctico para la prevención de la trombosis venosa trombosis venosa profunda y sus complicaciones.

El uso prolongado de estos elementos, las restricciones que se dan de manera estricta en el cuidado a esta población, aunado a la presión por miedo al contagio del trabajador de la salud y sus familiares, está generando sobrecargas emocionales, y afectaciones en la salud mental de los trabajadores. Por esta razón, se hace necesario fomentar la salud mental positiva, con la finalidad de «sentir y estar lo mejor posible dentro de las circunstancias en que se encuentre». Para que funcione, es necesario desde la administración de las entidades de salud, la creación de espacios lúdicos dentro de las entidades, para mejorar las relaciones sociales dentro de ese entorno, y promover actividades que liberen la tensión por la situación actual. (Ortega, J y González, J. M. 2020).

En este tipo de pacientes dentro de la vigilancia establecida, se encuentra la necesidad de usar elementos biomédicos exclusivos para la atención individualizada, y la realización de la desinfección antes de terminar con la atención, los equipos al ser de uso exclusivo no salen de la unidad del paciente, asimismo, se hace énfasis en la restricción de visitas al paciente, por parte de los cuidadores, y por parte del equipo de atención en salud, restringiendo las valoraciones de acuerdo a la necesidad imperativa de las mismas. Es necesario la restricción de los traslados para toma de exámenes complementarios posterior a la transferencia de hospitalización por la cual se sugiere en la medida de las posibilidades tomar los estudios de forma portátil con la respectiva desinfección antes y después de la toma. (Ramírez, P. M. 2020).

Torres et al., (2020) mencionaron en el artículo "¿Qué ha sucedido con los cuidados durante la pandemia COVID-19?" qué el grupo de trabajo Rehabilitación de la Sociedad Española Enfermería Intensiva y Unidades Coronarias debatieron respecto al tratamiento administrado a los pacientes, los aspectos importantes:

- La duración en de decúbito prono y ventilación mecánica, que en algunos pacientes se vieron incrementados llegando a estar más días de los esperados; 
- La alteración en los parámetros ventilatorios y el modo en el que podían influir en la movilización precoz y la fisioterapia respiratoria;

- Desaturaciones importantes ante la movilización activa y el ejercicio físico, se opta por una terapia más progresiva, con sesiones más cortas, pero más frecuentes;

- Sedestación, bipedestación y/o verticalización del paciente y la utilización de los sistemas de oxigenoterapia para un tratamiento eficaz de movilización precoz y fisioterapia respiratoria, intentando evitar agudizaciones y prevenir la debilidad Adquirida en $\mathrm{UCl}$, que en algunos casos fue muy severa;

- Manejo de secreciones y diseminación de aerosoles.

Estas interrogantes facilitaron la comunicación del equipo interprofesional para visibilizar la necesidad de la integración definitiva del fisioterapeuta en el equipo de $\mathrm{UCl}$, y poner de manifiesto que la movilización temprana es una implementó fundamental en el abordaje del paciente crítico.

En la limitación de tratamientos de soporte vital (LTSV) se consideraba el pronóstico del paciente, la futilidad del tratamiento y la toma de decisiones compartidas, siendo obligatoria la participación de la enfermera para aportar la mirada paliativa que permite la detección precoz de aquellos pacientes que se encuentran en proceso de muerte, evitando caer en la obstinación terapéutica.

Sharma, et al., 2020 manifestaron en el artículo "El desempeño del personal de Enfermería durante la pandemia de la COVID-19" respecto a los cuidados paliativos en pacientes con COVID-19 en la etapa final: se debe asegurar el bienestar para el paciente considerando la salud física y mental previa, sus deseos, últimas voluntades y de la familia con respeto a su opinión sobre la limitación terapéuticos, si dispone de dicha información.

\subsection{Cuidados de enfermería post-mortem}

Realice una correcta higiene de manos y asegure el uso de EPIs (delantal resistente al agua, gafas, máscara N95, guantes) antes de atender a un cadáver. Retirar todos los tubos, drenajes catéteres y desinfectar los orificios de punción, las heridas con solución de hipoclorito de sodio $(\mathrm{NaOCl})$ al $1 \%$ antes de cerrarlas con material impermeable. Tapar todos los orificios como la nariz, la boca, el recto, la uretra y la vagina con calibradores de algodón empapados en $\mathrm{NaOCl}$ empapados de algodón. 
El embalsamamiento del cadáver no debe hacerse y debe colocarse en una bolsa de plástico con cierre de cremallera a prueba de fugas (150 micrómetros de grosor) y desinfectar la superficie exterior de la bolsa con una solución de $\mathrm{NaOCl}$ y, a continuación, entregarlo a la familia o enviarlo a un mortuorio, donde se almacenará a 40C. Horno eléctrico (cremación) o entierro profundo (4-6 metros) con cementación se aconseja para evitar la infección cruzada. Por último, la sala de aislamiento, el mobiliario, las máquinas y el instrumental deben ser limpiarse y desinfectarse con $\mathrm{NaOCl}$ sumergiéndolos durante un mínimo de 30 minutos. Los residuos biomédicos deben ser tratados con una solución de $\mathrm{NaOCl}$ al 1-2 \% y desecharse en contenedores codificados por colores según la política local o nacional de gestión de BMW. (Sharma, S., Nuttall, C., Kalyani, V., \&Hemlata, H. (2020)).

\section{ENFERMERÍA EN LA PROMOCIÓN Y PREVENCIÓN DE COVID-19.}

EI SARS-CoV-2 es altamente contagioso y se encuentra transmitido a través de gotitas respiratorias y por contacto. El aerosol cargado de virus puede viajar hasta 4 metros de distancia del paciente infectado. No tocar la nariz, los ojos, la boca, la cara y mantener una distancia de 1-2 metros con los demás, pero un nuevo estudio ha descubierto que el virus puede viajar hasta 4 metros. (Sharma, S., Nuttall, C., Kalyani, V., \& Hemlata, H. (2020))

La OMS (2021) señaló en su documento "Manejo clínico de la COVID-19” que los casos presuntos o confirmados de COVID-19 se les debe pedir que utilicen mascarillas quirúrgicas...Debe indicarse a los pacientes que al toser o estornudar se cubran la nariz y la boca con un pañuelo de papel o con la flexura del codo, tiren inmediatamente el pañuelo a un recipiente cerrado, y se laven las manos tras el contacto con secreciones respiratorias. En las zonas en las que existe transmisión comunitaria de la COVID-19 las visitas deben restringirse a aquellas que sean esenciales, tales como los padres de los pacientes pediátricos y los cuidadores, y se les debe pedir que utilicen mascarilla.

Deitrick, Adams \& Davis (2020) mencionaron en el artículo "Atención de enfermería de emergencia a pacientes con enfermedad del nuevo coronavirus 2019" se debe recomendar encarecidamente a los pacientes que eviten salir en público. Se deben entregar alimentos y medicamentos, si es posible. Los pacientes deben distanciarse lo más posible de los demás (al menos 6 pies) y deben usar una máscara 
en todo momento cuando deban estar cerca de otros. Dada la baja sensibilidad del hisopo nasal, los pacientes deben ser informados específicamente de que una prueba negativa no significa que no tengan COVID-19, y deben permanecer en cuarentena hasta que los síntomas se hayan resuelto. Los CDC recomiendan que los pacientes permanezcan aislados durante 7 días después de que comiencen los síntomas y 3 días después de que desaparezcan. La Organización Mundial de la Salud, por el contrario, recomienda que los pacientes permanezcan aislados durante 14 días después de que se resuelvan los síntomas. La cuarentena para pacientes sin síntomas, pero el contacto con un paciente que se sabe que tiene COVID-19 puede durar hasta 14 días para los trabajadores de la salud.

\section{CONCLUSIONES}

La pandemia SARS-CoV-2 puso una situación emergente y critica no solo al personal de enfermería sino a todos los servicios de salud en cuestión de reorganización de los servicios, la estructuración de los espacios, nueva elaboración de documentos para el trabajo de la gestión y administración para COVID-19, la necesidad de crear, restablecer y actualizar planes, protocolos, procedimientos para un mejor servicio y cuidado tanto para los usuarios portadores de COVID-19, familiares y personal del área de la salud.

Los cuidados de enfermería hacia los pacientes de Covid-19 se basan en el tratamiento de los síntomas leves y los casos críticos, no existe una cura en sí contra el virus resultado de la enfermedad depende de la calidad de los cuidados de apoyo proporcionados por las enfermeras para la recuperación y la prevención de complicaciones. Cabe mencionar que con la pandemia de COVID-19 la labor de enfermería se ha destacado aún más, debido a que la mayor parte del tratamiento es asintomático y requiere de cuidados de enfermería gran parte del tiempo. Esto nos motiva aún más a seguir investigando y actualizando sobre medidas de tratamiento y cuidado para pacientes con esta enfermedad.

El trabajo en grupo y el fortalecimiento de las interacciones laborales en pro de aceptar la emergencia sanitaria como un equipo con diferentes funcionalidades, sin embargo, con un mismo fin, se constituye como un componente defensor para la salud emocional que se vio demasiado afectada por los cambios de vida poblacional de todo el planeta. 


\section{REFERENCIAS}

Andrés-Gimeno, B., Solís-Muñoz, M., Revuelta-Zamorano, M., Sánchez-Herrero, H., SantanoMagariño, A., Bodes Pardo, R. M., José López Coca, M., Cachinero Murillo, A., Jiménez De Prada, M., Quiñones Higuero, N., Jaime Arranz, M., Cazallo Navarro, P., Rull Bravo, P., \& Gallego Paz, M. (2021). Cuidados enfermeros en el paciente adulto ingresado en unidades de hospitalización por COVID-19. Enfermería Clínica, 31, 49-S54. https://doi.org/10.1016/j.enfcli.2020.05.016

Canova-Barrios, C., \& Salvador, S. (30 de Junio, 2020). Cuidados de enfermería en la infección por COVID-19: y entonces, ¿Cómo procedemos? Cuidados de Enfermería y Educación en Salud, 5(10), 43-45. https://revistas.userena.cl/index.php/cuidenf/article/view/1256/1350

Deitrick, K., Adams, J., \& Davis, J. (2020). Emergency Nursing Care of Patients With Novel Coronavirus Disease 2019. Journal of EmergencyNursing, 46(6), 748-759. https://doi.org/10.1016/j.jen.2020.07.010

Gómez de Segura García, L. L. (Mayo, 2021). Cuidados de Enfermería en Pacientes con COVID-19 en Posición Prono con Ventilación Mecánica Invasiva. Facultad de Ciencias de la Salud, 2-9. https://academicae.unavarra.es/bitstream/handle/2454/39873/Gomez\%20de\%20Segura\%20Garcia\%2 c\%20Luc\%c3\%ada\%20Luisa.pdf?sequence $=1 \&$ isAllowed $=\mathrm{y}$

Lahite-Savón, Y., Céspedes-Pereña, V., \&Maslen-Bonnane, M. (2020). El desempeño del personal de Enfermería durante la pandemia de la COVID-19. Revista Información Científica, 99(5), 494-502.

http://www.revinfcientifica.sld.cu/index.php/ric/article/view/3086

Maglio, I., Valdez, P., Camera, L., Finn, B., Klein, M., Pinceminp, I., Ferraro, H., Galvalizi, N., Alessandrini, G., Manera, J., Musacchio, H., Contreras, P., Garea, M., Lüthy, V., Nemerovsky, J., Baldoma, F., Cherro, A., Ranzuglia, L., Malfante, P., . . . García, A. (2020). Guías éticas para la atención durante la pandemia covid-19.

Recomendaciones multisocietarias para asignación de recursos. Medicina Buenos Aires, $\quad 80$ (III), 45-64. https://www.medicinabuenosaires.com/indices-de2020/volumen-80-ano-2020-s-3-indice/guias eticas/

Organización Mundial de la Salud. (2021, 6 abril). Manejo clínico de la COVID-19: orientaciones evolutivas, 25 de enero de 2021. Apps.Who.Int. https://apps.who.int/iris/handle/10665/34062

Sharma, S., Nuttall, C., Kalyani, V., \&Hemlata, H. (2020). Clinical nursing care guidance for management of patient with COVID-19. Journal of the Pakistan Medical Association, 70(5), 1. https://doi.org/10.5455/jpma.29

Torres-González, J., Arias-Rivera, S., Velasco-Sanz, T., MateosDávila, A., PlanasPascual, B., Zaragoza-García, I., \&Raurell-Torredà, M. (2020). What has happened to care during the COVID-19 pandemic? Enfermeríalntensiva (English ed.), 31(3), 101-104. https://doi.org/10.1016/j.enfie.2020.07.001 
World Health Organization. (s. f.). Nuevo coronavirus 2019. Recuperado 14 de julio de 2021, de https://www.who.int/es/emergencies/diseases/novel-coronavirus-2019

Zhang, F. J., Hu, D. Y., Liu, Y. L., Li, H., Zhu, X. P., \& Pan, S. S. (2020). Expert Consensus on Nurses' Human Caring for COVID-19 Patients in Different Sites. Current Medical Science, 40(4), 602-607. https://doi.org/10.1007/s11596-020-2222-0 


\section{MANAGER}

Edilson Antonio Catapan has a $\mathrm{PhD}$ and Master degree in production engineering from Federal University of Santa Catarina, Brazil (2005 and 2001), has a specialization course as manager in a electric energy provider from Federal University of Paraná, Brazil (1997), specialization course in economic engineering from the Administration and Economics Instituition, Brazil (1987) and graduated in Administration from the Positivo University, Brazil (1984). He was a financial executive of the Paranaense Company of Energy, Brazil (COPEL/PR) for 33 years $(1980$ - 2013) holding the offices of Financial and Budget planning Superintendent, Costs and Economical studies Superintendent, Controllership superintendent and board assistant. Served as a Holder Member of the Advisory Board of Copel Foundation, Brazil. Was Director of the budget Comittee of Copel, Director of Audit Committee of Copel Telecommunications and other Administrations Comittees in the equity holdings of Copel, Brazil. 
U.S. ISBN Agency at Bowker ISBN: 978-1-7361138-3-7 